\title{
Informing a Tidal Turbine Strike Probability Model through Characterization of Fish Behavioral Response using Multibeam Sonar Output
}

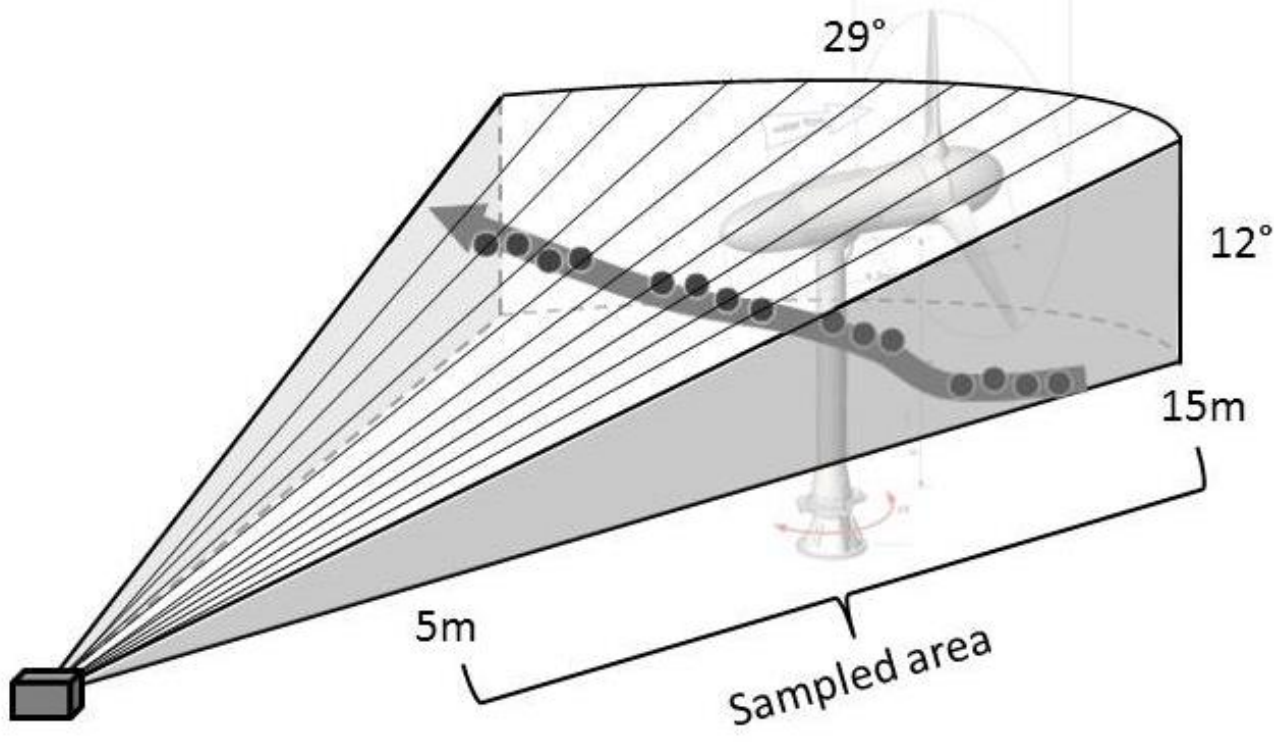

Approved for public release. Distribution is unlimited.
Mark Bevelhimer Jonathan Colby Mary Ann Adonizio Christine Tomichek Constantin Scherelis July 2016 


\title{
DOCUMENT AVAILABILITY
}

Reports produced after January 1, 1996, are generally available free via US Department of Energy (DOE) SciTech Connect.

Website http://www.osti.gov/scitech/

Reports produced before January 1, 1996, may be purchased by members of the public from the following source:

\author{
National Technical Information Service \\ 5285 Port Royal Road \\ Springfield, VA 22161 \\ Telephone 703-605-6000 (1-800-553-6847) \\ TDD 703-487-4639 \\ Fax 703-605-6900 \\ E-mail info@ntis.gov \\ Website http://www.ntis.gov/help/ordermethods.aspx
}

Reports are available to DOE employees, DOE contractors, Energy Technology Data Exchange representatives, and International Nuclear Information System representatives from the following source:

Office of Scientific and Technical Information

PO Box 62

Oak Ridge, TN 37831

Telephone 865-576-8401

Fax 865-576-5728

E-mail reports@osti.gov

Website http://www.osti.gov/contact.html

This report was prepared as an account of work sponsored by an agency of the United States Government. Neither the United States Government nor any agency thereof, nor any of their employees, makes any warranty, express or implied, or assumes any legal liability or responsibility for the accuracy, completeness, or usefulness of any information, apparatus, product, or process disclosed, or represents that its use would not infringe privately owned rights. Reference herein to any specific commercial product, process, or service by trade name, trademark, manufacturer, or otherwise, does not necessarily constitute or imply its endorsement, recommendation, or favoring by the United States Government or any agency thereof. The views and opinions of authors expressed herein do not necessarily state or reflect those of the United States Government or any agency thereof. 
Environmental Sciences Division

\title{
INFORMING A TIDAL TURBINE STRIKE PROBABILITY MODEL THROUGH CHARACTERIZATION OF FISH BEHAVIORAL RESPONSE USING MULTIBEAM SONAR OUTPUT
}

\author{
ORNL/Verdant \\ Mark Bevelhimer, Oak Ridge National Laboratory \\ Jonathan Colby, Verdant Power \\ Mary Ann Adonizio, Verdant Power \\ Christine Tomichek, Kleinschmidt Associates \\ Constantin Scherelis, Oak Ridge National Laboratory
}

Date Published: July 2016

\author{
Prepared by \\ OAK RIDGE NATIONAL LABORATORY \\ Oak Ridge, TN 37831-6283 \\ managed by \\ UT-BATTELLE, LLC \\ for the \\ US DEPARTMENT OF ENERGY \\ under contract DE-AC05-00OR22725
}





\section{CONTENTS}

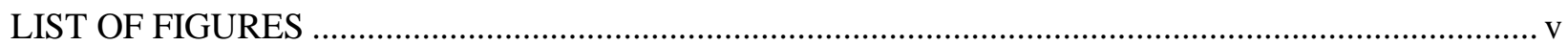

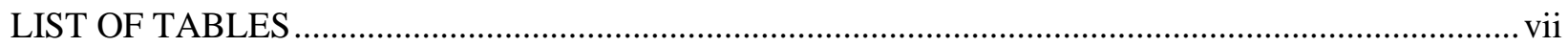

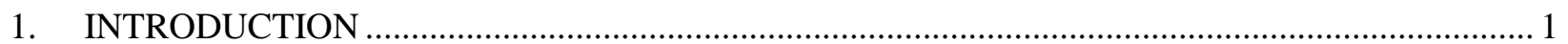

1.1 PHYSICAL INTERACTIONS WITH HYDROKINETIC TURBINES ................................ 1

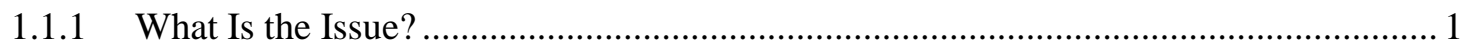

1.1.2 Existing Tools for Addressing Fish Interactions with Hydrokinetic Turbines ............. 2

1.2 ROOSEVELT ISLAND TIDAL ENERGY PROJECT ................................................... 3

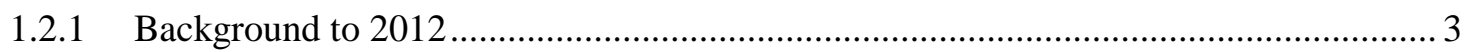

1.2.2 RITE Project Moving Forward Beyond2012 ................................................ 5

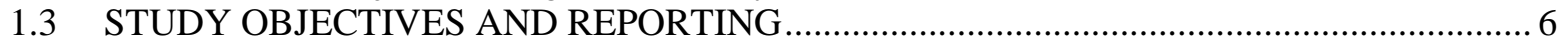

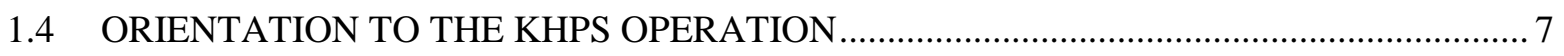

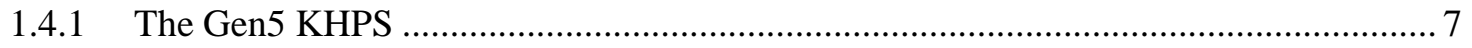

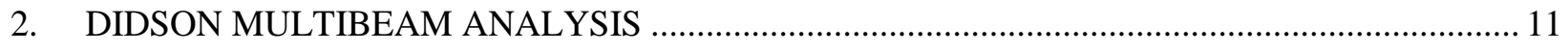

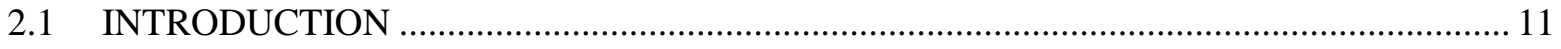

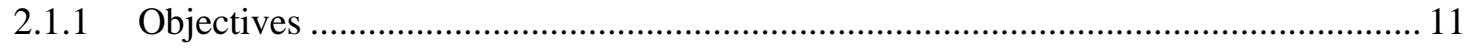

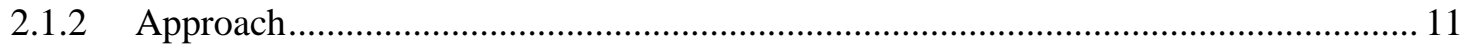

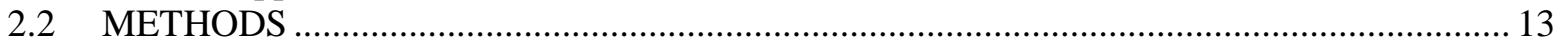

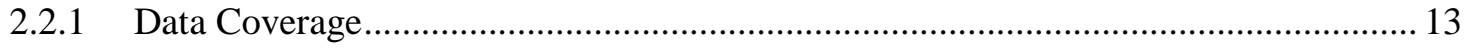

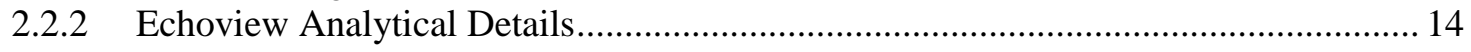

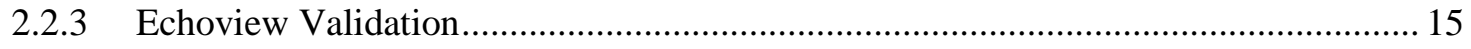

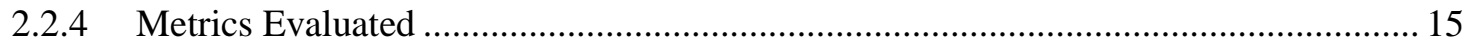

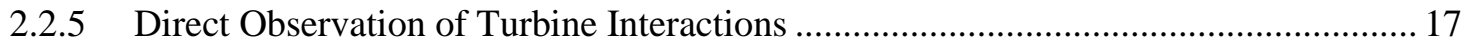

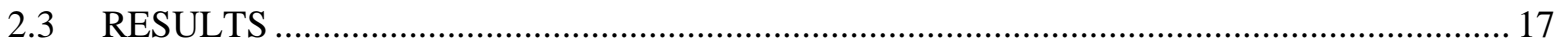

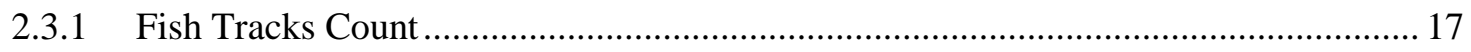

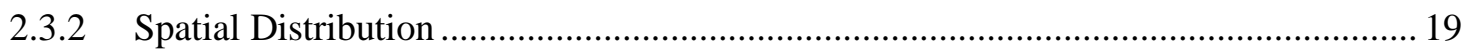

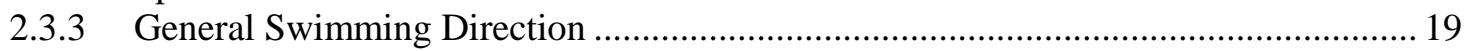

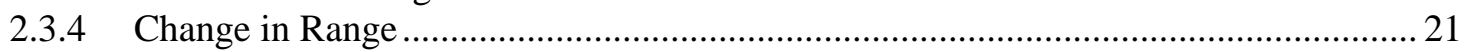

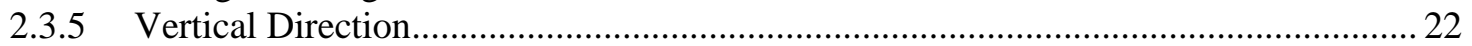

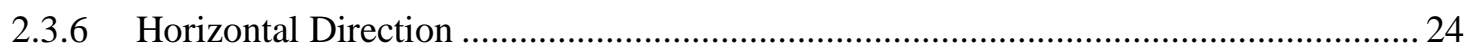

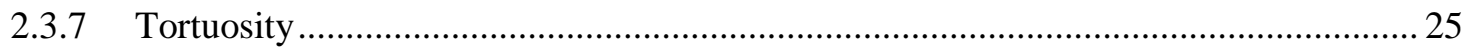

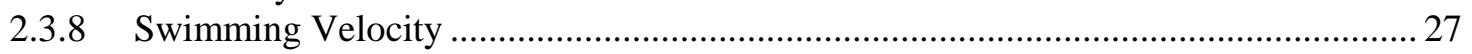

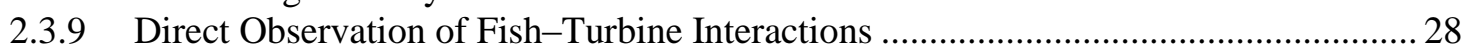

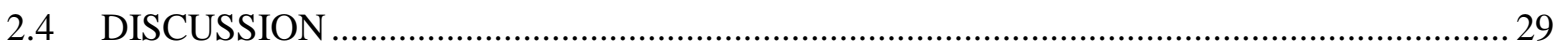

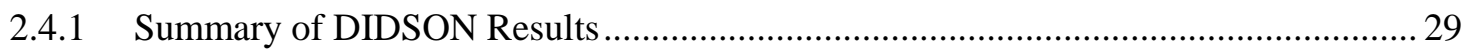

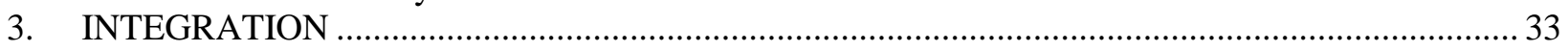

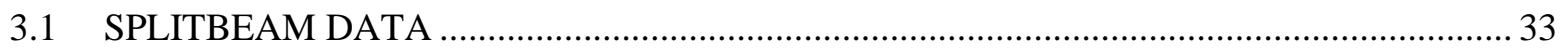

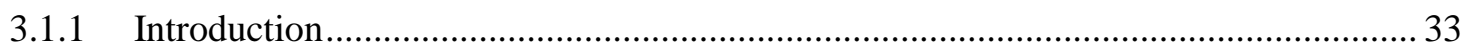

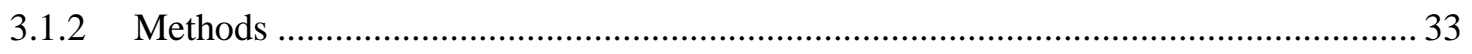

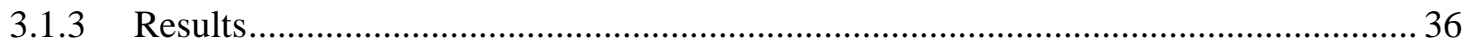

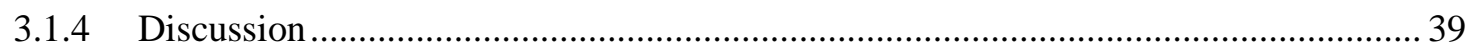

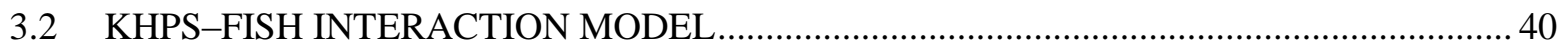

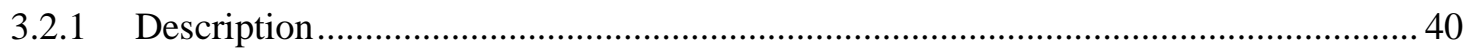

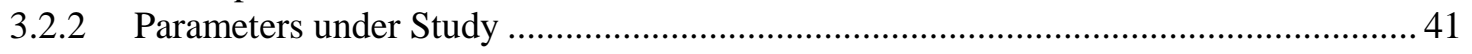

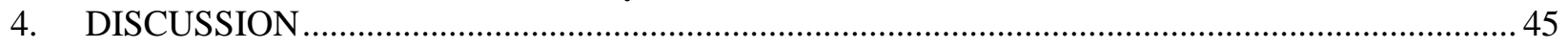

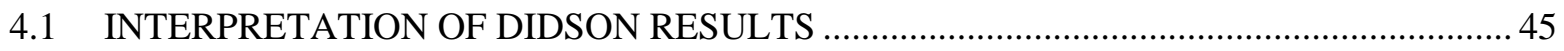

4.2 INTERPRETATION OF FISH INTERACTION MODEL ............................................. 45

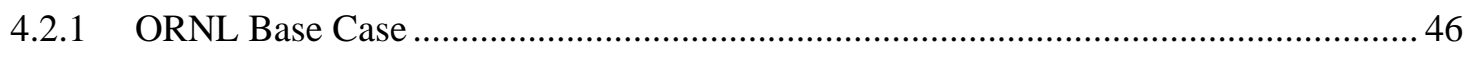

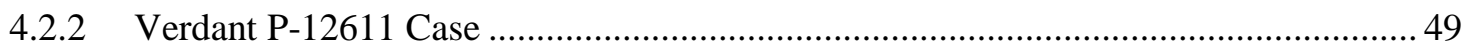


4.3 RESULTS OF UPDATE TO THE KHPS-FISH INTERACTION MODEL ........................ 50

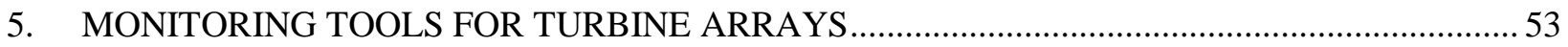

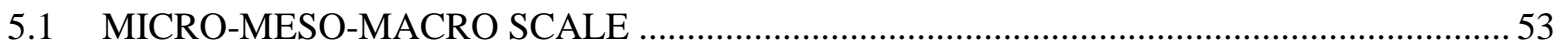

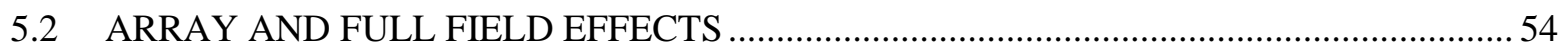

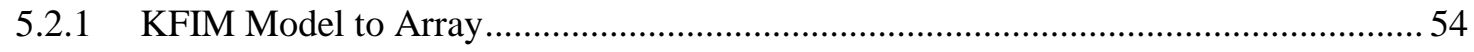

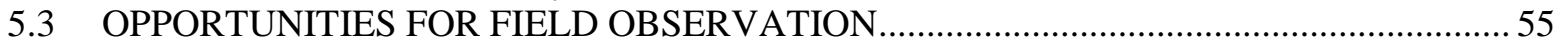

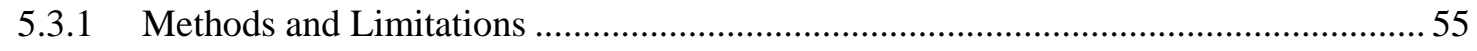

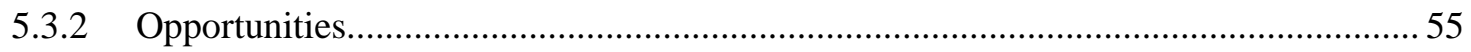

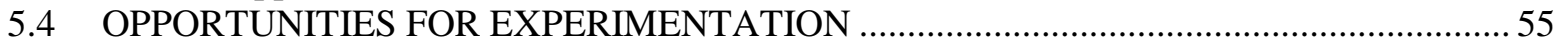

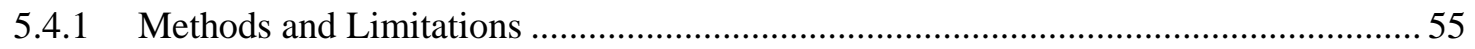

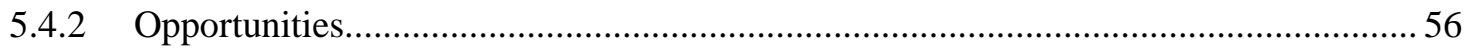

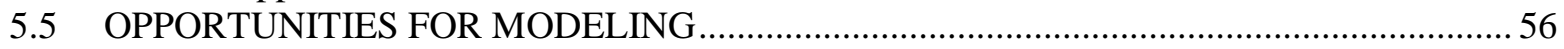

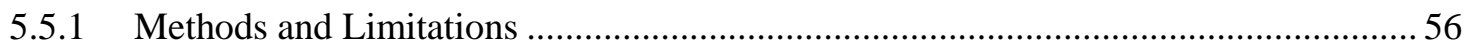

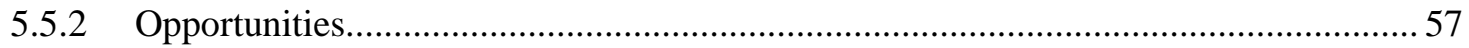

6. CONCLUSIONS AND OPPORTUNITIES FOR FUTURE RESEARCH …...............................59

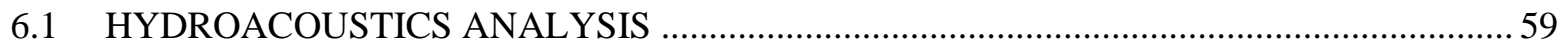

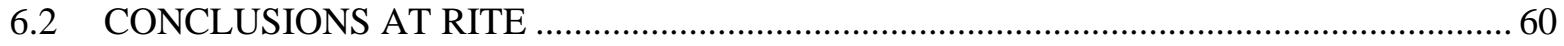

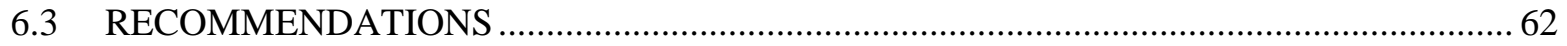

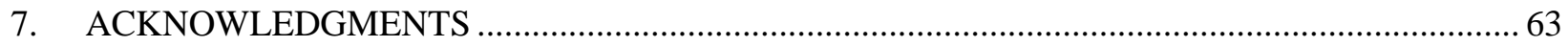

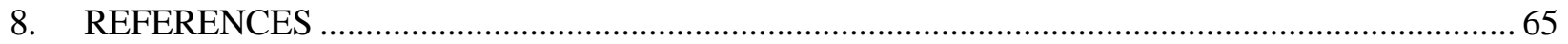




\section{LIST OF FIGURES}

Figure 1-1. Verdant Power Roosevelt Island Tidal Energy project site-New York, east channel,

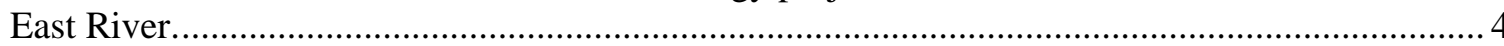

Figure 1-2. Verdant Power kinetic hydropower system Gen5 turbine .................................................. 6

Figure 1-3. Gen5 KHPS turbine deployment with DIDSON (RAD) system being deployed

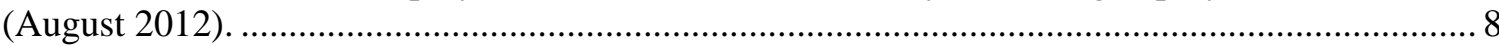

Figure 1-4. Deployed RAD system at RITE, September 2012 ..................................................... 9

Figure 2-1. Dimensions of the surveyed field of the DIDSON multibeam hydroacoustics system with an example of a fish track (arrow) through the field constructed from individual signal returns (circles) of the same fish four times through time.

Figure 2-2. Plan view of the DIDSON acoustic camera field (5 to $15 \mathrm{~m}$ from DIDSON unit) with the DIDSON unit located $5 \mathrm{~m}$ above the field showing (A) two individual fish at a single point in time when the turbine was absent during ebb tide and (B) a composite image of every other ping of a single fish track over a 3 -s interval during flood tide.

Figure 2-3. (Top) Number of hours of DIDSON data collection (analyzed and unanalyzed) by tide cycle and turbine operation mode.

Figure 2-4. Number of fish tracks per hour during three operation modes (no turbine, turbine not rotating, and turbine rotating) summarized by distance from the DIDSON unit ( $1 \mathrm{~m}$ blocks) and by three current velocity classes (high, medium, and low).

Figure 2-9. The distribution of horizontal direction of fish tracks in degrees (normalized to the total tracks for these two cases, 9,533 and 1,350) for fish swimming with and against the current during ebb tide with a RAD aim of 1 and when no turbine was present versus an operating turbine.

Figure 3-1. Overhead view of eight frames, three splitbeam transducers each, at the RITE site.

Figure 3-2. Cross-sectional view of field of view of three splitbeam transducers on a single frame relative to location of two turbines.

Figure 3-4. Distribution of fish (mean number per day) in 18 zones (see Figure 3-2) as determined by splitbeam hydroacoustics systems at three frames during ebb, slack and flood tides.

Figure 3-5. Distribution of swimming velocities of fish swimming with and against the current. $\mathrm{X}$-axis values represent the mid-point of $1 \mathrm{~m} / \mathrm{s}$ ranges.

Figure 3-6. Mean swimming velocity by $0.2 \mathrm{~m} / \mathrm{s}$ current velocity bins for fish swimming with the current for each of the three splitbeam transducer frames.

Figure 3-7. The probability of the blade impacting an Atlantic sturgeon and shortnose sturgeon as a function of water velocity.

Figure 4-1. ORNL 2015 case-modification to P5 and P6; comparative KHPS-fish strike probabilities, RITE project

Figure 4-2. P-12611 case - modification to P3, P5, P6 and P7; comparative KHPS-fish strike probabilities, RITE project.

Figure 4-3. RITE project KFIM model output comparisons. 



\section{LIST OF TABLES}

Table 2-1. Number of fish tracks observed per hour of data analyzed during three turbine operation modes for ebb and flood tide directions..... 18

Table 2-2. Number of fish tracks observed per hour of data analyzed during three turbine operation modes for ebb and flood tide direction and three velocity classes.

Table 2-3. Summary of distribution of fish tracks against the current (\%) for three operating conditions, ebb and flood tides and three current velocity classes

Table 3-1. Results of analysis of variance testing the effects of current speed, target strength (i.e.,

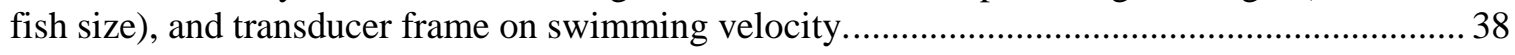

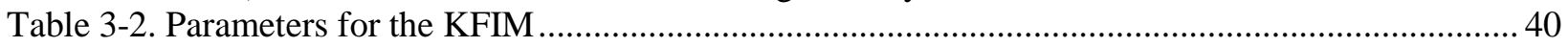

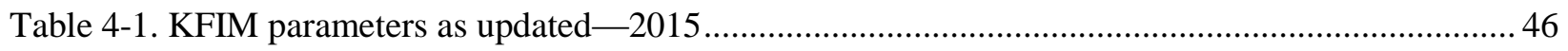

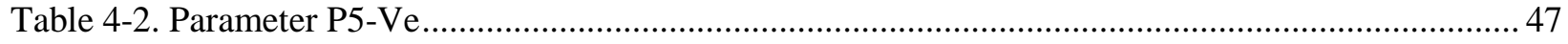

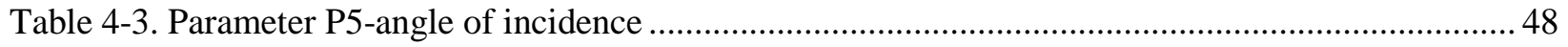

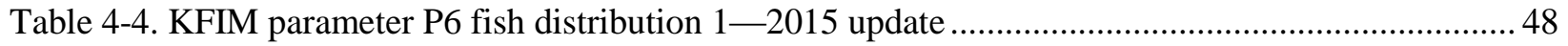

Table 5-1. Overall KHPS-fish strike probabilities for proposed RITE project....................................... 54

Table 5-2. Summary matrix of monitoring tools useful for monitoring turbine arrays. ........................... 57 


\section{INTRODUCTION}

\subsection{PHYSICAL INTERACTIONS WITH HYDROKINETIC TURBINES}

\subsubsection{What Is the Issue?}

One of the most important biological questions facing the marine and hydrokinetic (MHK) energy industry is whether fish and marine mammals that encounter MHK devices are likely to be struck by moving components. For hydrokinetic ${ }^{1}(\mathrm{HK})$ devices, i.e., those that generate energy from flowing water, this concern is greatest for large organisms because their increased length increases the probability that they will be struck as they pass through the area of blade sweep and because their increased mass means that the force absorbed if struck is greater and potentially more damaging (Amaral et al. 2015). Key to answering this question is understanding whether aquatic organisms change their swimming behavior as they encounter a device in a way that decreases their likelihood of being struck and possibly injured by the device. Whether near-field or far-field behavior results in general avoidance of or attraction to HK devices is a significant factor in the possible risk of physical contact with rotating turbine blades (Cada and Bevelhimer 2011).

Although numerous hydrokinetic device designs are under development (see DOE 2009 for a description of the technologies and their potential environmental effects), the ultimate goal for most developers is to deploy multiple devices in a large array positioned in high-velocity (high-energy) zones of rivers or tidal channels. The diverse designs imply a diversity of environmental impacts (Čada et al. 2010), but a potential impact common to most is the risk of blades striking aquatic organisms. Only a limited number of studies have been conducted to examine the risk of blade strike from HK technologies to freshwater fish (Turnpenny et al. 1992; NAI 2009; Schweizer et al. 2011; EPRI 2011; Amaral et al. 2015; CastroSantos and Haro 2015).

Recent federal licensing requirements (e.g., see projects by Verdant Power in New York, New York and Ocean Renewable Power Company in Eastport, Maine) have included evaluation of possible interactions by fish and marine mammals with devices and additional monitoring as pilot arrays are deployed. Until it is demonstrated that these devices provide little risk of injury to aquatic organisms, this concern will likely persist for all device types and aquatic environments. These concerns are officially addressed by regulators under several regulatory statutes. For example, Section 7(a)(2) of the Endangered Species Act (ESA) requires federal agencies to ensure that their actions are not likely to jeopardize the continued existence of federally listed threatened and endangered species, or result in the destruction or adverse modification of their designated critical habitat. The Marine Mammal Protection Act (MMPA) prohibits, with certain exceptions, the "take" (defined under the statute as actions that are or may be lethal, injurious, or harassing) of marine mammals in US waters and the high seas. Section 10(j) of the Federal Power Act requires the Federal Energy Regulatory Commission (FERC), when issuing a license, to include conditions based on recommendations by federal and state fish and wildlife agencies, submitted pursuant to the Fish and Wildlife Coordination Act, to "adequately and equitably protect, mitigate damages to, and enhance fish and wildlife (including related spawning grounds and habitat)" affected by the project.

\footnotetext{
${ }^{1}$ The International Electrotechnical Commission (IEC) created a Technical Committee (TC114) to develop standards for the MHK industry, including a technical specification on common industry terminology, such as marine energy converters and hydrokinetic. This committee (IEC TC114) and the MHK industry at large include wave, current (tidal, river, ocean) and ocean thermal technologies; hydrokinetic energy refers to those that generate energy from flowing water.
} 


\subsubsection{Existing Tools for Addressing Fish Interactions with Hydrokinetic Turbines}

Field observations and studies - Because this technology is so new and because so few devices have been in the water for extended periods of time, there are very few field studies on the interactions of fish with HK devices. Balloon tag studies performed with fish released into a ducted axial flow turbine in Hastings, Minnesota, found survival rates for many species of 99\% or greater (NAI 2009). Researchers from the University of Maine partnered with Ocean Renewable Power Company have been collecting hydroacoustics (i.e., sonar) data at both a barge-mounted and a bottom-deployed horizontal axis turbine in Cobscook Bay, Maine. Among other findings, these studies found that (1) fish seemed to avoid an operating turbine more than a still one, (2) avoidance increased during the day and with fish size, and (3) avoidance of an operating turbine was detectable up to $140 \mathrm{~m}$ upstream of the turbine (Shen et al. 2015; Viehman and Zydlewski 2015). Hammar et al. (2013) monitored fish interactions with a vertical axis turbine of the coast of Mozambique using a video camera system and found near-field avoidance by fish and no collisions by the few fish that passed through the rotors. Verdant Power has monitored a horizontal axis turbine at its test site in the East River, New York, off and on for several years (Verdant 2008, 2010). As described above, Verdant Power undertook studies on presence, abundance, and species interaction with operating full-scale KHPS turbines at the Roosevelt Island Tidal Energy (RITE) project and most recently collected dual-frequency identification sonar (DIDSON, Sound Metrics Corporation, Bellevue, Washington) video data during a deployment of a single Gen5 KHPS turbine for a period of 2 weeks in August-September 2012.

Lab studies - Only a handful of laboratory studies have evaluated the effects on fish of passage through an HK turbine. Alden Engineering Lab and the Electric Power Research Institute (EPRI) collaborated on studies using a Lucid spherical (cross flow) turbine and the Welka UPG (axial flow propeller) turbine; they found that survival rates normally exceeded $98 \%$ for two species tested (EPRI 2011). When allowed time to respond behaviorally before being entrained in the turbine, most of the fish avoided passage through the turbine. Alden, EPRI, and Oak Ridge National Laboratory (ORNL) recently completed similar tests with a Free Flow Power half-scale ducted horizontal axis turbine and found survival rates above $95 \%$ for the three species tested, but a high incidence of de-scaling or injury for one species when entrained (Amaral et al. 2015). Recent studies conducted at Conte Anadromous Fish Research Center in Turners Falls, Massachusetts, exposed Atlantic salmon smolts and adult American shad to a full-scale vertical axis turbine in a large open-channel flume (Castro-Santos and Haro 2015). They found no sign of injury caused by passing through the turbine and a $48 \mathrm{~h}$ survival rate that did not differ from control fish.

Modeling - Several investigators have attempted to model interactions between aquatic organisms and HK turbines.

Wilson Probability Model-Wilson et al. (2007) described a simple model to estimate the probability that aquatic animals will enter the path of a marine turbine. The model is based on the density of the animals and the water volume swept by the rotor. The volume swept by the turbine can be estimated from the radius of the rotor and the velocity of the animals and the turbine blades. The researchers emphasized that their model predicts the probability that an animal will enter the region swept by a rotor, not collisions. Entry into the path toward the rotor may lead to a collision, but only if the animal does not take evasive action or has not already sensed the presence of the turbine and avoided the encounter. Applying this simplified model (no avoidance or evasive action) to a hypothetical field of 100 turbines, each with a 2bladed rotor $16 \mathrm{~m}$ in diameter, they predicted that $2 \%$ of the herring population and 3.6 to $10.7 \%$ of the porpoise population near the Scottish coast would encounter a rotating blade. At this time, there is little information about the degree to which marine animals may sense the presence of turbines, take appropriate evasive maneuvers, or suffer injury in response to a collision. Wilson et al. (2007) suggested that marine vertebrates may see or hear the device at some distance and avoid the area, or they may evade the structure by dodging or swerving when in closer range. 
ORNL Strike Model-Researchers at ORNL combined ideas from Wilson et al. (2007) with similar models for conventional hydropower turbines to construct a model that accounted for probabilities of encounter, turbine entrainment, and blade strike (Schweizer et al. 2011). Their model included a behavioral component that would account for avoidance, evasion, and fish swimming speed; but they had no real-world data to parameterize these features of the model.

Verdant Power/Kleinschmidt Fish Interaction Model-As part of the FERC licensing process, Verdant Power, in collaboration with Kleinschmidt Associates, developed a Kinetic Hydropower System - Fish Interaction Model (KHPS-KFIM) specifically to address the probabilities of endangered species interacting with a pilot project array of up to 30 KHPS turbines operating in the east channel of the East River (FERC 2012; NOAA 2012). Although the model was developed for sturgeon species it is applicable to other species simply by changing species-specific input parameter values. The model does not make any assumptions about fish behavior; that is, it does not incorporate any likelihood that if a fish detected the presence of the turbines, it would avoid an interaction. As adult shortnose sturgeon are highly mobile, it is likely that the model presents a very conservative estimate of the likelihood of interactions between an individual fish and the turbines. The model uses nine parameters (water velocity distribution; channel geometry; physical and operation characteristics of the turbines; and specific fish characteristics, such as size, burst swimming speed, and swimming velocity and endurance) and was applied to calculate the strike probability for a single turbine, as well as for an array of up to 30 turbines.

University of Maine Model - In collaboration with Ocean Renewable Power Company's testing of a tidal turbine in Cobscook Bay (Eastport, Maine), researchers at the University of Maine developed a turbine interaction model based on fish density data that they collected onsite (Shen et al. 2015). The model includes three primary parameters: the probability of fish being at the device depth; the probability of fish behavior changing to avoid the device in the far-field; and the probability of fish behavior changing to avoid the device in the near-field.

\subsection{ROOSEVELT ISLAND TIDAL ENERGY PROJECT}

\subsubsection{Background to 2012}

Since its inception in 2000, Verdant Power has advanced the state of the art in kinetic hydropower research and demonstrated the utility and efficiency of a water-to-wire turbine system in converting the kinetic energy in flowing water into electric power, with concurrent environmental permitting and assessment. During 2006-2008, Verdant Power conducted a demonstration of its patented system, the KHPS, at its RITE project, located in the East River in New York City (Figure 1-1). During the RITE demonstration, the KHPS met expectations, showing a turbine peak efficiency of 38 to $44 \%$ in water current speeds of 0.9 to $2.1 \mathrm{~m} / \mathrm{s}$ (1.8 to 4.2 knots) while delivering emission-free, renewable electricity to two commercial end users.

When Verdant Power first embarked on the development of the RITE project in 2002, with the filing of a FERC Preliminary Permit for the RITE site in the East River in New York, there was no precedent for the process in the United States, neither regulatory nor environmental, to evaluate this new type of project and tidal technology. Verdant proceeded within the federal context of a FERC hydropower process, which requires the development of an Initial Consultation Document (ICD) under the FERC Traditional Licensing Process. Therefore, when in October 2003 Verdant issued its ICD, the discussion of the potential environmental effects of KHPS technology was new to both resource agencies and stakeholders. 


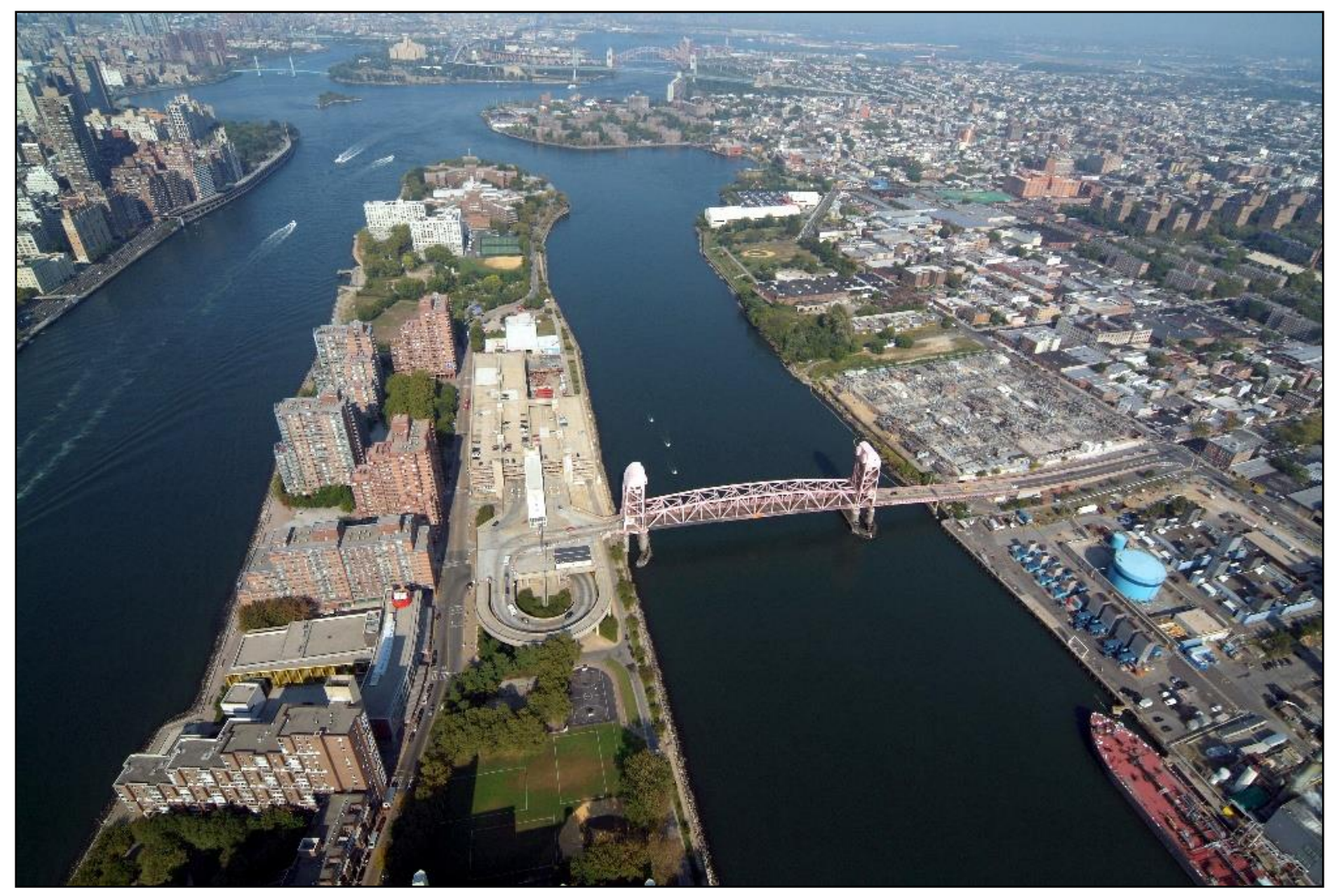

Figure 1-1. Verdant Power Roosevelt Island Tidal Energy project site—New York, east channel, East River.

In general, the opportunity for a new source of clean energy was well received during scoping meetings held in 2004; but it also raised significant concerns regarding the regulatory scheme for the gridconnected generation of such technology, as well as the potential environmental impacts of operation. In 2005, to demonstrate its technology and gather data that could begin to address these concerns, Verdant Power sought permission from FERC to test a six-turbine array of KHPS in the RITE project site in the east channel of the East River (RITE demonstration). In a precedent-setting declaratory order, the "Verdant Order," FERC ruled that this activity did not require a license under the Federal Power Act, as it was consistent with the following findings:

1) The technology in question is experimental

2) The proposed facilities are to be utilized for a short period for the purpose of conducting studies necessary to prepare a license application, and

3) Power generated from the test project will not be transmitted into, or displace power from, the national electric grid. $^{2}$

As such, the RITE demonstration project could proceed to begin to examine many of the environmental issues. Subsequent to this, the FERC issued its April 2007 rules regarding Pilot Licenses.

\footnotetext{
2111 FERC 61, 024 - April 14, 2005; the "Verdant Order"
} 
During the RITE demonstration, Verdant Power conducted environmental monitoring efforts, including a specific Fish Monitoring and Mitigation Plan (FMMP) required under project permits, to advance the understanding of fish presence, abundance, species characterization, and fish interaction with operating kinetic hydropower turbines. This monitoring involved various applications of hydroacoustic detection devices in an effort to understand fish interaction with HK devices. ${ }^{3}$ A third deployment of operating turbines in the fall of 2008 included the collection of additional information (as discussed later in this report). The results of this effort culminated in the December 2010 filing of a hydrokinetic pilot license application with the FERC for pilot development of the RITE project (FERC No. P-12611). Included in the draft license application were a set of environmental monitoring plans for RITE, termed the RITE Monitoring of Environmental Effects (RMEE) plans, as well as a KFIM for the Biological Assessment. The RMEE plans and KFIM are available at http://www.theriteproject.com as Volume 4 of the Final RITE Pilot License Application; they are further discussed in the context of this study.

\subsubsection{RITE Project Moving Forward Beyond2012}

In January 2012, FERC issued the first 10 year US pilot license to Verdant Power for the installation of up to 30 KHPS turbines in the east channel of the East River, accepting the results of the KFIM for both Endangered Species Act species and Essential Fish Habitat and incorporating a suite of seven RMEE plans in a staged monitoring strategy with adaptive management. Implementing this suite of monitoring plans was projected to cost more than $\$ 2.3$ million over the course of the pilot license. Of importance in this project are RMEE-2, "Seasonal DIDSON Observation," and to a lesser extent RMEE-4, "Tagged Species Detection."

As part of the start of construction and the final technology development - with partial funding from the New York State Energy Research and Development Authority (NYSERDA) ${ }^{4}$ and the US Department of Energy $^{5}$ (DOE) - following a year of preparatory work in September 2012, Verdant successfully completed an in-water test of an updated KHPS turbine rotor including composite blades and concurrently deployed a remotely aimed DIDSON (RAD) system (Figure 1-2). The RAD incorporates a DIDSON, a ROS PT25 2-axis servo, a ROS $400 \mathrm{ft}$ underwater cable, a custom-designed river bottom gravity mount, and an executive program for control and data collection of an operating KHPS turbine in the East River under the RMEE-2 plan as a beta test of the monitoring equipment. The results of the data collection effort - over 370 hours of DIDSON RMEE-2 RAD video with and without the operation of a KHPS turbine-were initially shared with the agencies for their review as follows:

- Fish abundance varies significantly with the seasonal migration at the site (April-May and September-December).

- Equivalent abundance is seen day and night.

- The greatest movement is seen by fish observed moving in the direction of the tides or at slack tide (when KHPS turbines are not operating).

- Fish zonal location is near shore, not in the zones of the operating turbines.

- DIDSON technology did show "some signs" of avoidance behavior and showed promise for future monitoring - hence the development (and adoption) of the RMEE-2 plans.

\footnotetext{
${ }^{3}$ The efficacy of splitbeam transducers, various DIDSON mounts (stationary, mobile, and RAD), and netting is discussed later in this report.

${ }^{4}$ NYSERDA Grant 20802.

${ }^{5}$ DOE Grant DE-FG36-08GO18168, "Improved Structure and Fabrication of Large, High-Power KHPS Rotors."
} 


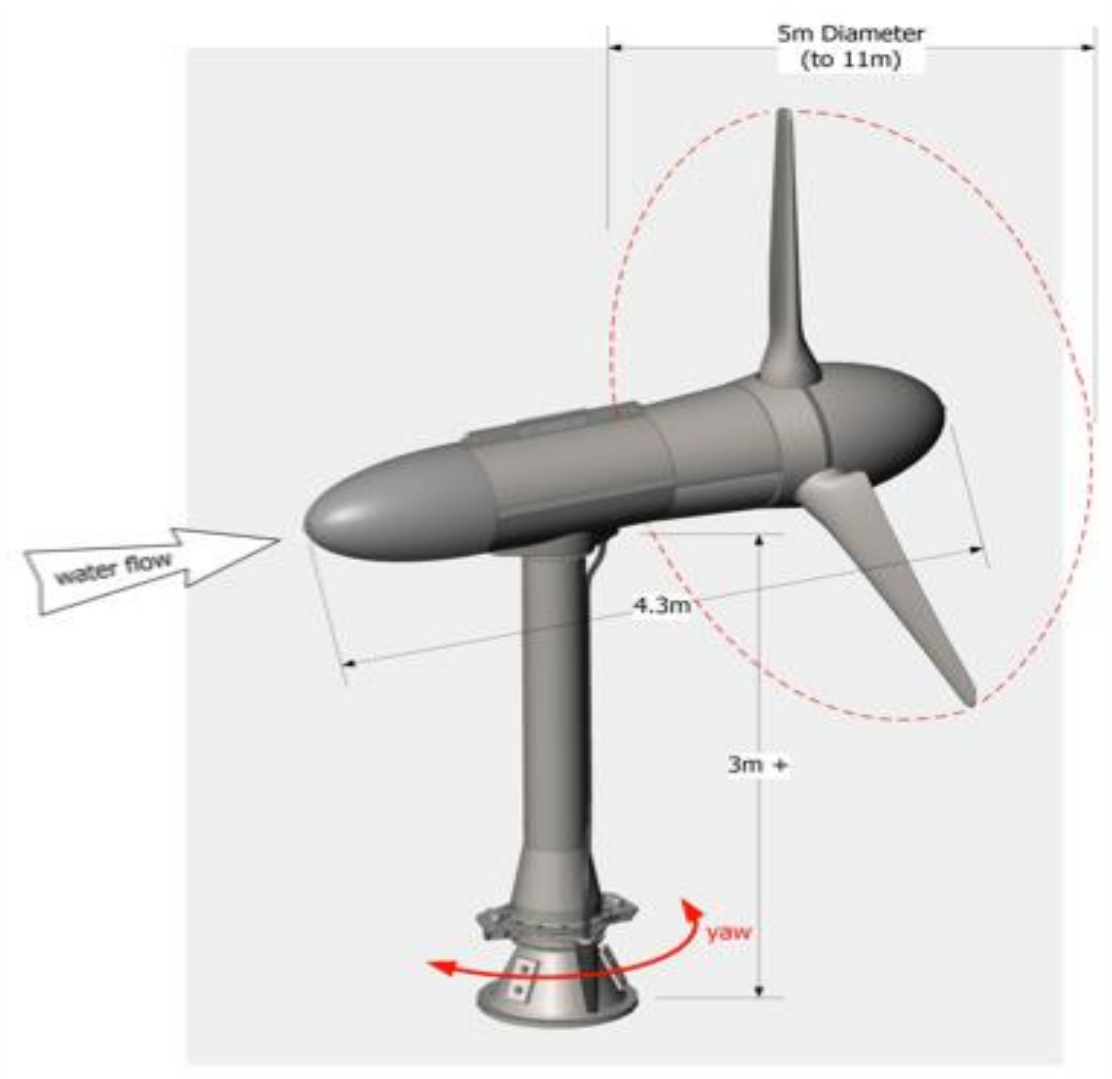

Figure 1-2. Verdant Power kinetic hydropower system Gen5 turbine.

The RAD hydroacoustics data are the subject data that are further analyzed in this report. As required by the FERC license, the actual deployment and operation of a full-scale kinetic hydropower device and the concurrent deployment of a DIDSON provided the unique opportunity to observe and address the questions most important to aquatic resource managers and regulators:

1. How do fish behave around operating KHPS turbines?

2. Can fish behavior be inferred by tracking a fish's swimming location and direction or its reaction in relation to the rotating blades?

3. Do the DIDSON observations provide some added meaning and value (correlation) to the body of collected data on fish presence, abundance, movement pattern, and species in and around the operating KHPS turbine?

4. What, if anything should be changed in the DIDSON operating protocol to improve evaluation of the effects of operating KHPS turbines?

These questions and answers will be addressed in Section 6 of this report, the summary.

\subsection{STUDY OBJECTIVES AND REPORTING}

The project objectives are as follows: 
1. Quantify near-field (i.e., within $12 \mathrm{~m}$ ) behavioral response and swimming trajectories of fish encountering an operating HK turbine using 373 hours of video from a deployed DIDSON multibeam hydroacoustics system. This is discussed in Section 2.

2. Quantify the far-field normal swimming trajectories and distribution of fish in the vicinity of the deployment site using previously collected data from a splitbeam hydroacoustics system during the same seasonal period. This is discussed in Section 3.1.

3. Characterize the relationship between flow dynamics and changes in behavior and distribution (nearand far-field) with correlation of concurrently collected acoustic Doppler current profiler (ADCP) data. This is discussed in Sections 2 and 3.1.

a. Near-turbine fish trajectories, avoidance behavior, and general distribution relative to near-field hydraulics (i.e., water velocity and tide direction) with and without the influence of a turbine.

b. Far-field vertical and horizontal distributions and trajectories of fish relative to water velocity and tide stage (ebb, flood and slack tide) with and without the influence of a turbine.

4. Update parameterization of existing fish interaction model developed for the East River and the RITE Project. This is discussed in Sections 3.2 and 4.2.

5. Use study results to assess which approaches (e.g., field observation, experimentation, models) will be most effective for predicting or monitoring the effects of turbine arrays. This is discussed in Section 5.

\subsection{ORIENTATION TO THE KHPS OPERATION}

Three fundamental understandings of the operation of the Verdant Power KHPS form the basis for this study. This section orients the reader to these elements: the KHPS turbine, operation in the tidal cycle, and the orientation of RMEE-2 seasonal DIDSON operation in September 2012 to the operating Gen5 KHPS.

\subsubsection{The Gen5 KHPS}

The KHPS turbine is a three-bladed horizontal-axis turbine (Figure 1-2) with four major assemblies:

- A rotor with three fixed blades that rotate at the relatively slow and constant speed of approximately 40 revolutions per minute (rpm) with tip-speeds of 35 feet per second. This is well below normal water vessel propeller speeds and conventional hydropower turbine blade speeds. The blade movement "self starts-stops" at flow speeds of approximately $1.0 \mathrm{~m} / \mathrm{s}$.

- A sealed nacelle, pylon, and passive yaw mechanism that are hydrodynamically designed to allow the turbine to self-yaw into the prevailing current flow when in the flood tide position like a weathervane, so that the blades are optimally aligned to generate energy. In the $180^{\circ}$ opposite direction, the ebb tide position, the yaw stop holds the turbine in a stationary position preventing it from self-seeking a variable flow orientation. Note that this feature will be important in the DIDSON analysis that follows.

- An enclosed generator and drivetrain within the nacelle serve as a horizontal-axis custom-designed drivetrain unit that integrates the bearing housing with a special long-life planetary gearbox with mechanical shaft seals and a minimum of sealed lubricants. 
- A streambed mounting system, which can vary depending on site conditions, as a single monopile, tri-frame mount (holds three turbines), or single concrete gravity-based structure.

For the effort completed in 2012 - which generated the DIDSON data- a modified Gen5 KHPS turbine was used on an existing in-river monopile for the period August 29, 2012 through and including September 10, 2012 (Figure 1-3).

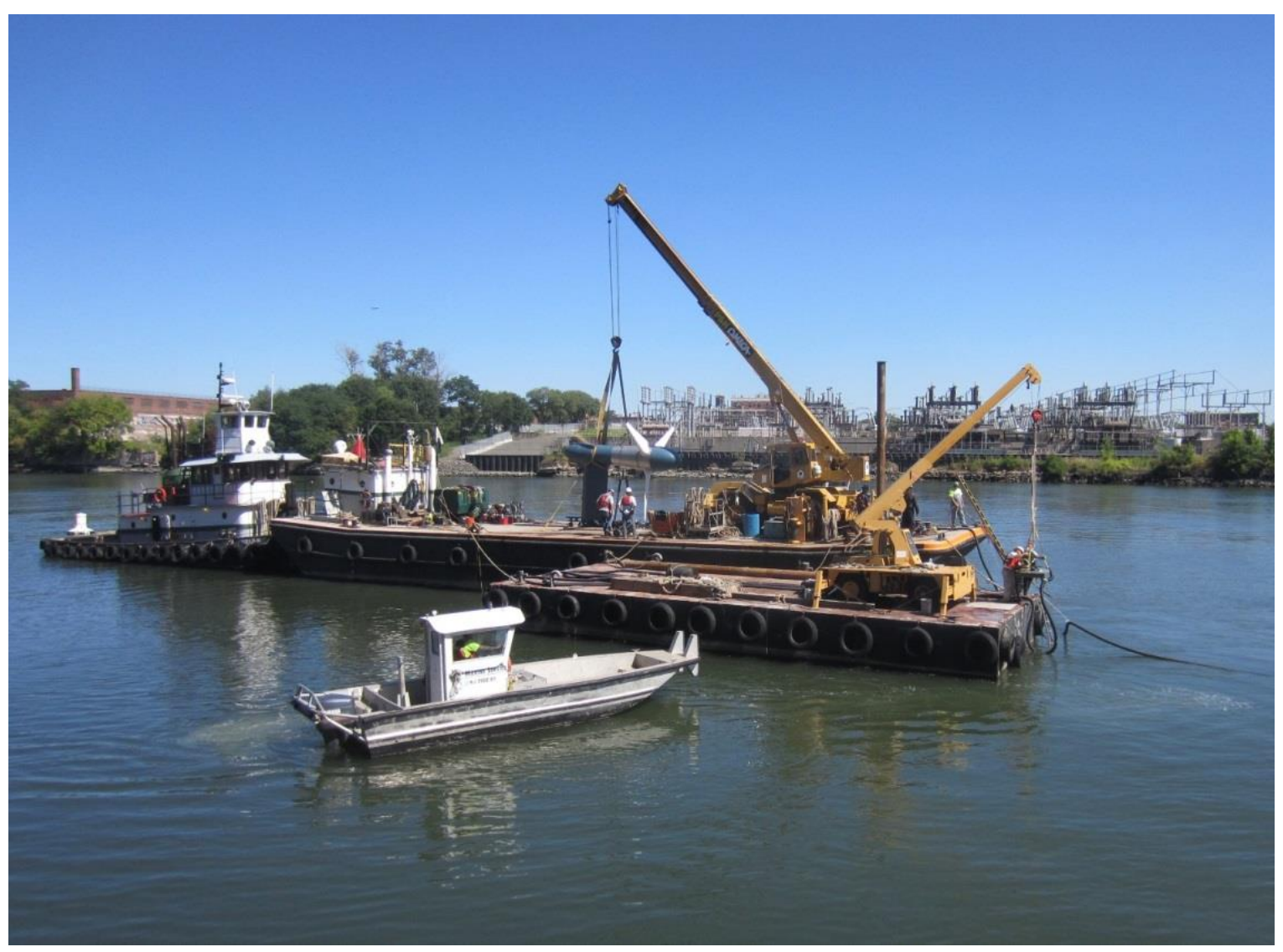

Figure 1-3. Gen5 KHPS turbine deployment with DIDSON (RAD) system being deployed (August 2012).

The multibeam hydroacoustics data analyzed in this study were collected using the RAD system deployed in the east channel of the East River in New York in September 2012. Figure 1-4 shows the orientation beam of the DIDSON relative to the operating Gen5 KHPS turbine. 


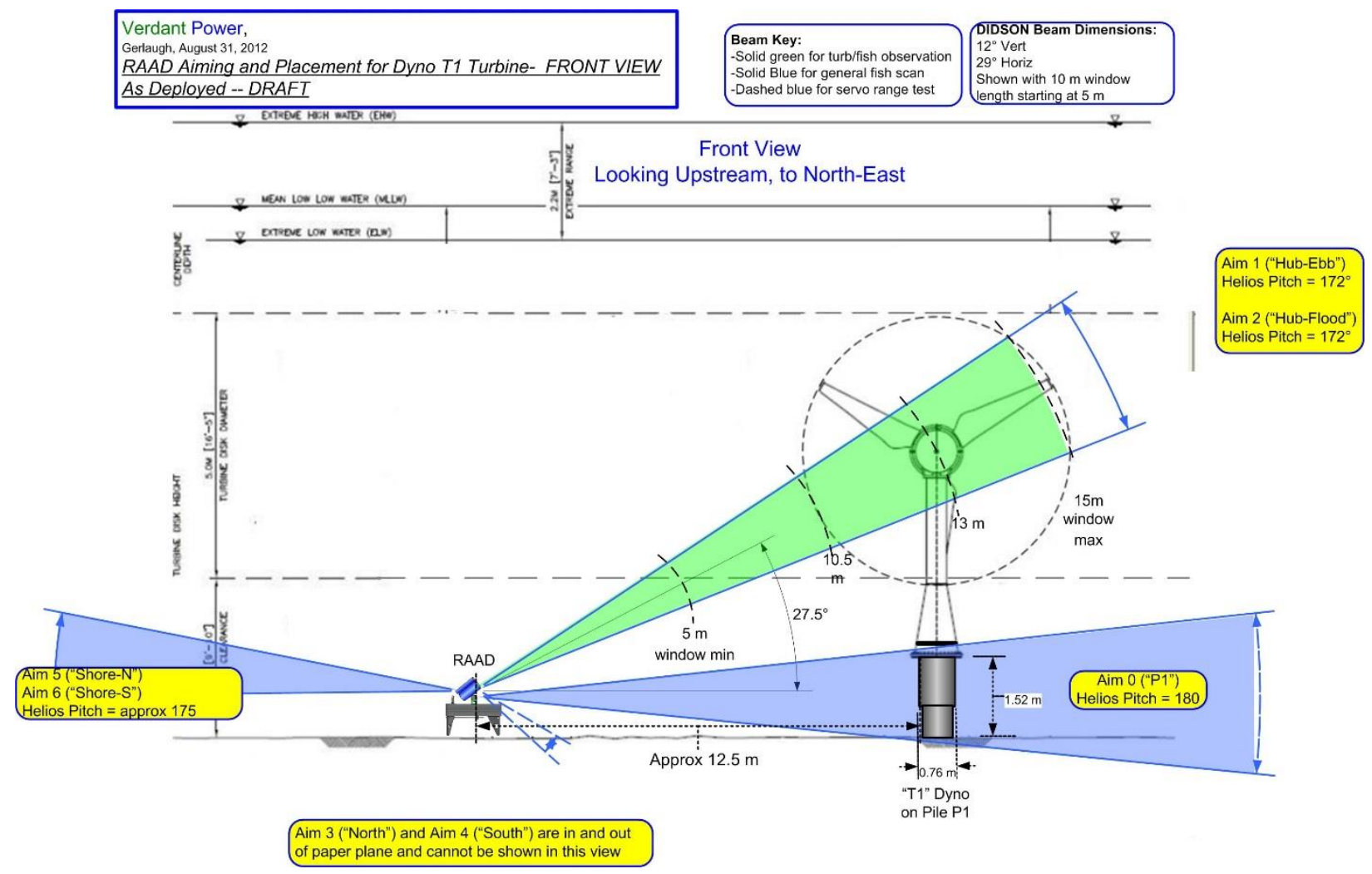

Figure 1-4. Deployed RAD system at RITE, September 2012. 



\section{DIDSON MULTIBEAM ANALYSIS}

\subsection{INTRODUCTION}

During 2012 construction testing of its Gen5 KHPS turbine at the RITE site (P-12611) in the East River, Verdant Power used a RAD system to collect images of passing fish in the vicinity of the turbine. In addition to the DIDSON, the RAD consisted of a ROS PT25 2-axis servo, a ROS underwater cable, a river bottom gravity mount, and a custom execution program that integrated the DIDSON aim and data collection. Concurrent stationary ADCPs also collected detailed tidal velocity measurements as the Gen5 horizontal axial turbine operated. These data were collected continuously for 19 days (August 30September 18, 2012) through multiple tidal cycles, including periods with and without the turbine in place and periods (according to water velocity conditions and video observation) when the turbine rotor was turning and when it was stationary. From August 29 through September 3, the RAD was put through various tests to ensure proper data collection and operation of the remote-control aiming system. Data were collected during this time, and the turbine was allowed to operate only during flood tides. Turbine operation began during ebb tides as well as flood tides on September 4 and continued through September 7. On September 8, the turbine testing was terminated, and turbine removal was completed on September 11. The DIDSON continued to collect data aimed at where the turbine had been located through September 14.

\subsubsection{Objectives}

The primary objective of this task was to analyze the multibeam hydroacoustics data to quantify nearfield fish behavior, such as a change in water-column position, swimming direction, and velocity, in response to encountering an operating full-scale HK turbine. Specifically, we wanted to determine whether fish actively avoided the operating turbine and, if not, whether there was any indication of actual contact with the rotating blades. The results of this analysis were used to augment the fish interaction model (see Section 3) and to assess whether multibeam acoustics is an effective approach for future monitoring of the effects of turbine arrays on fish behavior.

\subsubsection{Approach}

The DIDSON unit consists of 90 individual transducers lined up side to side (Figure 2-1), each of which sends out an acoustic ping approximately eight times per second. The effective sampling range from the DIDSON is 5 to $15 \mathrm{~m}$ from the unit. The column on which the turbine with $5 \mathrm{~m}$ diameter blades rotates is located at approximately $12.5 \mathrm{~m}$ from the DIDSON; but depending on the flow direction effect on the turbine position, the blade tips can be as close as $9.7 \mathrm{~m}$. The DIDSON data can be viewed as individual snapshots in time (Figure 2-2) or in the form of a video (this is why this technology is often referred to as an "acoustic camera"). These videos can be analyzed manually, but the results are only semi-quantitative; and for the amount of data collected in this study, manual analysis would not have been practical.

Therefore, we chose to analyze the data in an automated fashion using Echoview software (v5, Myriax Software Pty Ltd, Hobart, Tasmania, Australia). 


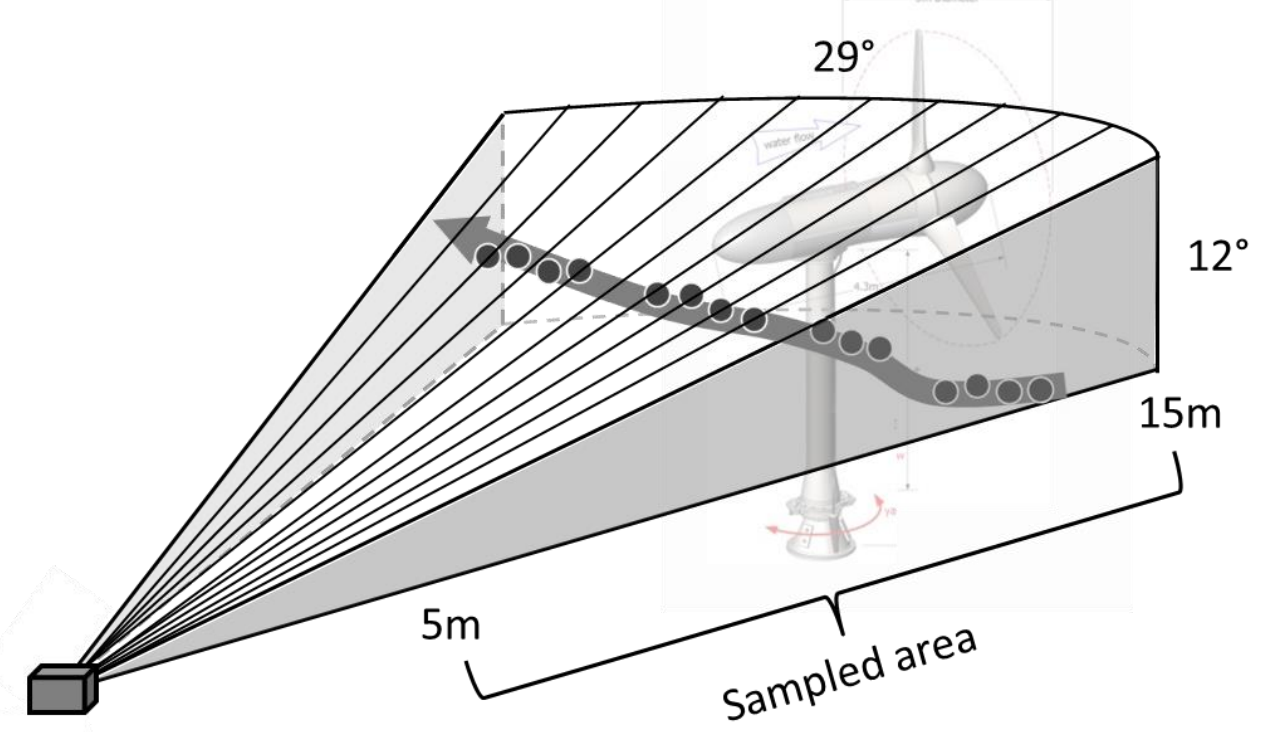

Figure 2-1. Dimensions of the surveyed field of the DIDSON multibeam hydroacoustics system with an example of a fish track (arrow) through the field constructed from individual signal returns (circles) of the same fish four times through time. This illustration shows only ten individual transducer fields, whereas in reality there are 90 .
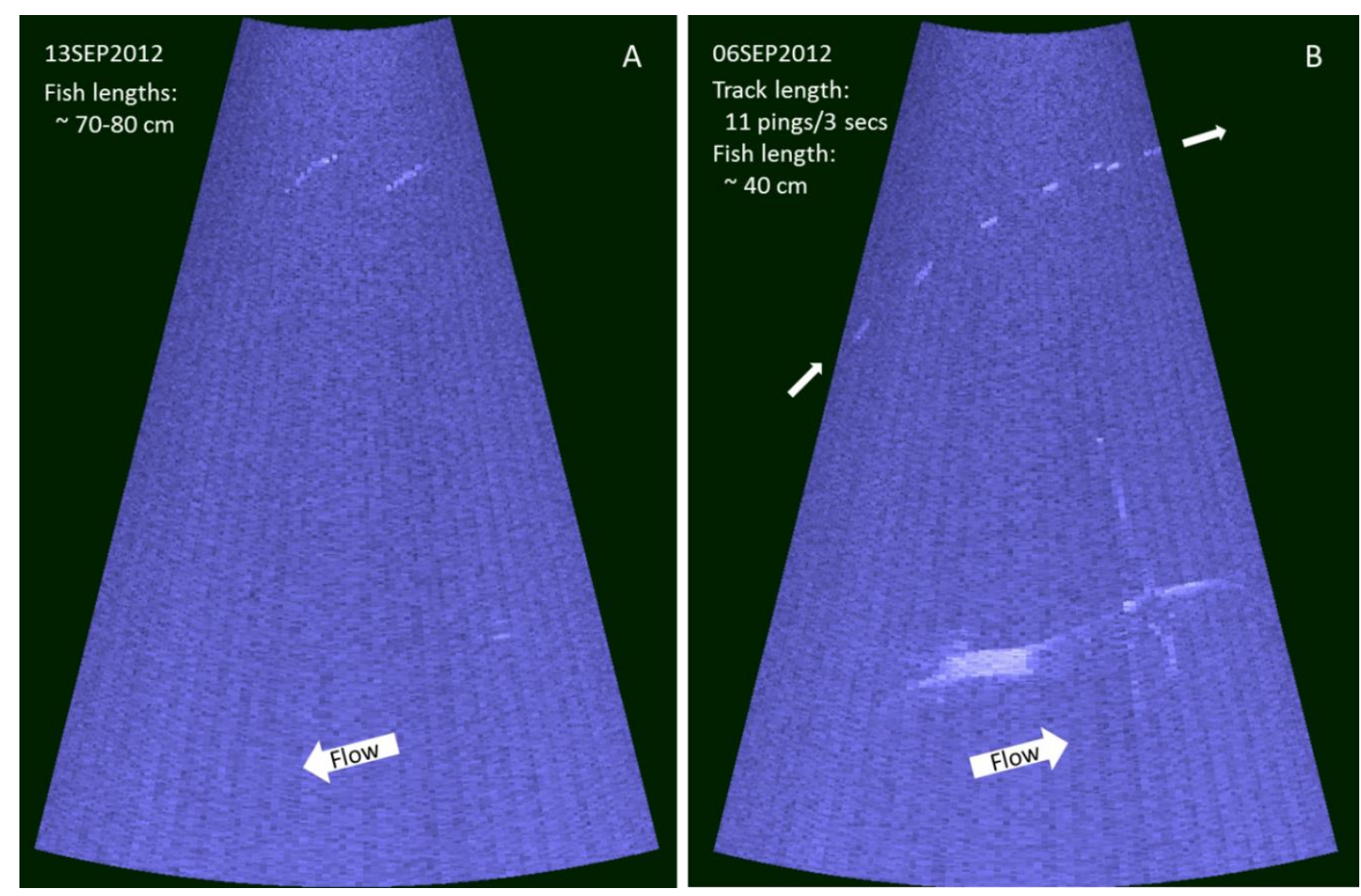

Figure 2-2. Plan view of the DIDSON acoustic camera field (5 to $15 \mathrm{~m}$ from DIDSON unit) with the DIDSON unit located $5 \mathrm{~m}$ above the field showing (A) two individual fish at a single point in time when the turbine was absent during ebb tide and $(B)$ a composite image of every other ping of a single fish track over a 3-s interval during flood tide. In panel $\mathrm{B}$, the turbine is at the bottom of the figure with the blades at the right end. 
An echo that returns after bouncing off a fish target (henceforth referred to as a target) to any of the 90 transducers includes information on the xyz location of the target within a particular transducer's field of view. A single fish is typically picked up by two or more transducers depending on the size and orientation, and through data processing, pings returned to adjacent transducers can be joined together as a single target, based on pre-defined time and distance thresholds for categorization as the same fish. The Echoview analysis assigns the joined target an estimate of target strength (a surrogate for size) and an xyz location within the DIDSON field. Targets identified in successive pings within a predefined distance of each other can be linked to create a track of an individual fish as it passes through the DIDSON sampling area (Figure 2-1). Analysis of individual tracks can provide information on direction of travel and swimming velocity.

We hypothesized that active avoidance might be detected in one or more metrics that measure direction and speed of travel, and we structured our automated analysis so that we could compare changes in fish behavior as a result of turbine presence or operation. We analyzed the data to provide comparisons of the metrics among the three modes of operation (turbine absent, turbine present but not rotating, and turbine rotating) during periods of the same tidal cycle (i.e., ebb or flood), and comparisons of differences in metrics based on nearness to turbine within each of the same operation modes individually.

\subsection{METHODS}

\subsubsection{Data Coverage}

The data sets were filtered to address normal operating conditions of a tidal turbine, including the signature associated with rotating blades, self-seeking flow orientation in the opposite direction (flood) instead of the firm position at the yaw stop (ebb), and the normal change of turbine orientation four times daily with tidal flow. Not all periods of data collection provided useful data for analysis, since some periods included turbine maintenance, RAD aimed away from the turbine, and turbine removal. Of 373 hours of useful DIDSON data, we analyzed 239 (64\%) distributed across ebb and flood tides, operation modes, and velocity classes (Figure 2-3). Note that since the turbine rotor would rotate only at velocities greater than $1 \mathrm{~m} / \mathrm{s}$, there were no observations for the low-velocity, turbine operating category. 

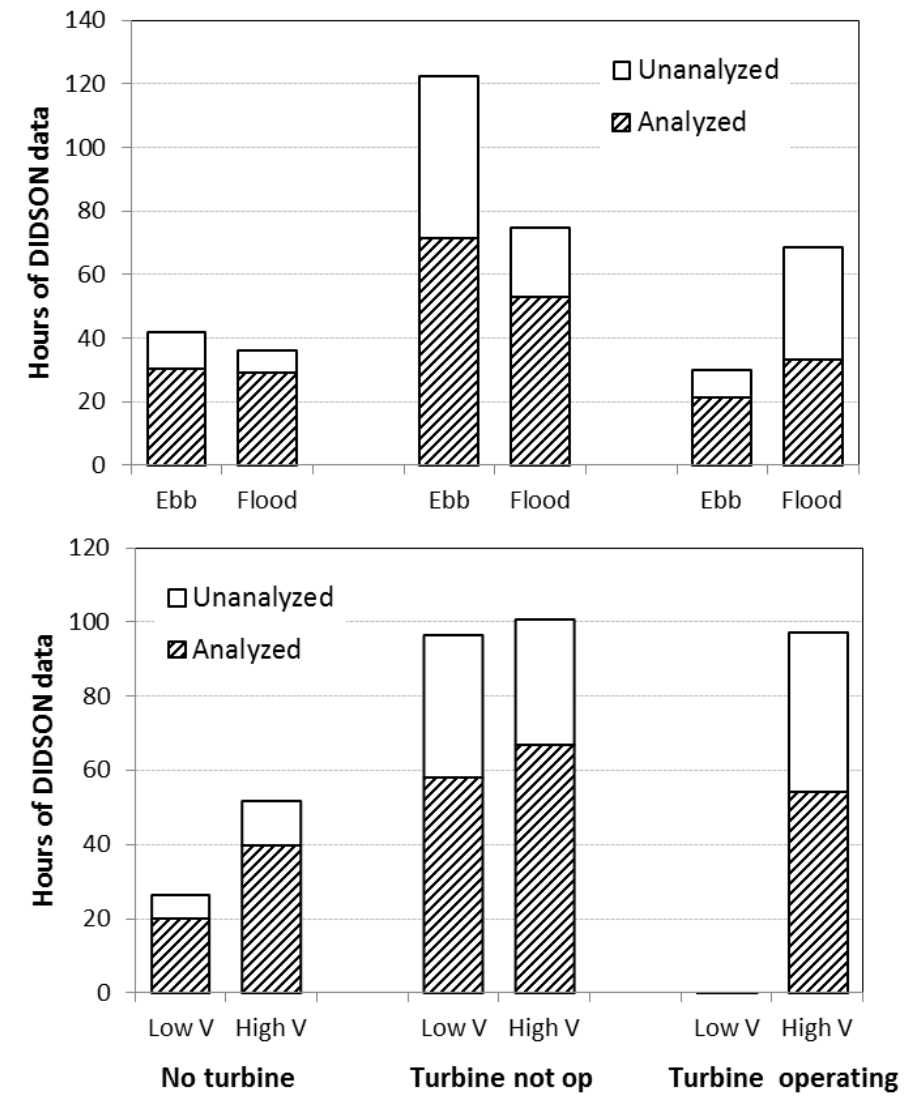

Figure 2-3. (Top) Number of hours of DIDSON data collection (analyzed and unanalyzed) by tide cycle and turbine operation mode. (Bottom) Number of hours of DIDSON data collection (analyzed and unanalyzed) by water velocity class and turbine operation mode.

\subsubsection{Echoview Analytical Details}

The raw DIDSON data files were divided into subsets by RAD aim and turbine position and operation. Each subset was processed with a series of filtering techniques to remove noise, interference, and the echo from stationary objects (e.g., the non-rotating turbine) so that all that remained were echoes of a signal strength greater than the smallest fish of interest. These data were then processed as described earlier to identify first fish targets at each point in time and then fish tracks from individual targets that were joined based on signal strength and distance.

Stationary objects, such as the locked turbine in the ebb position, are relatively easy to filter from the analysis, leaving the rest of the field open for analysis of fish targets. However, the moving rotor was difficult to filter from the DIDSON field, especially when the turbine was in the flood position and not locked in place but allowed to reposition itself to seek the optimal position for rotor rotation. Therefore, when the turbine was operating, we had to set an exclusion line across the DIDSON field at the point where the turbine was closest to the DIDSON unit. The exclusion zone for the different data subsets ranged from 9.7 to $12.1 \mathrm{~m}$ from the DIDSON depending on turbine rotor location, which depended on operation mode and tide direction. Fish movements in the area beyond the exclusion zone were analyzed manually for a subset of the period when the turbine was operating. Because the flow moves across the DIDSON beam, we used the surface area of the vertical side of the ensonified region to standardize among groups of analyses that excluded different amounts of the DIDSON sampled region. Without any exclusion, the sampled vertical area was $21.0 \mathrm{~m}^{2}$. With a still turbine, the vertical area sampled was 12.8 
$\mathrm{m}^{2}$ during ebb tide and $12.3 \mathrm{~m}^{2}$ during flood tide. With an operating turbine, the vertical area sampled was $12.5 \mathrm{~m}^{2}$ during ebb tide and $9.8 \mathrm{~m}^{2}$ during flood tide.

We used Echoview to generate two types of output files. The first was a csv file of every fish track along with associated information for over 20 descriptive variables. The second was a csv file of individual targets that included information on each fish each time it was identified, including an estimate of body length based on the distance between the two echoes most distant from each other that comprised the fish. For the best estimate of the body length of a fish in a track we searched the individual target data set and extracted the maximum length of those individual targets with a ping number that corresponded to the range of pings defined for a fish track.

\subsubsection{Echoview Validation}

Correct identification of fish targets is primarily based on establishing a signal strength threshold that captures fish of the size of interest while at the same time excluding fish smaller than the size of interest. Because the fish orientation, its distance from the transducer, and other factors affect the strength of a returned signal, the range of signal strengths for fish of a given size can be quite variable. In other words, it is impossible for automated analysis to capture every fish of a desired size that passes through the acoustic field. Therefore, we performed a validation exercise to determine the efficiency of our calibrated analysis.

We observed 112 min of DIDSON data in video form from September 1 and September 5 and, without knowledge of the automated processing results, noted the time, ping numbers, minimum and maximum range (i.e., distance from DIDSON), and length of each fish target that appeared to be roughly $>10 \mathrm{~cm}$. These data were compared with the automated results for the same periods. Of the 181 unique tracks (individual and schools) observed by the two methods, $74 \%$ were captured via the automated analysis. Of those not captured by the automated analysis, nearly all were small in size (based on visual observation) and likely just below the signal strength threshold established for inclusion; a few were larger but were seen only for two consecutive pings. Based on our validation, we believe that the automated method provided an accurate accounting of fish of the size range of interest that passed through the DIDSON beam during the sampling period.

During validation of the Echoview analysis, and while performing other visual assessments of the data, we used the measuring tool in Echoview to hand measure more than 100 individual fish of all sizes. These measurements were made on the clearest image of a track sequence and should be accurate within 10$20 \%$ in most cases. The manual measurements were compared with the estimated maximum size for the same individual generated through analysis of the Echoview output, and unfortunately, we found poor agreement between the two estimates. Therefore, we did not include size as a variable in further analysis of the automated data collection. We did, however, use the signal strength to identify likely large fish for our manual analysis of fish passing near the rotating turbine blades.

\subsubsection{Metrics Evaluated}

Output from the Echoview analysis included location, heading, and velocity of each fish as it passed through the multibeam field. Each track included information about the beginning and ending xyz location in the beam, time in the beam, and returned signal strength, from which direction of movement, velocity, track linearity, and fish size could be estimated. Fish avoiding the turbine might be expected to change depth, swim faster, swim in a direction away from the turbine, or deviate from a straight course. Key dependent variables that were evaluated included: 
- Horizontal direction (degrees): The linear direction (or compass heading) of a fish track in the plane roughly parallel to the surface of the water. This value ranged from 0 to $360^{\circ}$, with the ebb current running at a heading of approximately $40-55^{\circ}$ and flood at approximately $219-236^{\circ}$ depending on the aim of the DIDSON relative to the turbine location.

- Vertical direction (degrees: The linear direction of a fish track in the vertical plane (i.e., depth) with $+90^{\circ}$ being straight up and $-90^{\circ}$ being straight down .

- Lateral movement (m): The amount of change in position of a fish track relative to a straight line between the DIDSON and the turbine, ranging from 0 to $10 \mathrm{~m}$.

- Tortuosity (unitless): A measure of straightness of a track based on the xyz position of each point in time that makes up a track. It is calculated as the sum of the distances between adjacent targets in a track (that is, the total distance traveled) divided by the straight line distance between the first and last targets in a track (Johnson and Moursund, 2000). A value of 1 refers to a straight line, while the value of a crooked line is theoretically boundless.

- Swimming velocity $(\mathrm{m} / \mathrm{s})$ : Calculated as the total distance covered by a track divided by the duration of the track.

These behavioral responses were evaluated as a function of:

- Turbine presence or absence: The turbine was present from August 29 to September 8 and absent from September 11 to September 14.

- Turbine operation (rotating or not): When in place, the turbine rotor generally rotated at water velocities in excess of $1 \mathrm{~m} / \mathrm{s}$ except from August 29 through September 3, when the rotor was allowed to rotate only during flood tides for testing purposes.

- Tide (ebb or flood): A complete tidal cycle in the East River during the period of analysis was estimated at $12 \mathrm{~h} 24 \mathrm{~min}$, with flood tide leading up to a high tide averaging about $6 \mathrm{~h} 24 \mathrm{~min}$ in duration, and an ebb tide leading up to a low tide averaging about $6 \mathrm{~h}$.

- Current velocity (low, medium, high): Each fish track observation was associated with one of three current velocity classes based on the tidal cycle time. The first sixth of a tide $(1 \mathrm{~h}$ for ebb and $1 \mathrm{~h} 4$ min for flood) was classified as low velocity, the second sixth as medium, the third and fourth sixths as high, the fifth sixth as medium, and the last sixth as low. Although this did not provide a specific velocity cutoff for each category, it did provide bins of equal duration, which we believe provided for a better analysis given that velocities vary a little from day to day. On average, this meant that the low-velocity-class velocities were approximately 0 to $1.5 \mathrm{~m} / \mathrm{s}$, the medium class approximately $1.5-$ $2.1 \mathrm{~m} / \mathrm{s}$, and the high class approximately 2.1 to $2.5 \mathrm{~m} / \mathrm{s}$.

- Relative direction (with or against): Whether a fish was swimming with the current or against it was determined by comparing the horizontal direction output from Echoview with the direction of the tide for each fish track observation. Based on the distribution of horizontal direction data for two different RAD aims, directions between 145 and $325^{\circ}$ were considered to be traveling in the flood direction, and directions between 0 and $145^{\circ}$ and $>325^{\circ}$ were considered to be in the ebb direction. A fish swimming in the ebb direction during a flood tide was considered to be traveling against the current, and so forth. 
- Distance from the DIDSON (or conversely from the turbine): Data were collected within a range of 5 to $15 \mathrm{~m}$ from the DIDSON unit. The mean distance from the DIDSON for each track as it passed through the field was included in the analysis. For reference, the turbine body was located at about $11.5 \mathrm{~m}$ from the DIDSON and the turbine rotor from 10 to $15 \mathrm{~m}$ distance when present.

\subsubsection{Direct Observation of Turbine Interactions}

To minimize false detections caused by the moving rotor, we established an exclusion depth at the tips of the rotor blades for many analyses (typically 10-11 $\mathrm{m}$ from the DIDSON during ebb tides and 11-12 $\mathrm{m}$ during flood tides) beyond which signals were excluded from automated analysis. Therefore, since we were unable to automatically assess fish that might encounter the rotor directly, we used the output data to identify fish tracks that were most likely to cross the exclusion line and encounter the rotor; we evaluated those tracks manually. Such occurrences were most likely during ebb tides when the direction of the flow, which was not perpendicular to the DIDSON beam, was at an angle that would take fish across the exclusion zone if they were within a meter of the excluded area near the turbine. We filtered the 34,705 fish tracks based on tide (ebb), turbine operation (rotating), fish length (Echoview estimated $>15 \mathrm{~cm}$ ), and maximum target depth $(>9 \mathrm{~m})$. Alone, these three criteria were met by $69,10,16$, and $18 \%$ of the tracks; but in combination, they were met by only $\sim 0.1 \%$ (36 tracks). Each of these tracks was evaluated manually to determine if any culminated in turbine interaction or active avoidance.

During the previously described validation exercise that included $112 \mathrm{~min}$ of data, we also noted every fish that passed near the turbine that was not captured by the automated analysis. As well, during the processing of other subsets of the data, we noted anecdotally fish targets that had close encounters with the turbine.

\subsection{RESULTS}

\subsubsection{Fish Tracks Count}

Our analysis resulted in the identification of 34,705 fish tracks, distributed as 11,641 and 4,049 during ebb and flood tides, respectively, without a turbine in place; 10,490 and 5,076 during ebb and flood tides with a non-rotating turbine; and 1,734 and 1,715 during ebb and flood tides with a rotating turbine. Subsequent review of a subset of the tracks indicated that many of these tracks were actually schools of tens to hundreds of small fish and not individual fish. On a per-hour basis, more tracks were observed when the turbine was not in place than when it was (Table 2-1). These numbers were also evaluated after accounting for the smaller area analyzed when the turbine was rotating as described earlier, and, even with that correction, the rate of fish passing by the turbine was lowest when the turbine was operating.

Parsing the count of fish tracks by turbine operation mode, tide, and velocity revealed differences associated with each category (Table 2-2). The number of tracks per hour observed was generally higher during ebb tides than during flood tides and generally increased with increasing current velocity. The count per hour was highest when the turbine was absent and lowest when the turbine was rotating. 
Table 2-1. Number of fish tracks observed per hour of data analyzed during three turbine operation modes for ebb and flood tide directions. Hours of data analyzed are shown in parentheses. The grand average (total counts/total time) was standardized by the vertical area sampled, as determined by the location of the exclusion line necessary to avoid moving blades in analysis

\begin{tabular}{|c|c|c|c|c|c|c|c|}
\hline \multirow[b]{2}{*}{ Date } & \multicolumn{2}{|c|}{ No turbine } & \multicolumn{2}{|c|}{ Turbine not rotating } & \multicolumn{2}{|c|}{ Turbine rotating } & \multirow{2}{*}{$\begin{array}{c}\text { Grand } \\
\text { Total }\end{array}$} \\
\hline & Ebb & Flood & Ebb & Flood & Ebb & Flood & \\
\hline 20120829 & - & - & $\begin{array}{r}776.6 \\
(1.9)\end{array}$ & - & - & - & 776.6 \\
\hline 20120830 & - & - & $\begin{array}{r}310.8 \\
(3.6)\end{array}$ & $\begin{array}{r}135.7 \\
(6.0)\end{array}$ & - & - & 201.4 \\
\hline 20120831 & - & - & $\begin{array}{r}116.7 \\
(3.4)\end{array}$ & $\begin{array}{r}314.6 \\
(1.9)\end{array}$ & - & - & 109.2 \\
\hline 20120901 & - & - & $\begin{array}{r}152.9 \\
(11)\end{array}$ & $\begin{array}{r}365.8 \\
(3.4)\end{array}$ & - & $\begin{array}{l}21.7 \\
(3.8)\end{array}$ & 138.4 \\
\hline 20120902 & - & - & $\begin{array}{r}294.9 \\
(5.3)\end{array}$ & $\begin{array}{r}133.3 \\
(1.7)\end{array}$ & - & $\begin{array}{l}44.8 \\
(7.9)\end{array}$ & 210.2 \\
\hline 20120903 & - & - & $\begin{array}{l}59.3 \\
(6.5)\end{array}$ & $\begin{array}{r}16.0 \\
(1.4)\end{array}$ & - & $\begin{array}{l}74.8 \\
(1.9)\end{array}$ & 59.6 \\
\hline 20120904 & - & - & $\begin{array}{r}143.0 \\
(7.0)\end{array}$ & $\begin{array}{r}32.1 \\
(1.7)\end{array}$ & $\begin{array}{r}112.3 \\
(4.3)\end{array}$ & $\begin{array}{l}93.6 \\
(4.3)\end{array}$ & 113.0 \\
\hline 20120905 & - & - & $\begin{array}{l}28.2 \\
(4.1)\end{array}$ & $\begin{array}{r}136.2 \\
(3.8)\end{array}$ & $\begin{array}{l}78.8 \\
(8.2)\end{array}$ & $\begin{array}{l}69.4 \\
(7.2)\end{array}$ & 76.5 \\
\hline 20120906 & - & - & $\begin{array}{l}29.2 \\
(2.6)\end{array}$ & $\begin{array}{l}47.6 \\
(2.9)\end{array}$ & $\begin{array}{l}83.6 \\
(4.3)\end{array}$ & $\begin{array}{l}74.0 \\
(3.8)\end{array}$ & 62.8 \\
\hline 20120907 & - & - & $\begin{array}{r}7.3 \\
(1.0)\end{array}$ & - & $\begin{array}{l}60.0 \\
(4.1)\end{array}$ & $\begin{array}{l}18.1 \\
(0.7)\end{array}$ & 46.0 \\
\hline 20120908 & - & - & $\begin{array}{r}153.9 \\
(6.5)\end{array}$ & $\begin{array}{l}40.6 \\
(3.6)\end{array}$ & - & - & 113.4 \\
\hline 20120909 & - & - & $\begin{array}{r}70.4 \\
(12.7)\end{array}$ & $\begin{array}{r}32.5 \\
(11.3)\end{array}$ & - & - & 52.6 \\
\hline 20120910 & - & - & $\begin{array}{r}122.6 \\
(6.2)\end{array}$ & $\begin{array}{l}57.6 \\
(9.6)\end{array}$ & - & - & 83.2 \\
\hline 20120911 & $\begin{array}{r}216.7 \\
(0.5)\end{array}$ & - & $\begin{array}{l}80.0 \\
(0.1)\end{array}$ & $\begin{array}{l}69.8 \\
(5.8)\end{array}$ & - & - & 81.1 \\
\hline 20120912 & $\begin{array}{r}589.5 \\
(12.0)\end{array}$ & $\begin{array}{r}173.6 \\
(12.0)\end{array}$ & - & - & - & - & 381.5 \\
\hline 20120913 & $\begin{array}{r}302.9 \\
(12.0)\end{array}$ & $\begin{array}{r}145.8 \\
(11.3)\end{array}$ & - & - & - & - & 226.8 \\
\hline 20120914 & $\begin{array}{r}138.0 \\
(6.0)\end{array}$ & $\begin{array}{l}53.5 \\
(6.0)\end{array}$ & - & - & - & - & 95.8 \\
\hline Grand average & 381.9 & 138.3 & 146.2 & 95.7 & 83.0 & 51.4 & \\
\hline $\begin{array}{l}\text { Standardized to } \\
\text { no turbine }\end{array}$ & 381.9 & 138.3 & 239.8 & 163.6 & 140.3 & 110.0 & \\
\hline
\end{tabular}


Table 2-2. Number of fish tracks observed per hour of data analyzed during three turbine operation modes for ebb and flood tide direction and three velocity classes. Each of the three velocity classes was equal to approximately $2 \mathrm{~h}$ of a $6 \mathrm{~h}$ tide cycle with low velocity generally equivalent to $0-1.5 \mathrm{~m} / \mathrm{s}$, medium velocity to $1.5-$

$2.1 \mathrm{~m} / \mathrm{s}$, and high velocity to $2.1-2.5 \mathrm{~m} / \mathrm{s}$

\begin{tabular}{lrrrrrrrr}
\hline \multirow{2}{*}{ Velocity } & \multicolumn{2}{c}{ No turbine } & \multicolumn{2}{c}{ Turbine not rotating } & \multicolumn{2}{c}{ Turbine rotating } & \multirow{2}{*}{ Row mean } \\
\cline { 2 - 7 } & Ebb & \multicolumn{1}{c}{ Flood } & Ebb & \multicolumn{1}{c}{ Flood } & Ebb & \multicolumn{1}{c}{ Flood } & \\
\hline Low & 217 & 104 & 79 & 93 & 78 & 83 & $\mathbf{1 0 5}$ \\
Medium & 350 & 116 & 166 & 100 & 70 & 40 & $\mathbf{1 3 3}$ \\
High & 589 & 194 & 223 & 98 & 88 & 52 & $\mathbf{1 9 3}$ \\
Column mean & $\mathbf{3 8 2}$ & $\mathbf{1 3 8}$ & $\mathbf{1 4 6}$ & $\mathbf{9 6}$ & $\mathbf{7 9}$ & $\mathbf{4 9}$ & $\mathbf{1 4 3}$ \\
\hline
\end{tabular}

\subsubsection{Spatial Distribution}

In addition to consideration of operation mode, tide, and current velocity, the number of fish tracksspecifically the number per hour-can also be viewed relative to the nearness to the turbine (or distance from the DIDSON unit; Figure 2-4). In all cases, the greatest number of tracks occurred in the nearshore region, i.e., farthest from the turbine. For the different categories (e.g., high velocity, no turbine) 65-80\% of the tracks were in the region of 5-8 $\mathrm{m}$ from the DIDSON unit even though this portion of the beam has the smallest cross-sectional area and sampling volume. The observation we noted earlier that the number of tracks with no turbine present is greater than when the turbine is present but not operating which is in turn greater than when turbine is present and operating is consistent for all distances from the turbine.

\subsubsection{General Swimming Direction}

An evaluation of fish swimming direction relative to current direction revealed that overall $16 \%$ of the fish tracks were in a direction against the current (Table 2-3). Among velocity classes, swimming against the current at low velocity was roughly twice as frequent as at higher velocities. Differences among operations were small, but fewer fish swam against the current when the turbine was operating than when it was absent. Differences between ebb and flood tides were minimal when the turbine was absent but were markedly different with a non-operating turbine (higher against the current during flood tide) and even more different when the turbine was operating. 

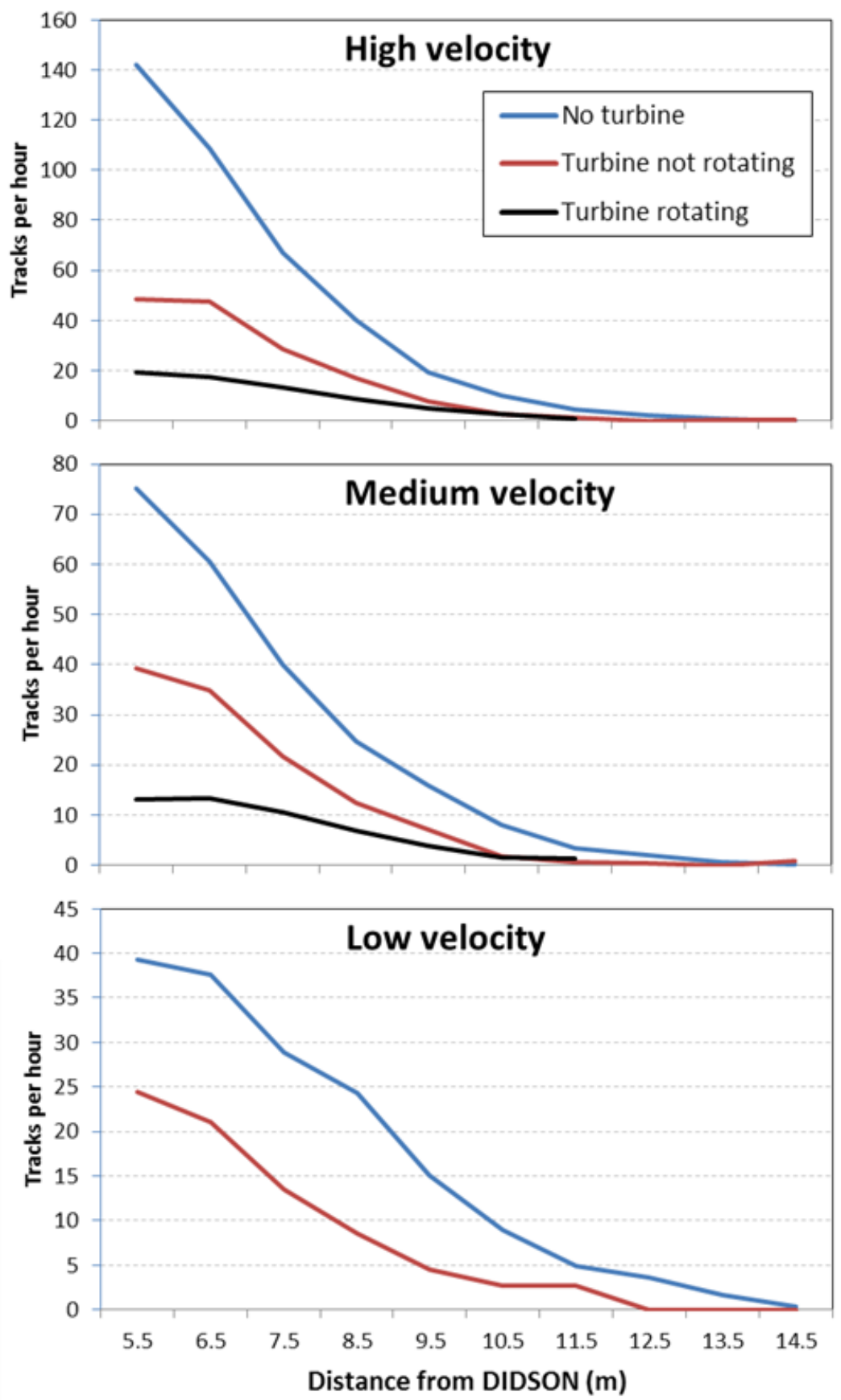

Figure 2-4. Number of fish tracks per hour during three operation modes (no turbine, turbine not rotating, and turbine rotating) summarized by distance from the DIDSON unit ( $1 \mathrm{~m}$ blocks) and by three current velocity classes (high, medium, and low). The low-velocity/turbine rotating class was not included, as there was less than an hour of data for this group because the turbine does not rotate below $1 \mathrm{~m} / \mathrm{s}$. 
Table 2-3. Summary of distribution of fish tracks against the current (\%) for three operating conditions, ebb and flood tides and three current velocity classes

\begin{tabular}{|c|c|c|c|c|c|c|c|c|c|c|}
\hline \multirow{2}{*}{$\begin{array}{c}\text { Velocity } \\
\text { class }\end{array}$} & \multicolumn{3}{|c|}{ No turbine } & \multicolumn{3}{|c|}{ Turbine not rotating } & \multicolumn{3}{|c|}{ Turbine rotating } & \multirow{2}{*}{$\begin{array}{l}\text { Row } \\
\text { mean }\end{array}$} \\
\hline & Ebb & Flood & All & Ebb & Flood & All & Ebb & Flood & All & \\
\hline Low & 32.2 & 22.1 & 29.2 & 21.1 & 30.4 & 25.9 & 4.8 & 19.0 & 14.6 & 26.9 \\
\hline Medium & 10.8 & 9.4 & 10.4 & 10.4 & 11.0 & 10.6 & 4.0 & 15.1 & 9.4 & 10.4 \\
\hline High & 14.9 & 17.2 & 15.5 & 12.3 & 10.9 & 12.0 & 8.2 & 18.8 & 13.3 & 13.9 \\
\hline Mean & 17.2 & 16.1 & 16.9 & 13.7 & 20.9 & 16.0 & 6.3 & 17.4 & 11.8 & 16.0 \\
\hline
\end{tabular}

\subsubsection{Change in Range}

Change in range refers to whether a fish moves closer to the turbine (positive values) or farther from it (negative values) during the time when it crosses through the DIDSON beam. Because the DIDSON position relative to the turbine is not perpendicular to the flow, the modes of the distributions for ebb and flood tides do not center around 0 (Figure 2-5). Both distributions suggest there is little difference between no turbine and a rotating turbine; however, during ebb tide, fish observed with a non-rotating turbine seemed to move away from the turbine location more than fish observed when the turbine was absent. The general direction of flow during ebb tides is in a direction that is angled slightly away from the DIDSON and toward the turbine, and vice versa for the flood tide. Change in range can also be evaluated as a function of nearness to the turbine (Figure 2-6). During flood tides, fish exposed to the turbine (operating or not) seemed to maintain a heading alongside the turbine as they got closer to it instead of moving away as when the turbine was absent.

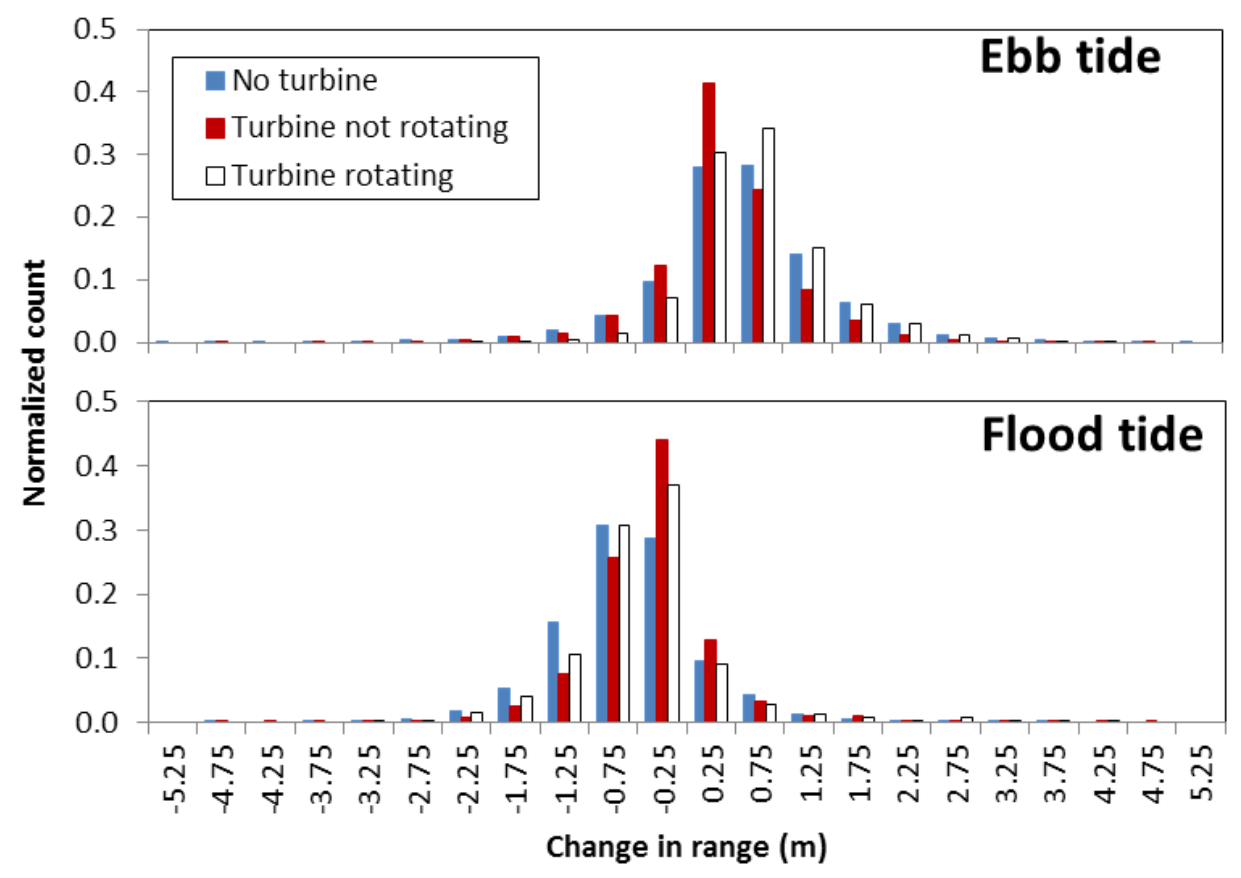

Figure 2-5. The distribution (normalized to the total tracks for any operating mode and tide combination) of lateral movement distance, i.e., moving toward [+] or away from [-] turbine for three turbine operation modes and ebb and flood tides. Each $\mathrm{x}$-axis value is the midpoint of a $0.5 \mathrm{~m}$ bin. 

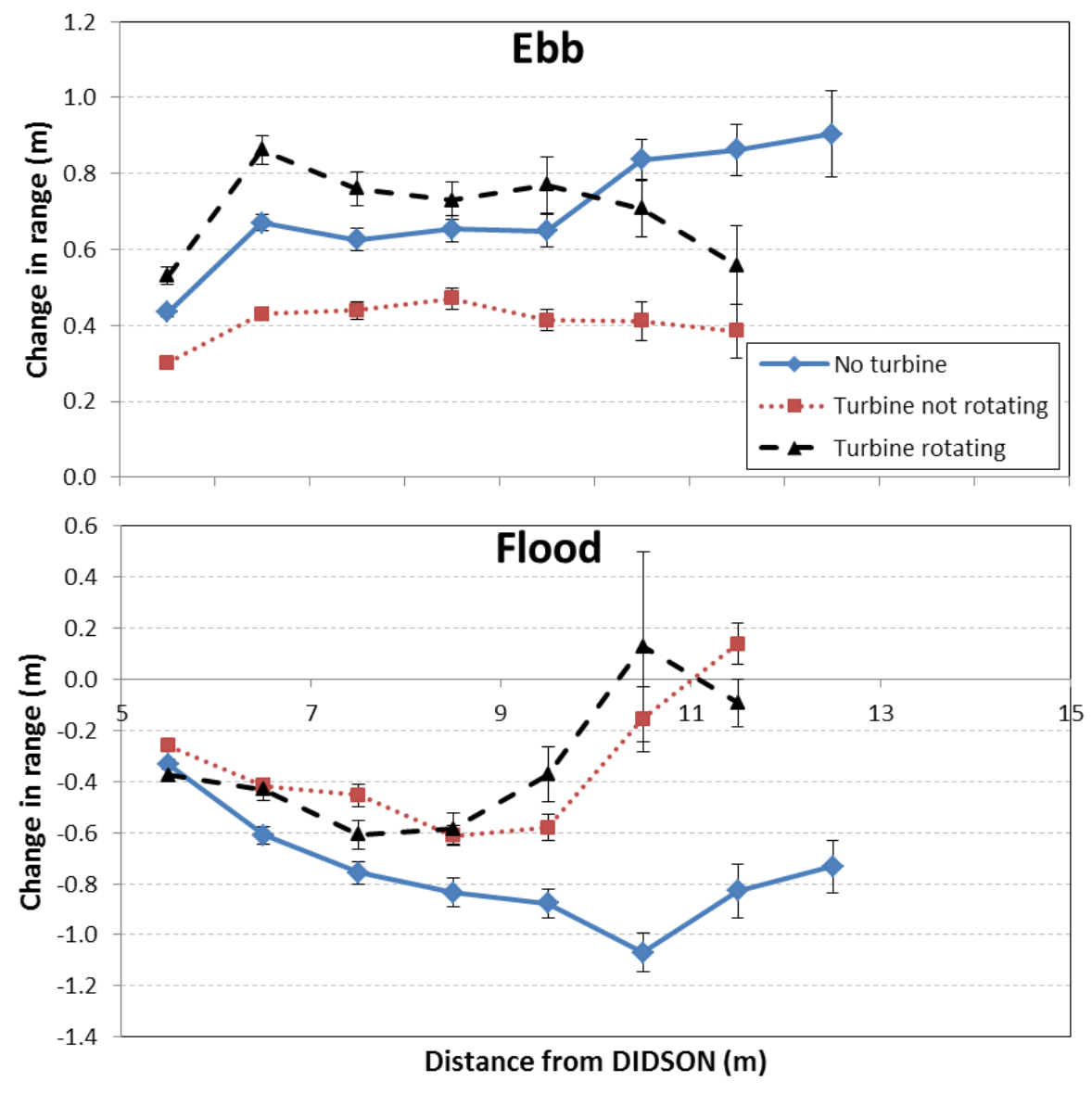

Figure 2-6. Mean ( $\pm 1 \mathrm{SE})$ change in range $(\mathrm{m})$ for each fish track as a function of the mean distance from the DIDSON acoustic unit. Note that the DIDSON is located at $0 \mathrm{~m}$ and the turbine between 11 and 15, depending on orientation and operation.

\subsubsection{Vertical Direction}

Vertical movement was analyzed as either upward ( 0 to $+90^{\circ}$ angle) or downward movement ( 0 to $-90^{\circ}$ angle) irrespective of what depth the track originated from with +90 indicating movement straight up and with -90 being straight down. An analysis of the distributions of vertical direction data for the three operating modes and two tides revealed that neither ebb nor flood tide distributions are centered on 0 (Figure 2-7), probably for a combination of two reasons: (1) the DIDSON was not aimed completely parallel to the surface, and (2) the bottom topography creates prevailing currents that most fish ride that also are not parallel to the surface. For both tides, the distributions for the no turbine case and the operating turbine case are similar; but for both tides, the non-rotating turbine case produced tracks with less vertical slope, meaning less upward or downward movement over the course of the track. Analysis of vertical direction as a function of nearness to the turbine produced mixed results but also showed that the non-rotating turbine often resulted in tracks with less change in vertical position (Figure 2-8). The rotating-turbine tracks differed the most from the no-turbine tracks (1) during ebb tides, and (2) during flood tides when the tracks were close to the turbine for downward tracking fish. During flood tide there was a large increase in downward movement near the stationary (not rotating) turbine at 10-12 $\mathrm{m}$ range but there were not enough observations when the turbine was absent or when rotating for a comparison. 


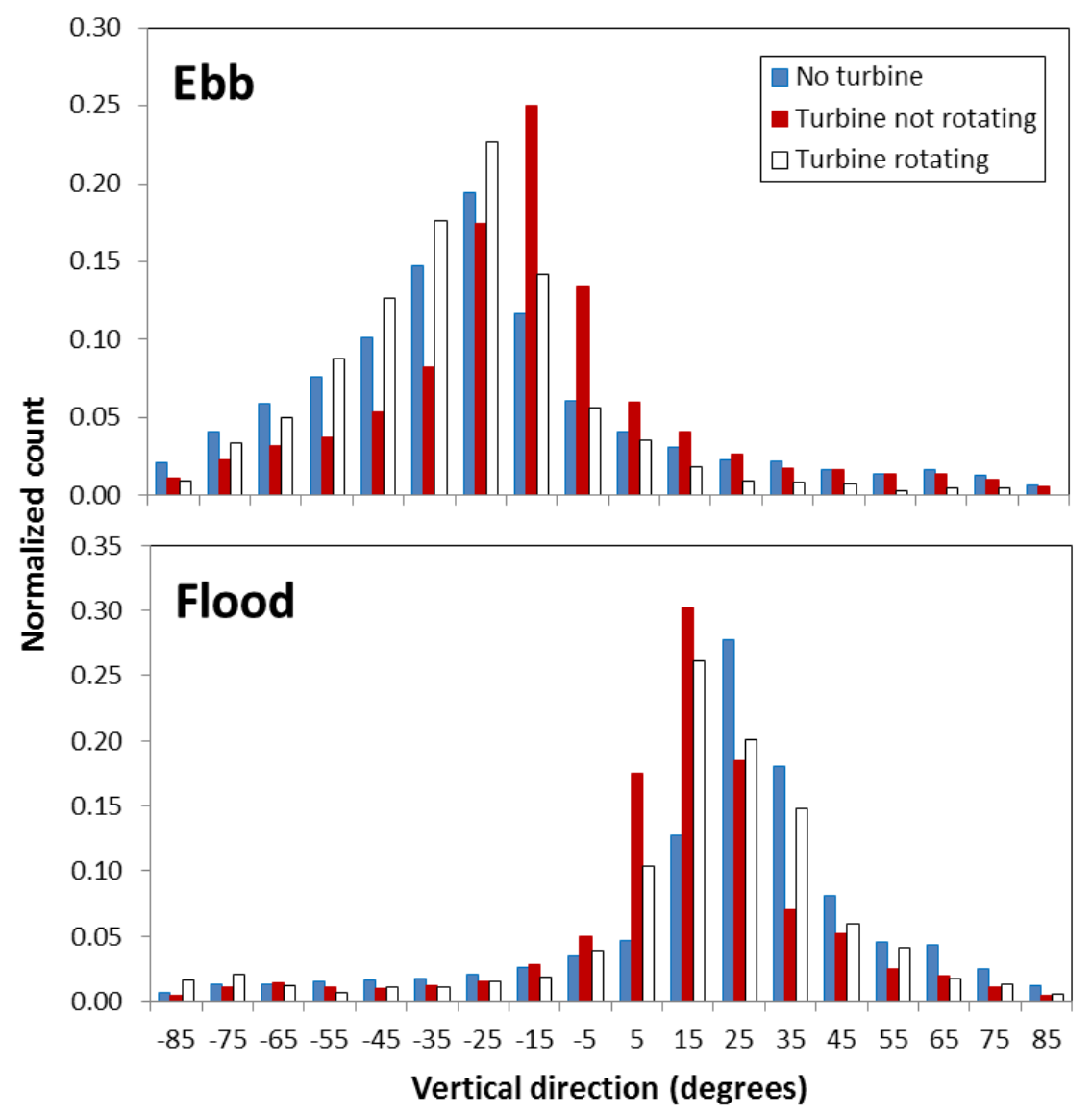

Figure 2-7. The distribution (normalized to the total tracks for any operating mode and tide combination) of vertical direction of fish tracks in degrees for three turbine operation modes and ebb and flood tides. Each $\mathrm{x}$ axis value is the midpoint of a $10^{\circ}$ bin. 

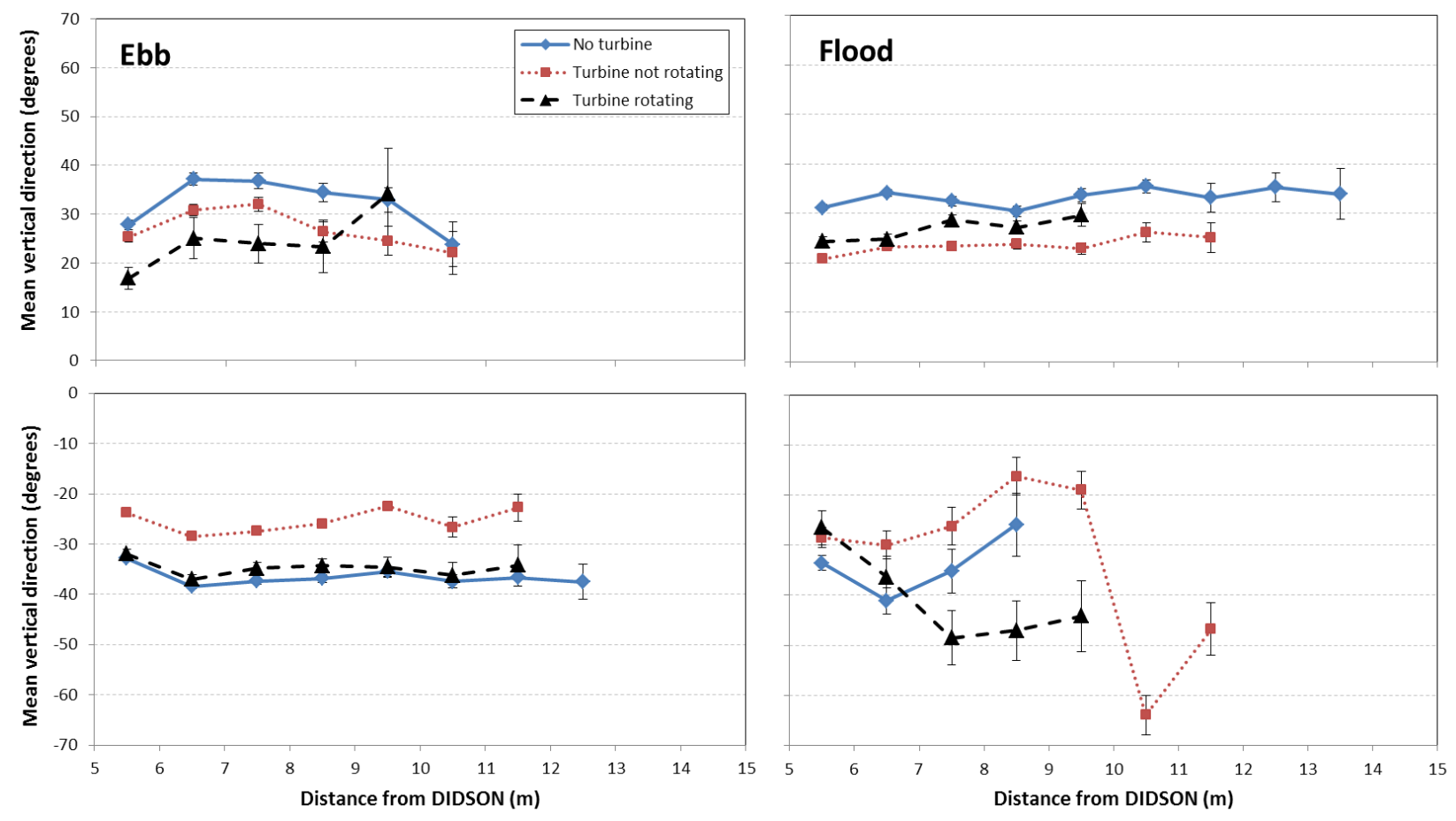

Figure 2-8. Mean $\left( \pm 1\right.$ SE) vertical direction $\left({ }^{\circ}\right)$ for each fish track during ebb and flood tides as a function of the mean distance from the DIDSON acoustic unit. Upward and downward moving tracks are presented separately in the top and bottom panels, respectively. Note that the DIDSON is located at $0 \mathrm{~m}$ and the turbine between 11 and 15, depending on orientation and operation.

\subsubsection{Horizontal Direction}

The prevailing current direction was a function of the tide direction and the camera aim selected. In addition, fish direction also had to be parsed by whether the fish were swimming with or against the current. Only one combination of tide (ebb) and RAD aim (1) provided enough tracks over two different 4 day periods for a comparison of no turbine (September 11-14) versus operating turbine (September 0407) (Figure 2-9). For both operation modes, the variation around the central tendency was greater for fish swimming against the current than for those swimming with the current. For both operating modes, the horizontal direction for $95 \%$ of the tracks was within a $2^{\circ}$ range. There is little indication of any effect of the operating turbine on horizontal direction for fish swimming with or against the current. 

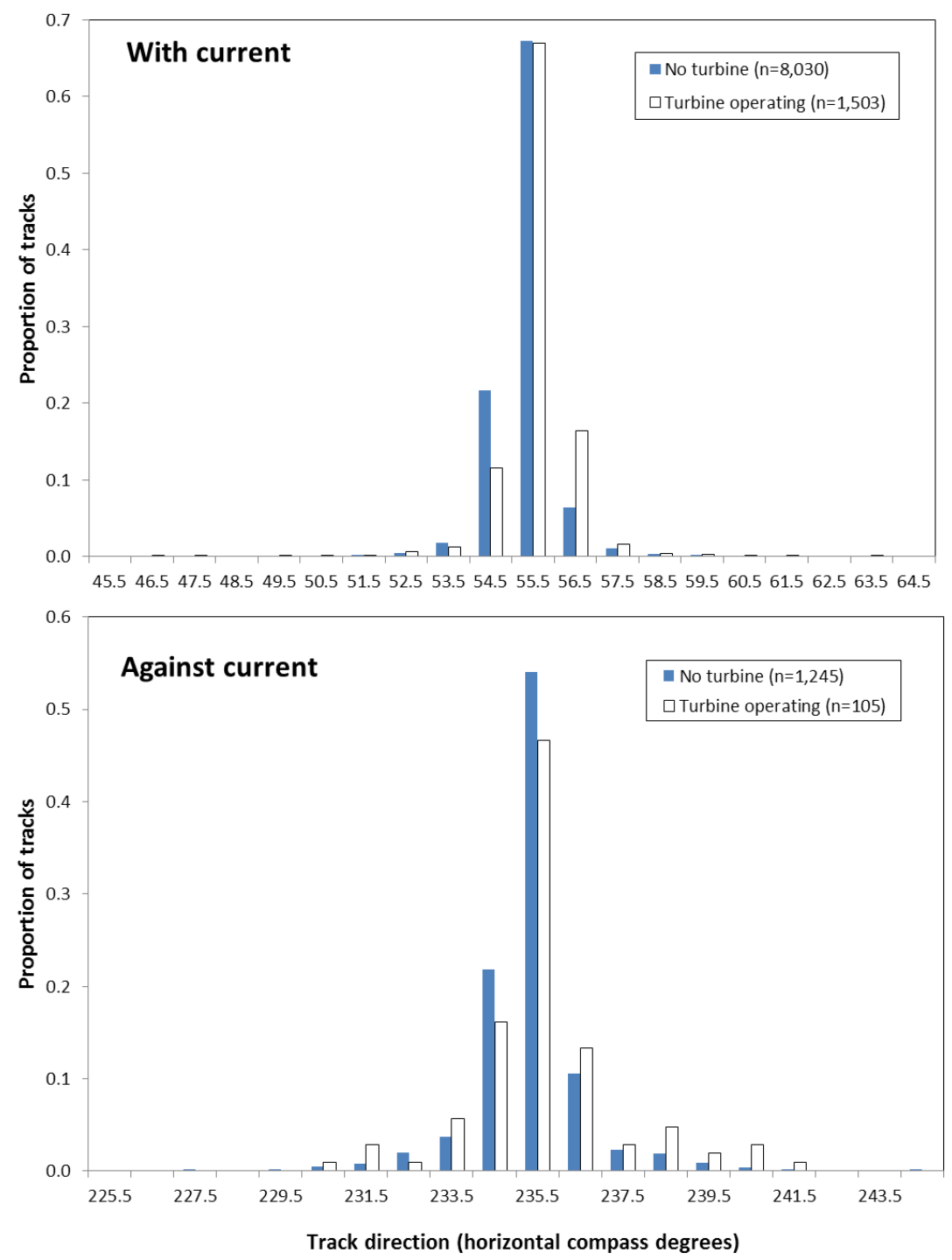

Figure 2-9. The distribution of horizontal direction of fish tracks in degrees (normalized to the total tracks for these two cases, 9,533 and 1,350) for fish swimming with and against the current during ebb tide with a RAD aim of 1 and when no turbine was present versus an operating turbine. The non-operating turbine case was not included in the figure because of the low sample size. Each $\mathrm{x}$-axis value is the midpoint of a $2^{\circ}$ bin.

\subsubsection{Tortuosity}

A fish track through the DIDSON field that is a straight line has a tortuosity value of 1 ; the larger the tortuosity value, the more crooked the path is. Most of the tracks were relatively straight, and there is only a slight indication of differences among the three operation modes based on the distribution of tortuosity values (Figure 2-10). Evaluation relative to the distance from the turbine showed that tortuosity gradually decreased (i.e., became straighter) as tracks neared the turbine location when the turbine was absent (Figure 2-11). Conversely, when the turbine was in place, either rotating or not rotating, tortuosity increased for tracks nearer the turbine. 


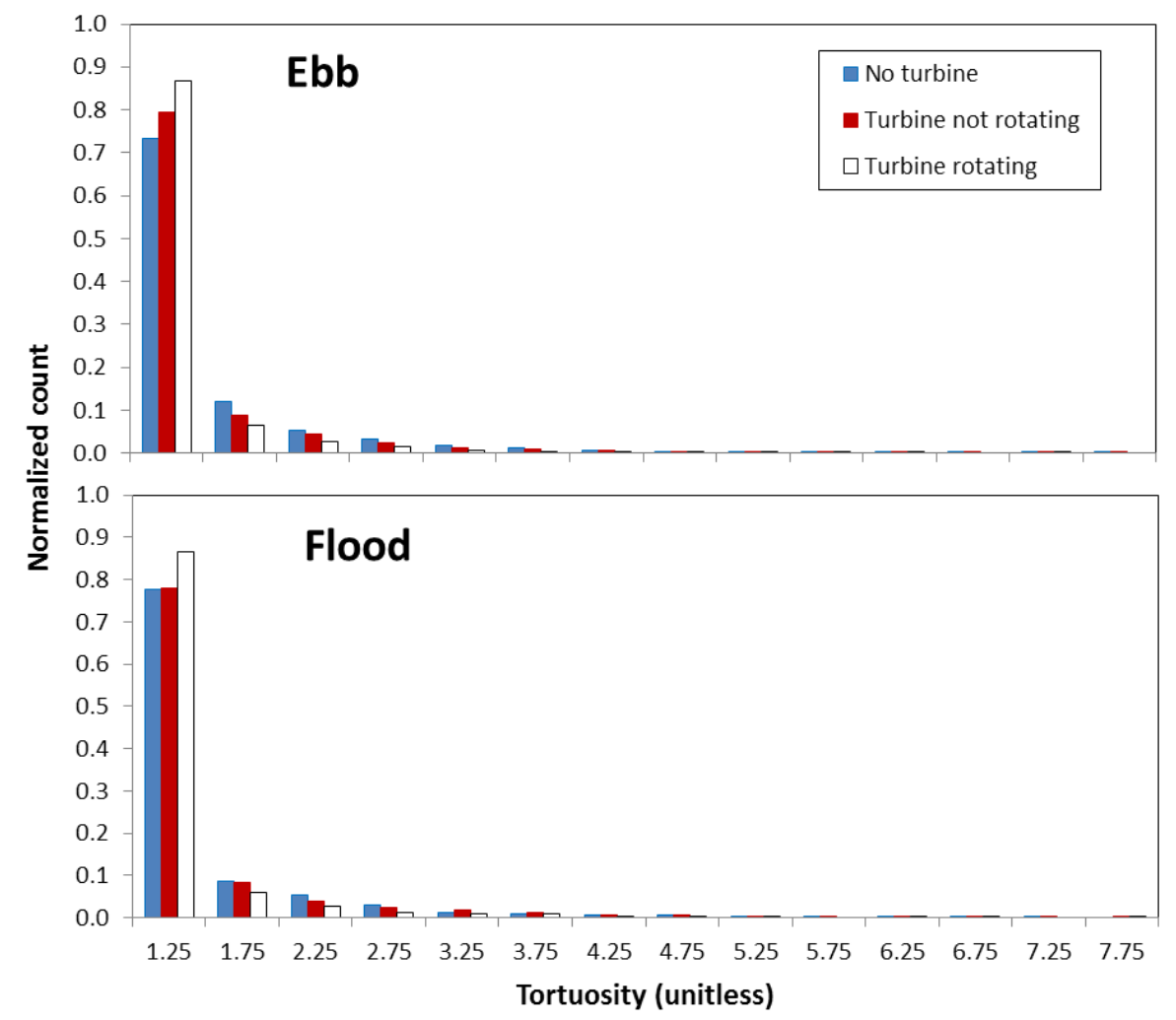

Figure 2-10. The distribution (normalized to the total tracks for each operating mode and tide combination) of tortuosity of fish tracks for three turbine operation modes during ebb and flood tides. Each $\mathrm{x}$-axis value is the midpoint of a 0.5 bin.

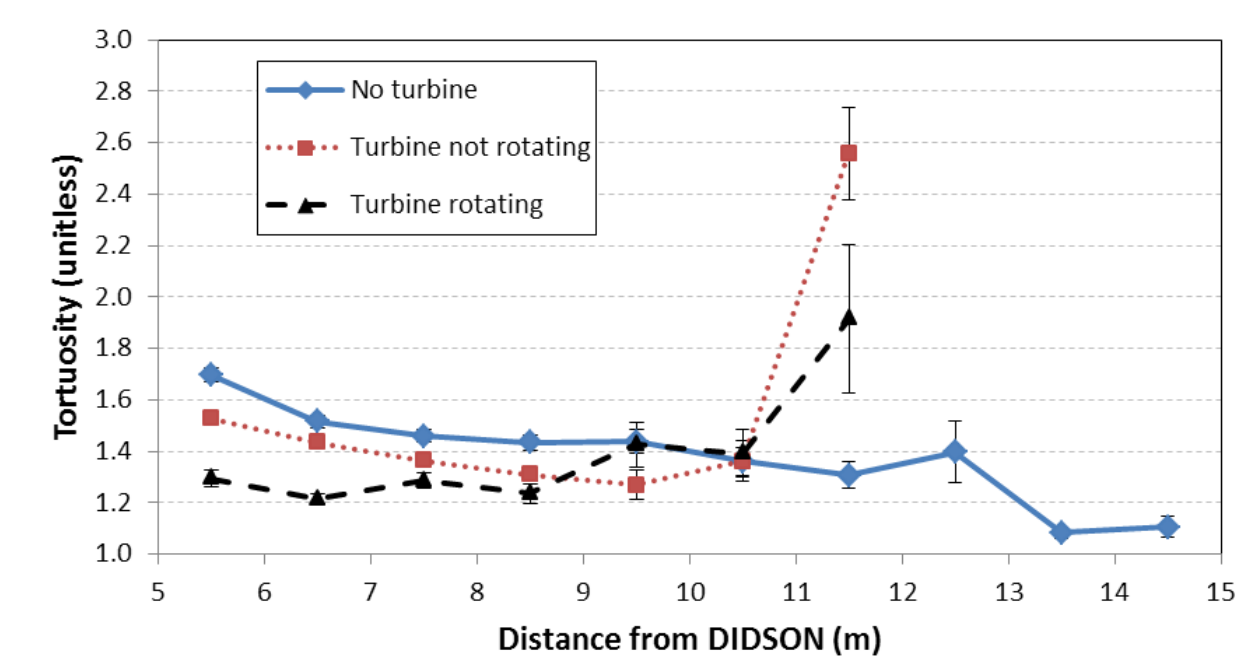

Figure 2-11. Mean ( \pm 1SE) tortuosity for each fish track during three turbine modes as a function of the mean distance from the DIDSON acoustic unit. Note that the DIDSON is located at $0 \mathrm{~m}$ and the turbine between 11 and 15 , depending on orientation and operation. 


\subsubsection{Swimming Velocity}

During ebb tides, the mean $( \pm 1 \mathrm{SE})$ swimming velocity of fish in the presence of a rotating turbine $(1.03 \pm$ $0.01 \mathrm{~m} / \mathrm{s})$ was slower than when the turbine was absent $(1.29 \pm 0.01 \mathrm{~m} / \mathrm{s})$, as can be seen in the frequency distribution (Figure 2-12). The difference was similar but less pronounced during flood tides (1.28 \pm 0.01 $\mathrm{m} / \mathrm{s}$ when the turbine was rotating versus $1.36 \pm 0.01 \mathrm{~m} / \mathrm{s}$ when it was absent). However, viewed in relation to distance from the turbine, the possible effect of the turbine on swimming velocity is much more noticable during flood tides than during ebb tides for both rotating and stopped turbines (Figure 2-13).

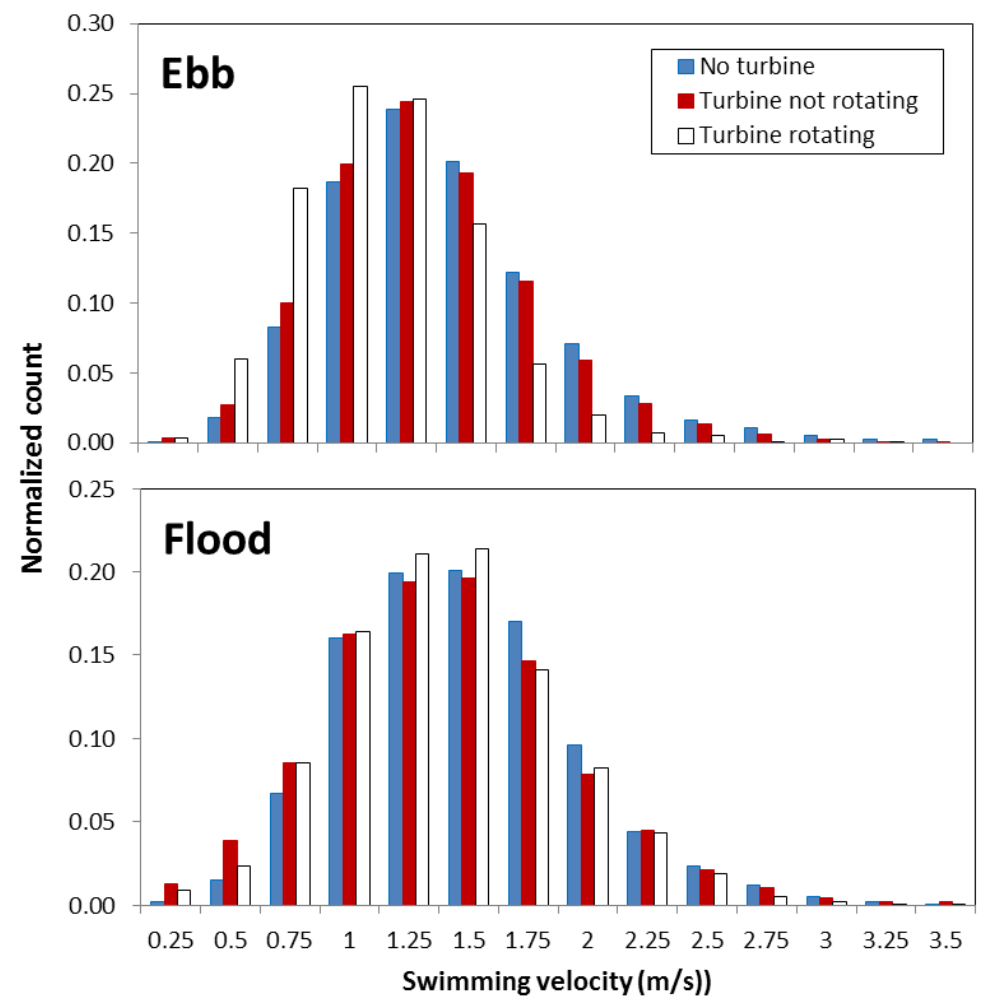

Figure 2-12. The distribution (normalized to the total tracks for each operating mode and tide combination) of fish track swimming velocities $(\mathrm{m} / \mathrm{s})$ for three turbine operation modes and ebb and flood tides. 

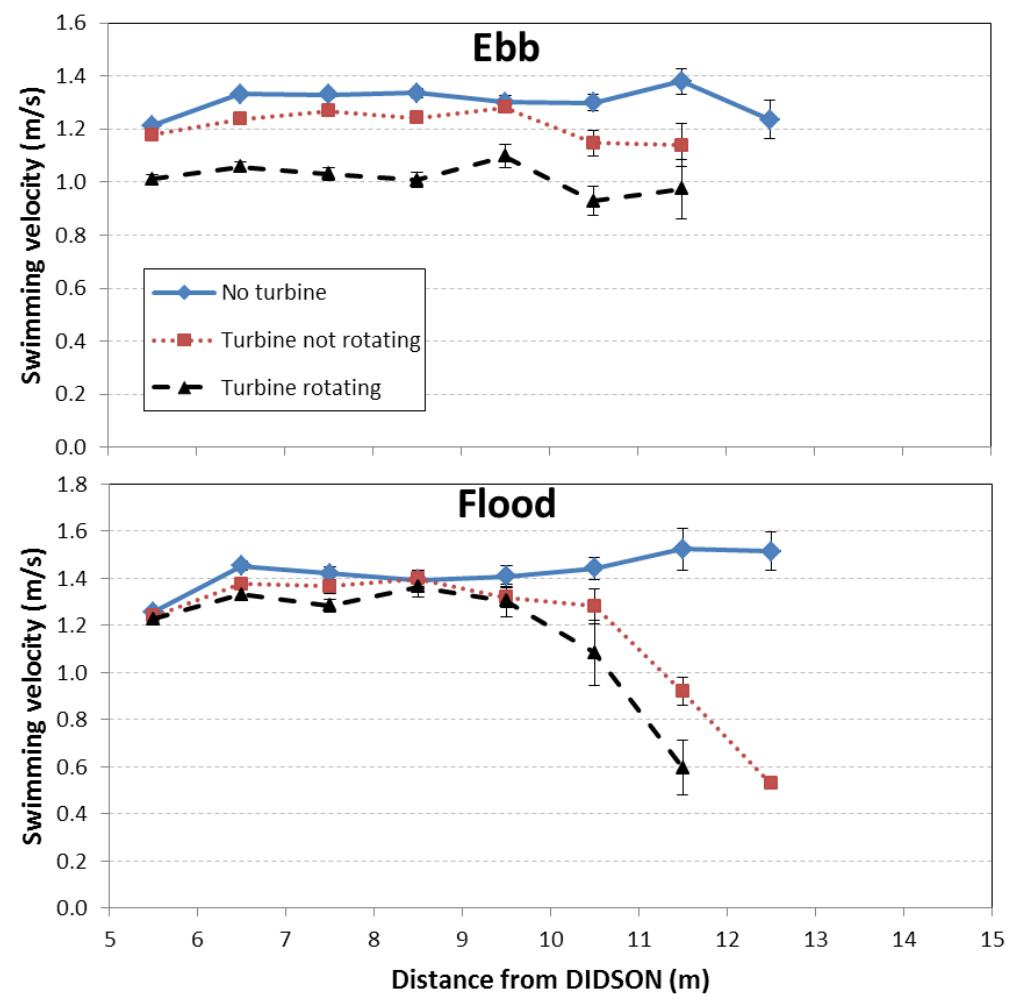

Figure 2-13. Mean ( \pm 1SE) swimming velocity $(\mathrm{m} / \mathrm{s})$ for each fish track during ebb and flood tides as a function of the mean distance from the DIDSON acoustic unit. Note that the DIDSON is located at $0 \mathrm{~m}$ and the turbine between 11 and 15, depending on orientation and operation.

\subsubsection{Direct Observation of Fish-Turbine Interactions}

An analysis of 36 tracks with a possibility of a close encounter with the turbine based on their nearness to the turbine and the direction of the flow revealed fish exhibiting three different behaviors. They either exhibited no change in direction (two schools and two individuals), avoided the turbine by angling away from it (two schools and eight individuals), or swam at the moving blades and then disappeared from the DIDSON view either just before or as encountering the turbine (four schools and two individuals). Some of the tracks were multiple tracks associated with the same school; therefore, the total did not sum to the original 36 tracks. There was no evidence of any fish being struck by the rotor.

During the validation exercise described earlier, we observed 38 schools and 82 individual fish during 112 min of video when the turbine was rotating. Only five (4\%) of these had what appeared to be direct encounters with the rotor blade. One individual and one school avoided the rotor by angling away from it, two individuals disappeared as they encountered the rotor, and one individual ( $20 \mathrm{~cm}$ in length) might have contacted the rotor. The fish that possibly came in contact with the rotor originated at the blade tip and swam in a direction rarely seen (i.e., directly toward the DIDSON and perpendicular to the flow). However, the swimming direction prior to its appearance could not be determined and actual contact with the blade was not observed. 


\subsection{DISCUSSION}

\subsubsection{Summary of DIDSON Results}

The automated data analysis we performed identified 34,708 fish tracks, which included both individual fish and schools. The number of tracks per hour of observation was generally higher during ebb tides than during flood tides and generally increased with increasing current velocity (Table 2-2). The count per hour was highest when the turbine was absent and lowest when the turbine was installed and rotating. The increase in rate with current velocity is probably more a function of the fact that more water passes by the DIDSON during increased flow, carrying with it more fish, and not a result of there being more fish in the water column during higher velocity. However, the latter is a possibility during some seasons for some migratory species that might be taking advantage of the currents to move in a particular direction. The most likely explanation for why more fish were observed during ebb tides than flood tides is that the seasonal migration patterns of many species is outward bound or southward during the fall. Because we could not alternate days of turbine presence and absence it is possible that the increased number of fish seen when the turbine was absent was a result of a natural change in abundance in the system. However, given that the change was a by factor of 3 or 4 and occurred in a single day (from 11 Sept to 12 Sept) suggests that it was most likely a response to turbine removal (Table 2-2).

In the near-field within the $10 \mathrm{~m}$ window viewed by the DIDSON, the number of tracks observed decreased sharply from near the DIDSON (away from the turbine location) to near the turbine location (away from the DIDSON) regardless of whether the turbine was absent, in place but not rotating, or in place and rotating (Figure 2-4). Because of the shape of the volume sampled by the DIDSON unit (see Figure 2-1), a correction by either volume sampled or vertical cross-sectional area sampled would make this difference between near-shore and offshore densities even larger. Given that the offshore decline is similar with and without a turbine in place, it does not appear that this particular observation is a result of turbine avoidance.

The best indications of near-field avoidance come from tracking the direction that fish move as they approach a turbine. The results we presented were specifically designed to compare the tracks of fish (1) in different turbine environments - i.e., absent, present but not rotating, and rotating - to see if turbine presence had an effect and (2) at different distances from the turbine to see if turbine proximity had an effect. Track direction was evaluated in one-dimensional space (change in range between the DIDSON and the turbine, two-dimensional space (change in vertical or horizontal direction), and three-dimensional space (path tortuosity).

Looking just at change in range (Figures 2-5 and 2-6), there are some differences between the no-turbine and operating-turbine conditions, but there is little evidence of fish moving away from the turbine.

Change in vertical direction was evaluated for four cases (ebb and flood tide by upward and downward movement). Most of the tracks fit into either the flood-tide upward-movement category or the ebb-tide downward-movement category, and there is no evidence of any change in behavior relative to vertical direction for these two cases (Figure 2-8). For change in horizontal direction, we evaluated the case with the largest sample size, i.e., ebb tide with RAD position 1, and found no evidence of any change in horizontal direction relative to turbine presence or operation (Figure 2-9). Note that the horizontal direction was very consistent, and nearly $87 \%$ of the tracks going with the current were within $\pm 1^{\circ}$ of the mode and $99 \%$ within $\pm 5^{\circ}$ of the mode. We did see differences in tortuosity that might be in response to the deployed turbine. Without the turbine in place, fish tracks became straighter as distance from shore increased. However, when the turbine was present, rotating or not, the tracks of fish nearest the turbine (i.e., most offshore) were the most crooked (Figure 2-11), suggesting that fish made evasive moves. 
The last metric evaluated for change in behavior was swimming velocity, which we found to be slower in the presence of the operating turbine (Figures 2-12), especially within $2 \mathrm{~m}$ of the turbine during flood tide (Figure 2-13).

One might expect that, if fish were responding to the turbine, the case of the non-rotating turbine would fall somewhere between no turbine and an operating turbine; but for some metrics (see Figures 2-5, 2-6, and 2-7), this does not appear to be the case. It is possible that when the turbine is not rotating and thus its signature is smaller (wake and noise), the fish are not alerted to the presence of the turbine until later (i.e., closer to the turbine). Fish seem to react to the rotating turbine well before they reach the turbine, so they might not sense the non-rotating turbine and therefore don't avoid the stationary object until they are much closer (i.e., within a few $\mathrm{m}$ ). Fish may have changed direction much earlier in their approach to the rotating turbine, if its presence was felt earlier.

From our direct observations of small subsets of the DIDSON videos, we found that individual fish and schools that were headed toward rotating blades usually avoided the blades by adjusting their horizontal swimming direction slightly and angling away. Others disappeared just before encountering the rotor (i.e., within $1 \mathrm{~m}$ ), which we assume to have happened because the fish changed vertical direction, swimming either above or below the turbine and therefore out of view of the DIDSON beam. The automated analysis did not detect this change in vertical direction, but that analysis was not able to assess movements by fish that approached the swept area directly because of the interference created by the moving blades. A direct contact with the rotor by a large fish $(>50 \mathrm{~cm}$ ) would likely have been apparent if it had occurred, but the DIDSON resolution makes it difficult to observe actual contact for fish smaller than $50 \mathrm{~cm}$. We occasionally saw some abrupt changes in direction, but we never confirmed contact with a rotor blade or observed fish swimming directly through the swept area and out the back side.

In addition to the intended analysis of near-field effects, the DIDSON data also provide some information about possible far-field avoidance. For example, the density of fish in the DIDSON sample area when the turbine was absent was roughly twice what it was when the turbine was in place, for both rotating and not rotating. This suggests that some avoidance may be occurring before fish are close enough to the turbine to be observed by the DIDSON. This response is similar to that observed by Shen et al. (2015) at a tidal energy site in Cobscook Bay, Maine, where they found evidence of general fish avoidance of a tidal energy device at up to $140 \mathrm{~m}$ from the device.

Some results of this analysis were used as input values for the fish interaction model discussed elsewhere in this report. Most notably, the distribution of the horizontal direction of fish tracks was used to inform the angle-of-incidence parameter. The angle at which a fish encounters the rotor has a significant effect on its probability of being struck by a blade. We presumed that the body of a fish is in a direct line with the direction in which it is swimming, and used the distribution of swimming direction to inform angle of incidence. Since there is so little variation in the direction in which fish swim relative to the direction of the flow, and therefore the position of the turbine, this parameter was revised in the fish interaction model so that nearly all the fish have an angle of incidence perpendicular to the direction of the rotor blades.

The use of multibeam acoustics proved to be a useful tool for evaluating the near-field interactions of fish with an operating KHPS turbine. However, because of its limited range and the size of the turbine, the position and aim of the DIDSON unit was critical for capturing the most useful information. This poses a particular challenge in tidal environments with turbines that change orientation with the direction of flow. The movement of the turbine (nacelle and rotor) also presented a challenge in automating data analysis, which was necessary because weeks of continuous data are required to adequately capture fish interactions under all conditions of flow and turbine operation. Manual analysis would take longer than data collection itself. Future advances in data analysis techniques should make dealing with operating turbines more feasible. 
Although some investigators are starting to be successful in identifying fish by species with multibeam systems, doing so was not practical in this study. However, from previous fish sampling in the East River in the vicinity of RITE, we know that common species include winter flounder (Pseudopleuronectes americanus), Atlantic tomcod (Microgadus tomcod), striped bass (Morone saxatilis), grubby (Myoxocephalus aenaeus), bay anchovy (Anchoa mitchilli), Atlantic silversides (Menidia menidia), blueback herring (Alosa aestivalis), northern pipefish (Syngnathus fuscus), and Atlantic menhaden (Brevoortia tyrannus) (Verdant Power 2011). Atlantic silverside and northern pipefish are regular residents of the area, while the other species are seasonally abundant depending on species-specific migratory patterns. Other, less common species that likely migrate through the area on the way to and from spawning grounds include American eel (Anguilla rostrata), alewife (Alosa pseudoharengus), American shad (Alosa sapidissima), Atlantic sturgeon (Acipenser oxyrinchus), rainbow smelt (Osmerus mordax), and shortnose sturgeon (Acipenser brevirostrum). As multibeam system hardware and software improve, the capability for species identification are likely to become more accurate.

Although we found some evidence that the presence of an operating turbine affected the swimming behavior of fish, resulting in apparent avoidance in some cases, we were not able to accurately estimate the frequency or rate of avoidance. We are confident, however, that the likelihood of fish being struck and injured by an KHPS turbine at the RITE site is relatively low, based on the apparent long-range avoidance seen in another study and supported by this study, the apparent ability of most fish to avoid rotor blades when they are encountered at close range, and the paucity of evidence of direct blade strikes. 



\section{INTEGRATION}

\subsection{SPLITBEAM DATA}

\subsubsection{Introduction}

Little is known about the far-field behavioral response of fish to HK devices, although recent work by Shen et al. (2015) suggests that fish might exhibit avoidance as far away as $140 \mathrm{~m}$. The objective of this task was to quantify the distribution and trajectory of fish throughout the vicinity of the RITE site using a representative sample of hydroacoustics data collected with an array of BioSonics splitbeam transducers (SBTs) mounted at the RITE site from June 2007 to October 2009 during testing of an array of six tidal turbines. Significant data analysis of fish presence and abundance using these data was previously accomplished by Verdant Power in support of its FERC license application; however, an analysis of the swimming direction, trajectory, and velocity was not fully undertaken. For this task, we analyzed data collected from nine SBTs while up to two Verdant Power Gen4 KHPS turbines were operating in the array. These data were collected at virtually the same location and during the same time of year (September 1-14, 2008), but not the same year, as the DIDSON data described in Section 2 earlier. Our analysis focused on the effects of proximity to turbine, tide cycle, and current speed on fish distribution, swimming direction (with or against the flow), and swimming velocity.

\subsubsection{Methods}

Because of the amount of data collected over the 2 year period, we chose a manageable subset to accomplish our objectives. Three frames were chosen (frames 1, 2, and 3, Figure 3-1) for which nine transducers were fully functional through the period of interest and that represented locations both away from the turbines (approximately $100 \mathrm{ft}$; frame 1) and in close proximity to operating turbines (immediately in front of and behind; frames 2 and 3). Each frame supported three transducers, one aimed at the top third of the water column, a second at mid-column, and a third at the bottom third of the water column (Figure 3-2).

We analyzed output from a prior analysis of the raw splitbeam data that included observations of 18,077 fish targets for the 2 week period and 9 transducers and included the following data:

- Date and time

- Target strength (dB; an indicator of fish size)

- XYZ coordinates within splitbeam sampling cone

- Location by zone (1 to 18; see Figure 3-2)

- Fish track speed $(\mathrm{m} / \mathrm{s})$

- Fish track direction (north or south)

- Current speed $(\mathrm{m} / \mathrm{s})$, with positive numbers indicating northward direction and negative numbers southward

From the final two variables, we calculated an additional variable of swimming with $(+1)$ or against $(-1)$ the current. 


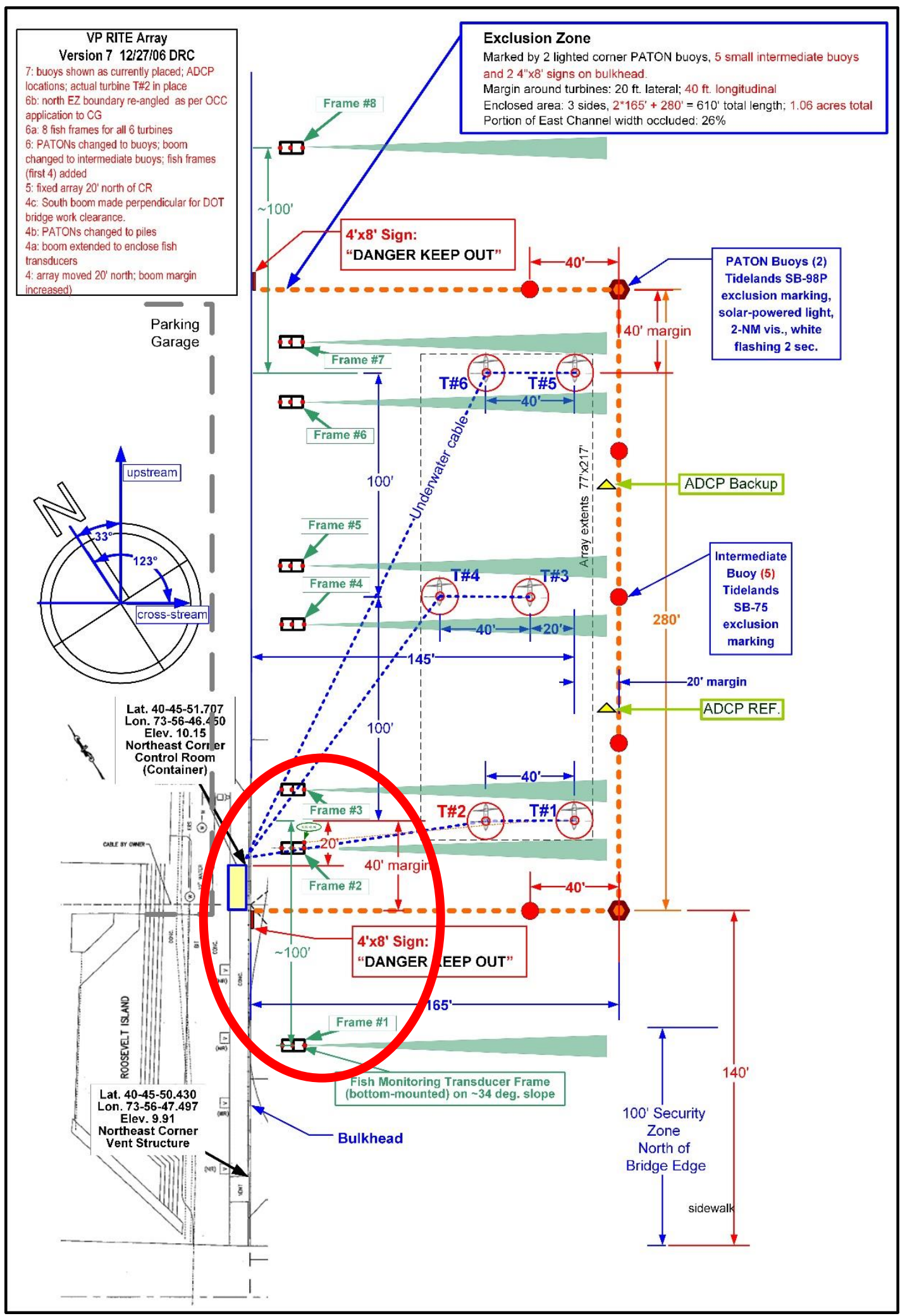

Figure 3-1. Overhead view of eight frames, three splitbeam transducers each, at the RITE site. Transducers were aimed in an offshore direction (toward right of figure). The analysis in this report was based on data from frames 1-3 circled in red. Source: FERC Draft License Application, Volume 4. 
Non-Impact Zones:

Inshore zone is $1,2,3$

Inshore west is zone 4, 5, 6

Median is zone $10,11,12$

Outshore is zone $16,17,18$

\section{Impact Zone 1 Inshore}

$\mathrm{T} 2, \mathrm{~T} 4$, and $\mathrm{T} 6$ are in zones $7,8,9$

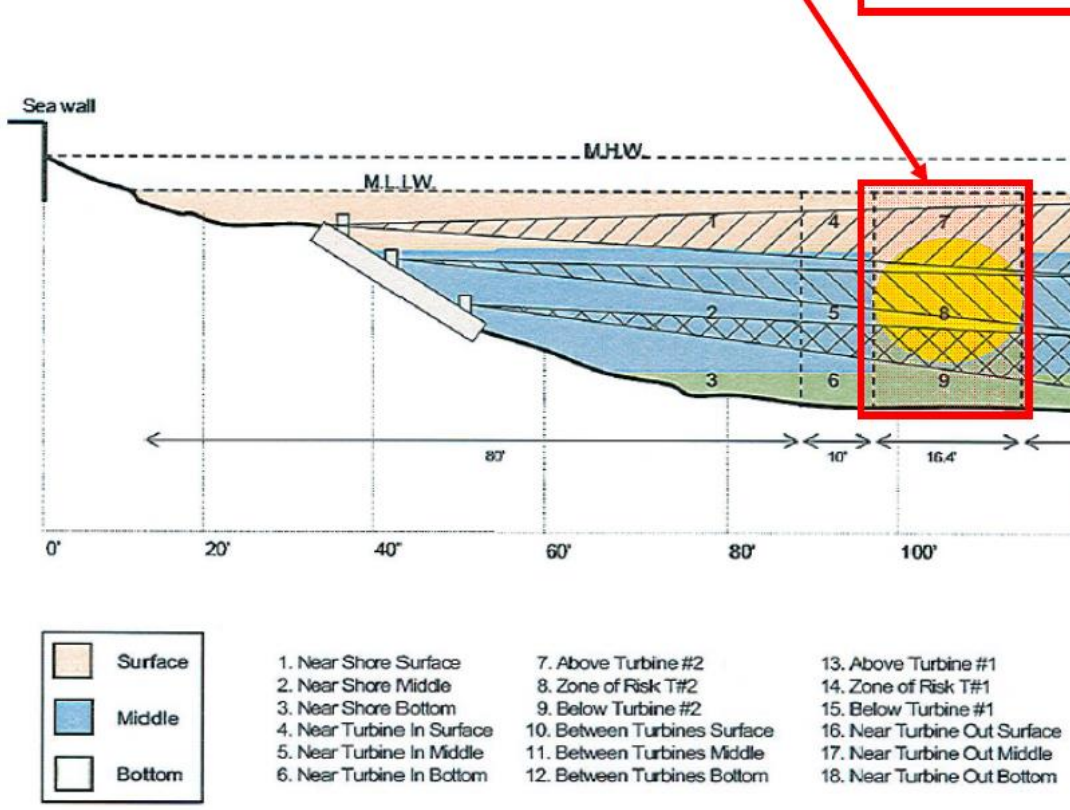

Figure 3-2. Cross-sectional view of field of view of three splitbeam transducers on a single frame relative to location of two turbines. The rotor-swept area for two turbines is indicated by yellow circles. The $\mathrm{x}$-axis is in feet. Source: FERC Draft License Application - Volume 4.

Targets with a signal strength of greater than $-20 \mathrm{~dB}$ were filtered from the original set to eliminate tracks that were unlikely to be fish targets, i.e., too large, based on Love's equation relating fish length to signal strength (Love 1977). Most of these filtered data came from one of the frames that sampled nearest the turbines, and these spurious observations were likely part of the turbine structure. This reduced the original number of tracks for the 14 day data set by 2,436 , leaving a sample size of 15,641 fish targets for our analyses.

We summarized abundance (distribution), swimming direction relative to river current, and swimming velocity based on size, location, current speed, and tide. We defined two size categories, less than and greater than $76 \mathrm{~cm}$ (30 in.) as defined by signal strengths less than or greater than $-30 \mathrm{~dB}$. Location was categorized using the original 18 zones and also as 6 larger combined zones which were identified as near shore (zones 1-3), near turbine inshore (4-6), inshore impact zone (7-9), between turbines (10-12), offshore impact zone (13-15), and near turbine offshore (16-18). River current speed was categorized into 26 bins of $0.2 \mathrm{~m} / \mathrm{s}$ ranges from -2.6 to $2.6 \mathrm{~m} / \mathrm{s}$; this resolution was chosen to match variables used in the fish interaction model. Tide direction was defined in three categories: ebb tide (current speed less than $-1 \mathrm{~m} / \mathrm{s}$ ), flood tide (current speed greater than $+1 \mathrm{~m} / \mathrm{s}$ ), and slack tide $(-1 \mathrm{~m} / \mathrm{s}>$ current speed $<+1 \mathrm{~m} / \mathrm{s})$. The -1 and $+1 \mathrm{~m} / \mathrm{s}$ thresholds correspond to the speeds below and above which the turbine rotors would rotate. 
We performed a standard analysis of variance (ANOVA) on the swimming velocity data to determine if there was a significant effect of current velocity, fish size (i.e., target strength) and proximity to turbine (frame 1 versus frames 2 and 3 ).

\subsubsection{Results}

After filtering the original data for the 14 days and three frames, we compiled 15,641 fish targets for further summarization. Total counts varied by about a factor of two among days within the data for a single frame and varied by a factor of 3 to 4 among frames with the greatest number of fish observed by the frame 1 transducers and the least by the frame 2 transducers (Figure 3-3).

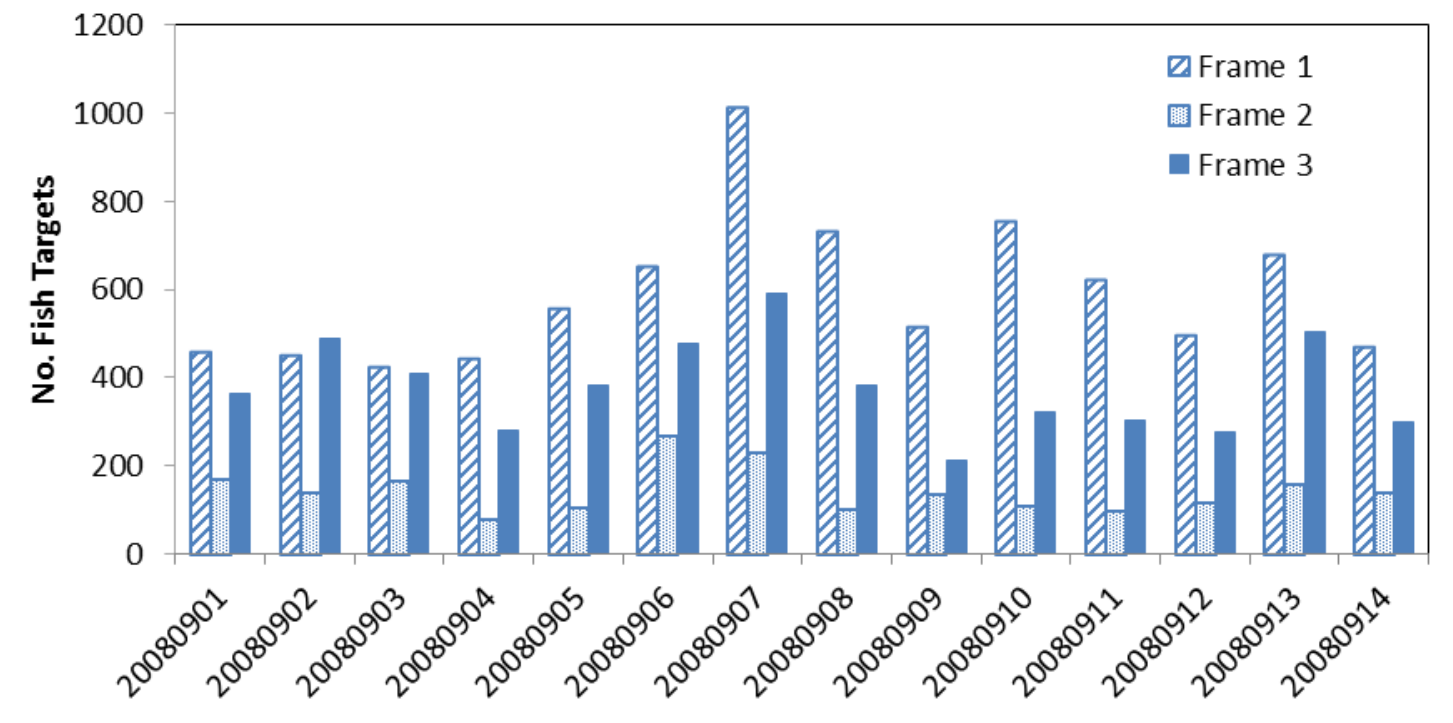

Figure 3-3. Counts of fish by date and splitbeam frame (total $n=15,641)$.

\subsubsection{Distribution}

Parsing the distribution by tide (ebb, slack, or flood) and frame $(1,2$, or 3$)$ reveals that most of the fish are near shore; and nearly twice as many fish were observed at frame 1, which was away from the turbines, than at the other two frames (Figure 3-4). In addition, many more fish were seen during slack tide (with no turbine operating) than ebb and flood tides, but the differences were largely at the inshore zones and not at the turbine locations. 
Ebb Tide

\begin{tabular}{|c|c|c|c|c|c|c|c|}
\hline \multirow[t]{3}{*}{ Frame 1} & surface & 19.14 & 4.93 & 1.21 & 0.00 & 0.00 & 0.00 \\
\hline & mid & 48.29 & 11.29 & 3.57 & 2.07 & 0.00 & 0.14 \\
\hline & bottom & 0.00 & 0.29 & 0.00 & 0.00 & 0.00 & 0.00 \\
\hline \multirow[t]{3}{*}{ Frame 2} & surf & 0.00 & 0.00 & 0.00 & 0.00 & 0.00 & 0.00 \\
\hline & mid & 31.93 & 6.00 & 2.86 & 1.36 & 0.07 & 0.00 \\
\hline & bottom & 0.00 & 0.14 & 1.07 & 0.00 & 0.00 & 0.00 \\
\hline \multirow[t]{3}{*}{ Frame 3} & surf & 0.57 & 2.43 & 4.00 & 0.07 & 0.00 & 0.00 \\
\hline & mid & 39.29 & 13.64 & 8.64 & 2.79 & 0.00 & 0.00 \\
\hline & bottom & 0.00 & 0.00 & 0.00 & 0.00 & 0.00 & 0.00 \\
\hline
\end{tabular}

\section{Slack Tide}

\begin{tabular}{|c|c|c|c|c|c|c|c|}
\hline \multirow[t]{3}{*}{ Frame 1} & surf & 47.21 & 14.64 & 5.93 & 0.14 & 0.00 & 0.00 \\
\hline & mid & 250.86 & 25.14 & 6.93 & 6.86 & 1.71 & 6.86 \\
\hline & bottom & 0.00 & 0.21 & 0.43 & 0.29 & 0.00 & 0.00 \\
\hline \multirow[t]{3}{*}{ Frame 2} & surf & 0.00 & 0.00 & 0.00 & 0.00 & 0.00 & 0.00 \\
\hline & mid & 50.71 & 4.14 & 6.29 & 7.43 & 0.36 & 0.00 \\
\hline & bottom & 0.00 & 0.00 & 0.00 & 0.14 & 0.00 & 0.00 \\
\hline \multirow[t]{3}{*}{ Frame 3} & surf & 1.07 & 4.57 & 6.00 & 0.57 & 0.00 & 0.00 \\
\hline & mid & 155.64 & 44.36 & 19.79 & 5.14 & 0.00 & 0.21 \\
\hline & bottom & 0.00 & 0.00 & 0.00 & 0.00 & 0.00 & 0.00 \\
\hline
\end{tabular}

Flood Tide

\begin{tabular}{|c|c|c|c|c|c|c|c|}
\hline \multirow[t]{3}{*}{ Frame 1} & surf & 52.29 & 4.07 & 1.21 & 0.00 & 0.00 & 0.00 \\
\hline & mid & 49.07 & 12.86 & 4.93 & 6.21 & 2.71 & 0.79 \\
\hline & bottom & 0.00 & 0.07 & 0.21 & 0.00 & 0.00 & 0.00 \\
\hline \multirow[t]{3}{*}{ Frame 2} & surf & 0.00 & 0.00 & 0.00 & 0.00 & 0.00 & 0.00 \\
\hline & mid & 21.07 & 3.93 & 4.64 & 4.14 & 0.00 & 0.00 \\
\hline & bottom & 0.00 & 0.00 & 0.36 & 0.14 & 0.07 & 0.07 \\
\hline \multirow[t]{4}{*}{ Frame 3} & surf & 1.64 & 1.00 & 3.79 & 0.71 & 0.00 & 0.00 \\
\hline & mid & 27.43 & 21.36 & 9.36 & 3.57 & 0.00 & 0.07 \\
\hline & bottom & 0.00 & 0.00 & 0.00 & 0.00 & 0.00 & 0.00 \\
\hline & & & & & & & 03 \\
\hline
\end{tabular}

\section{Distance from split-beam transducers (ft)}

Figure 3-4. Distribution of fish (mean number per day) in 18 zones (see Figure 3-2) as determined by splitbeam hydroacoustics systems at three frames during ebb, slack and flood tides. The relative locations of turbine rotor swept areas are indicated with yellow circles. Shades of red indicate relative density with dark red being greatest. Note that the two bottom cells from 0-50 feet were almost entirely out of range of the SBT beams. 


\subsubsection{Swimming direction}

For the entire data set, we found that $23 \%$ of the fish were swimming against the current and $77 \%$ with. However, many of these observations were at velocities $<1 \mathrm{~m} / \mathrm{s}$ around slack tide at a time when the turbines were not rotating. Considering only the time when the turbines would have been rotating, i.e., when current velocity exceeded $1 \mathrm{~m} / \mathrm{s}$, the proportion of fish swimming against the current was about $7 \%$. When the data were further subdivided by size class (above and below $-30 \mathrm{~dB}$ target strength or about 76 $\mathrm{cm}$ ), we found that at slow current (i.e., slack tide), smaller fish are more likely to swim against the current than large fish; but at faster current speeds, nearly all of the small fish swam with the current.

\subsubsection{Swimming velocity}

As expected, there is a large difference in the swimming velocity of fish swimming with the current as opposed to those against (Figure 3-5). Few fish swimming against the current swam at a velocity $>1 \mathrm{~m} / \mathrm{s}$. On the other hand, fish swimming with the current (which could be as high as $2.5 \mathrm{~m} / \mathrm{s}$ ) regularly swam faster than $1 \mathrm{~m} / \mathrm{s}$ and some nearly as fast as twice the current speed.

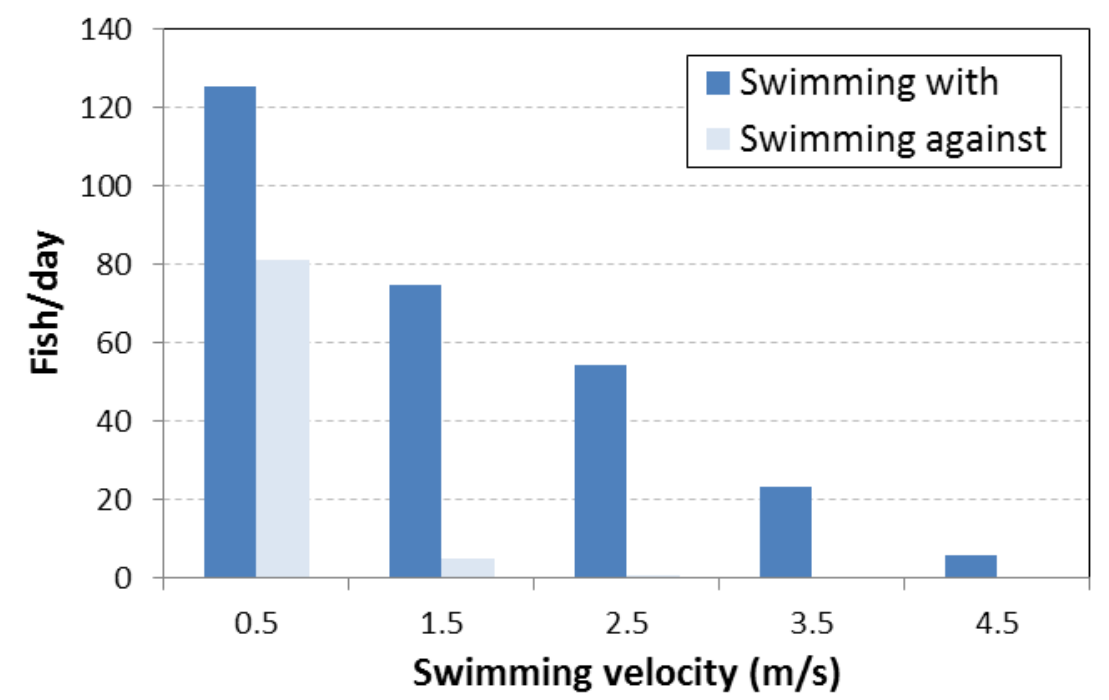

Figure 3-5. Distribution of swimming velocities of fish swimming with and against the current. $X$-axis values represent the mid-point of $1 \mathrm{~m} / \mathrm{s}$ ranges.

Results of the ANOVA indicate that swimming velocity is dependent on current speed and fish size and also differs among the three frames (Table 3-2). Figures 3-6 indicates that differences in swimming velocities among the frames are mostly apparent at the highest current speeds.

Table 3-1. Results of analysis of variance testing the effects of current speed, target strength (i.e., fish size), and transducer frame on swimming velocity.

\begin{tabular}{lrrrr}
\hline \multicolumn{1}{c}{ Variable } & Sum of squares & DF & F value & Pr(>F) \\
\hline Current speed & 5915.2 & 1 & 8953.4 & $<0.0001$ \\
Target strength & 481.2 & 1 & 728.4 & $<0.0001$ \\
Frame & 33.0 & 2 & 25.0 & $<0.0001$ \\
\hline
\end{tabular}




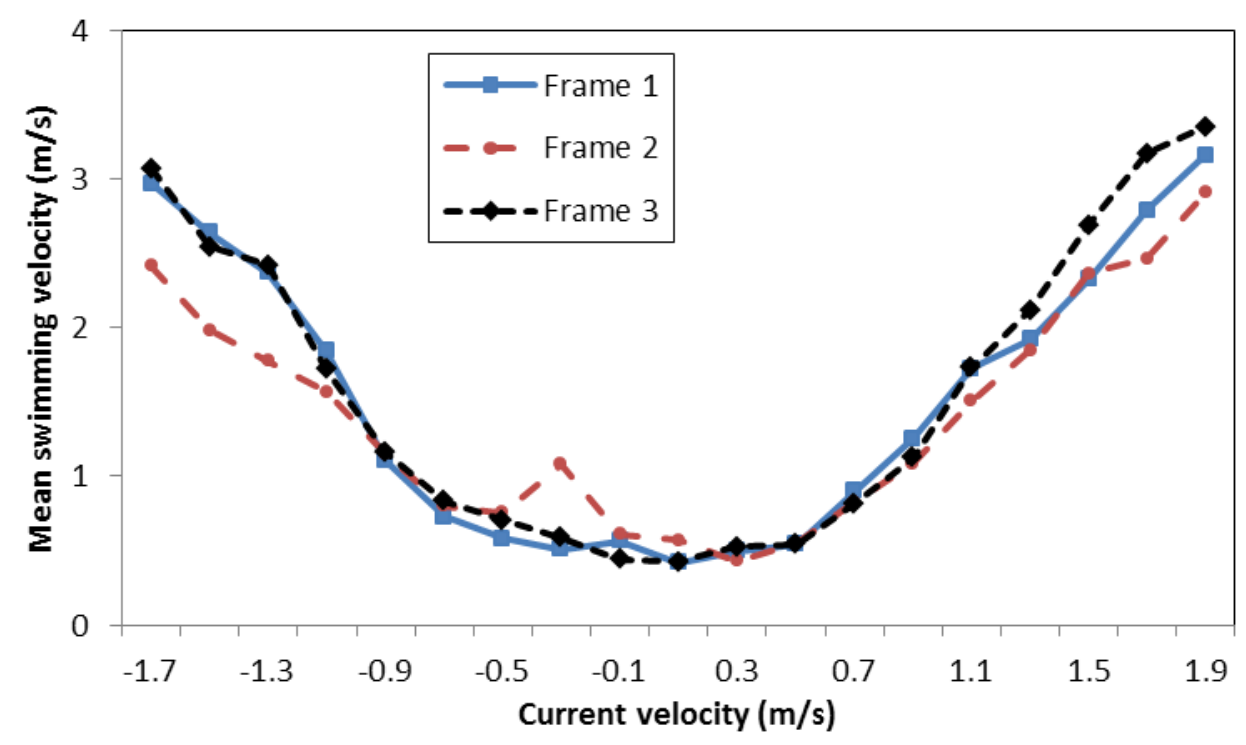

Figure 3-6. Mean swimming velocity by $0.2 \mathrm{~m} / \mathrm{s}$ current velocity bins for fish swimming with the current for each of the three splitbeam transducer frames. Positive current velocity values indicate that flow is in the flood tide direction and negative values indicate the ebb tide direction.

\subsubsection{Discussion}

Splitbeam hydroacoustics data collected in September 2008 were re-analyzed to evaluate the effects of turbine proximity and tide cycle (i.e., current velocity and direction) on the distribution and swimming direction and velocity of fish. The ultimate intent of this analysis was to update parameters in an existing KFIM that predicts the likelihood of KHPS encounter and injury by fish in the East River. We found the distribution of fish in the vicinity of the RITE project during the period of sampling to be heavily skewed to near shore areas and to periods of slack tide when water current velocities are the lowest. This is consistent with previous analysis done for Verdant's FERC license application. During high-velocity conditions, many fish probably move to the bottom or move further inshore than the splitbeam system sampled. Most fish observed during this sampling swam with the current, especially when current velocities were high. This observation might vary during seasons when fish are migrating in a particular direction (either upriver or downriver), but even then, for energetic reasons, most fish probably travel in their intended directions in the main channel and then move to low-velocity areas near the bottom or shore when traveling against the current. Of the three frames of transducers, the one farthest from the turbines produced the greatest number of fish track observations, suggesting that fish might be avoiding the waters nearest the turbines. This frame is also the closest frame to the Roosevelt Bridge, whose pilings often attract fish.

A change in velocity by fish close to an operating turbine might suggest some form of avoidance. We found some difference in swimming velocity among the three locations sampled, but the swimming velocity of fish at the site $100 \mathrm{ft}$ away was intermediate between those at the two locations on either side of the turbines. That finding suggests that the swimming velocity was a function of fish size and water velocity, as might be expected with larger fish and fish in faster currents swimming at higher velocities. 


\subsection{KHPS-FISH INTERACTION MODEL}

\subsubsection{Description}

In response to a request from the National Marine Fisheries Service (NMFS), Verdant and Kleinschmidt developed an in-stream KFIM for the East River. The overall intention of this model was to quantify the risk that Verdant's KHPS turbines present to fish at the proposed RITE project. Table 3-5 summarizes the parameters of the KFIM model and initial settings that were used by Verdant in assessing the KHPS-fish interaction in 2010.

Table 3-2. Parameters for the KFIM

\begin{tabular}{|c|c|c|c|}
\hline Term & $\begin{array}{l}\text { Parameter } \\
\text { Description }\end{array}$ & Relevance & RITE 2010 KFIM \\
\hline $\mathrm{P} 1$ & $\begin{array}{l}\text { Probability of blade } \\
\text { rotation }\end{array}$ & $\begin{array}{l}\text { Specific to the KHPS at water } \\
\text { velocity Vw of }>1 \mathrm{~m} / \mathrm{s} \text {; varies with } \\
\text { tidal site }\end{array}$ & $\begin{array}{l}\mathrm{P} 1=1 \text { at flows greater than } 1 \mathrm{~m} / \mathrm{s}, 0 \text { for all } \\
\text { flows less than } 1 \mathrm{~m} / \mathrm{s}\end{array}$ \\
\hline $\mathrm{P} 2$ & $\begin{array}{l}\text { Distribution of water } \\
\text { velocity over the tidal } \\
\text { cycle }\end{array}$ & $\begin{array}{l}\text { Vw as measured by ADCPs; varies } \\
\text { with tidal site }\end{array}$ & $\begin{array}{l}\text { See measured RITE Vw probability } \\
\text { distribution }\end{array}$ \\
\hline P3 & $\begin{array}{l}\text { Fish distribution } \\
\text { between east and west } \\
\text { channel }\end{array}$ & $\begin{array}{l}\text { An assumed distribution in the } \\
\text { configuration of the RITE project }\end{array}$ & $\mathrm{P} 3=0.5$ \\
\hline $\mathrm{P} 4$ & $\begin{array}{l}\text { Effective KHPS } \\
\text { turbine rotor area }\end{array}$ & A constant for a $5 \mathrm{~m}$ blade & $\mathrm{P} 4=0.0066$ \\
\hline P5 & $\begin{array}{l}\text { Blade interaction with } \\
\text { fish passing through } \\
\text { turbine disk }\end{array}$ & $\begin{array}{l}\text { Varies with shape of rotor, the } \mathrm{Vw} \\
\text { and presence of the subject of } \\
\text { investigation, and the approach } \\
\text { angle }\end{array}$ & $\begin{array}{l}\text { P5 follows formulae discussed below. Two } \\
\text { major parameters: } \\
\text { (1) } 80 / 20 \text { rule: assumes } 80 \% \text { of fish swim } \\
\text { with current, } 20 \% \text { against, for Vw less than or } \\
\text { equal to the endurance velocity (Ve) } \\
\text { (2) Angle of incidence: assumes all fish } \\
\text { approach blade from all angles within } 180^{\circ} \\
\text { uniformly }\end{array}$ \\
\hline P6 & Fish distribution & $\begin{array}{l}\text { Are ESA fish present in RITE east } \\
\text { channel? }\end{array}$ & $\begin{array}{l}\text { P6 = } 1 \text { equal likelihood that ESA fish are in } \\
\text { east channel }\end{array}$ \\
\hline P7 & $\begin{array}{l}\text { Fish avoidance } \\
\text { behavior }\end{array}$ & $\begin{array}{l}\text { Do fish avoid zones of operating } \\
\text { turbine }\end{array}$ & $\mathrm{P} 7=1$ conservative - no avoidance \\
\hline
\end{tabular}

$\mathrm{ESA}=$ Endangered Species Act

This is a spreadsheet, probability-based model that determines the overall risk of a turbine blade striking a fish (blade strike). The intent of the model was to initially concentrate on the turbine interaction with the shortnose sturgeon and Atlantic sturgeon, as these are protected species of interest at the RITE site However, comparative results were also generated for species identified in the Essential Fish Habitat Assessment that was performed as part of Verdant's Final Pilot License Application.

The National Oceanic and Atmospheric Administration/National Marine Fisheries Service, in its September 2012 Biological Opinion (Opinion) (REF3) concludes

.. Opinion of the effects of Verdant Power's Roosevelt Island Tidal Energy (RITE) Project including the Seasonal Species Characterization Netting plan as required by Article 401 of the Pilot License issued on January 23, 2012. In this Opinion, we conclude 
that the proposed action is likely to adversely affect, but not likely to jeopardize the continued existence of the threatened Gulf of Maine Distinct Population Segment (DPS) of Atlantic sturgeon or the endangered New York Bight, Chesapeake Bay, South Atlantic or Carolina DPSs of Atlantic sturgeon. We also conclude that the proposed action may affect but is not likely to adversely affect shortnose sturgeon or the Northwest Atlantic DPS of loggerhead sea turtles, or Kemp's ridley, green or leatherback sea turtles.

Thus the acceptance of the application and results of the RITE 2010 KFIM was affirmed.

\subsubsection{Parameters under Study}

Since the acceptance of the KFIM model for FERC licensing, and with the opportunity provided by this DOE grant, the objective of this task as described in Section 1.3 was to update parameterization of existing fish interaction model developed for the East River and the RITE Project. Two specific parameters can be examined as a result of the ORNL DIDSON/SBT data review: P5, the probability of a blade impacting the fish and its subparameter assumptions; and P6, Fish Distribution, as observed in the DIDSON and SBT data. New model simulations using the revised P5 and P6 parameters will be referred to in this report as the ORNL 2015 case. Additionally, as a result of concurrent efforts by Verdant on other RITE monitoring and as a model sensitivity exercise, two other parameters, P3 and P7, can also be updated. Those model results will be referred to as the Verdant P-12611 case. Table 3.2 and the text that follows discuss the KFIM parameter updates and the revised model results.

\section{ORNL 2015 Case}

\section{P5: Probability of the blade impacting the fish}

For fish that will be incident upon the rotor, parameter P5 provides the probability of the blade impacting the fish (at any point on its body). This quantity is determined only by the following:

- The speed of the fish approaching the turbine ( a function of species burst speed AND direction-the $80 / 20$ rule as defined below;

- the length of the fish, generally grouped as native species size: Essential Fish Habitat Species L $<45$ $\mathrm{cm}$ and ESA Species $\mathrm{L}=88 \mathrm{~cm}$ and $\mathrm{L}=104 \mathrm{~cm}$

- the rotational speed of the turbine blades (a known constant)

- the angle at which the fish is approaching the turbine (angle of incidence)

\section{i. $\quad$ P5 Subcomponent: $80 / 20$ rule}

The primary assumption included in this parameter is that a fish will move through the turbine blades by swimming at its maximum burst speed through the rotor. Based upon the body of data collected during the RITE demonstration, it may be possible to justify some additional spatial or zonal avoidance behavior. However, because no specific data are available for the sturgeon species of interest, no additional avoidance behavior is accounted for in the present model. The speed of the fish through the rotor will therefore be given only by the species' maximum burst speed plus the water velocity.

At RITE, fish likely swim through the east channel in both directions. However, over the course of the RITE demonstration, Verdant collected information on fish movements at the RITE east 
channel site that support the assumption that fish will typically be swimming with the current, especially at times of high velocity. From these data we made the assumption that when the water velocity is less than the regular endurance speed for a particular species, then $80 \%$ of fish will be swimming with the current and $20 \%$ against. For times when the water velocity is greater than the regular endurance speed, all fish will be swimming with the current. We term this assumption the $80 / 20$ rule and postulate that this parameter could be examined as part of the ORNL work discussed in this report.

\section{ii. P5 Subcomponent: Angle of Incidence}

In the 2010 KFIM model runs, the angle at which the fish will approach the turbine disk was not known; therefore, it was assumed that fish will be incident upon the rotor disk from an even distribution of angles $\left( \pm 90^{\circ}\right)$ centered on the direction of transit (upstream or downstream). As the angle of incidence for the fish moves away from the perpendicular, the effective length of the fish decreases; however, its velocity through the rotor is also reduced.

For a given water velocity and fish species, the probability of a strike for a fish incident on the turbine disk can be given by the following:

$$
\begin{gathered}
\mathrm{V}_{\text {apparent }}=\mathrm{V}_{\mathrm{W}}+\left(\mathrm{V}_{\mathrm{b}} \sin (\theta)\right) \\
\mathrm{L}_{\text {apparent }}=\mathrm{L} \sin (\theta)
\end{gathered}
$$

where:

$\begin{array}{llll}\text { Parameter } & \text { RITE 2010 } & \text { ORNL case } & \text { VP 12611 case } \\ \mathrm{Vw}=\text { Water velocity } & \text { From ADCP } & \text { No change } & \text { No change } \\ \mathrm{Vb}=\text { Species burst speed } & \text { See below } & \text { Modified } & \text { Same as ORNL case } \\ \mathrm{L}=\text { Species nominal length } & \text { See below } & \text { No change } & \text { No change } \\ \mathrm{n}=\text { number of blades } & \text { 3-Gen5 KHPS 5m } & \text { No change } & \text { No change } \\ \mathrm{R}=\text { Rotational speed } & 40 \mathrm{rpm}-\text { Gen5 KHPS } & \text { No change } & \text { No change } \\ \text { (revolutions per second) } & & & \\ \theta=\text { Angle of incidence } & \text { Uniform } 180^{\circ} & \text { Modified } & \text { Same as ORNL case }\end{array}$

This equation is highly dependent upon species-specific parameters, such as swim speed and overall length. Unfortunately, swim speeds for these species are less well determined, although burst swim speed may be taken as 4 times the nominal length per second. Endurance swim speed can typically be seen as being half of the burst swim speed [REF - Wardle, C.S. 1975. Limit of fish swimming speed. Nature 255, 725-727 (26 June 1975) doi:10.1038/255725a0]. For the species of interest at RITE the following parameters were assumed.

\begin{tabular}{llll} 
Species & \multicolumn{1}{c}{$\begin{array}{c}\text { Common length } \\
(\mathrm{cm})\end{array}$} & \multicolumn{1}{c}{$\begin{array}{c}\text { Endurance swim speed }(\mathrm{Ve}) \\
(\mathrm{m} / \mathrm{s})\end{array}$} & Burst swim speed $(\mathrm{Vb})(\mathrm{m} / \mathrm{s})$ \\
\hline Shortnose sturgeon & 88 & 1.76 & 3.52 \\
Atlantic sturgeon & 104 & 2.08 & 4.16 \\
EFH Fish & $20-45$ & $0.40-0.90$ & $0.80-1.80$
\end{tabular}


Given these assumptions and a uniform distribution of fish incident angles ( $\theta)$, P5 can be seen for Atlantic and Shortnose sturgeon in Figure 3-8.

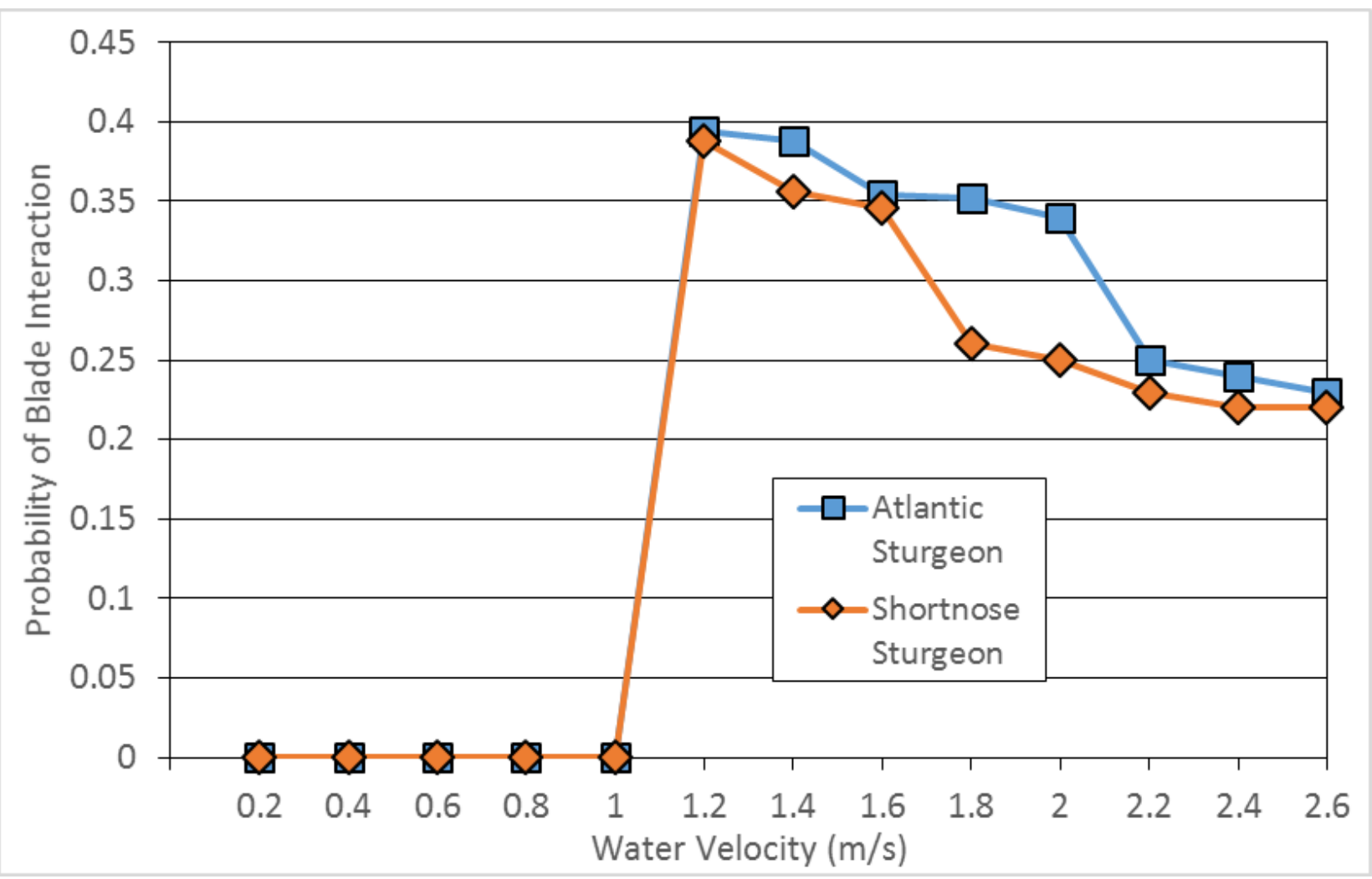

Figure 3-7. The probability of the blade impacting an Atlantic sturgeon and shortnose sturgeon as a function of water velocity.

Therefore, we postulate that the ORNL DIDSON video analysis could provide some new information on both the angel of incidence and the common length of fish that approach the rotor disk.

\section{P6: ESA Fish Distribution}

The ESA parameter was included in the KFIM for RITE to account for the transit of ESA species within the configuration at RITE, as described earlier. For the 2010 RITE KFIM cases, in the absence of further information on ESA fish species, the model assumed an even distribution of ESA fish in the East River. Therefore, $\mathrm{P} 6=1$ for all velocities. As information is gained from the proposed monitoring plans, this parameter can potentially be modified; it has been updated in the cases discussed in Section 4.

On further review, this parameter set at 1 for each velocity was applied as an extremely conservative value, rather than representing a uniform probability of 0.08 per velocity bin. The modification of this assumption will be reflected in the results.

\section{Verdant P-12611 Case}

Additionally, although it is outside the scope of this project, since the 2010 promulgation and 2012 acceptance of the KFIM model results, some additional new field data have been collected by Verdant 
under the RMEE-4 Tagged Species Detection Plan that might provide updated data for P3. As a result of the DIDSON and SBT results presented in this report, we also can postulate some adjustment to P7 fish avoidance behavior as a model sensitivity analysis. These details are the subject of a papers presented at the 2015 and 2016 Marine Energy Technical Symposium (Tomichek et al. 2015, 2016). The results of this are presented as a model sensitivity analysis in addition to the ORNL case discussed in Section 4.

\section{P3: Fish Distribution}

Unique to the RITE project, the East River bifurcates flow around Roosevelt Island, forming the east and west channels. The RITE project is located in the east channel. The cross sectional areas of the channels are roughly equal; both channels have a similar width of approximately $240 \mathrm{~m}$ and depth of $10 \mathrm{~m}$. The west channel has a slightly higher average flow speed, and the volume of water passing through both channels is equal to within approximately $5 \%$. Combined with the even fish distribution assumption explained earlier, it reasonably follows that half of any fish present will transit via the west channel and will therefore not be affected by the turbines present in the east channel.

The KFIM runs initially included a probability of $0.5(50 \%)$ to represent the equal likelihood that fish will take the east channel (and be at risk) over the west channel (and have no risk). This probability is fixed and is not dependent upon the water velocity.

For other project sites, this parameter could be used to reflect $100 \%$ probability that a fish would encounter a field, or array, of kinetic hydropower devices or reflect some cross sectional distribution less than $100 \%$.

\section{P7: Fish Avoidance Behavior}

In the KFIM, it was acknowledged that fish could indeed avoid the turbine blade; however, for the sake of completeness, the initial model runs took a conservative approach and assumed no avoidance behavior other than assuming that fish will speed up to avoid being struck. This increase in velocity was included in parameter P5. Thus for the 2010 model, P7=1, i.e., no fish avoidance behavior, was used for the Biological Assessment. It was noted that "as information is learned from the proposed monitoring plans this parameter can potentially be modified." 


\section{DISCUSSION}

\subsection{INTERPRETATION OF DIDSON RESULTS}

The automated data analysis we performed identified 34,708 fish tracks, which included both individual fish and schools. Various metrics that might indicate a behavioral response to the operating turbine (i.e., attraction or avoidance) were grouped into classes based on tidal cycle, current velocity, and swimming direction and evaluated with respect to turbine presence and operation and with respect to distance from the turbine. Significant findings from the automated analysis included:

- The density of fish in the DIDSON sample area when the turbine was absent was roughly twice what it was when the turbine was in place, both when rotating and when not rotating. This suggests that some avoidance may be occurring before fish are close enough to the turbine to be observed by the DIDSON.

- In the near-field within the $10 \mathrm{~m}$ window viewed by the DIDSON, the number of tracks observed decreased sharply from near shore (away from) to offshore (near to the turbine location) regardless of whether the turbine was in place and rotating or not.

- For fish swimming past the turbine, there were no changes in vertical, horizontal, or lateral trajectories of fish when the turbine was present or operating.

- Turbine presence, whether operating or not, resulted in more crooked tracks for fish near the turbine than for fish in the same location when the turbine was absent, suggesting that normal swimming behavior is disrupted.

- The last metric evaluated for change in behavior was swimming velocity which we found to be significantly slower in the presence of the operating turbine versus an absent turbine condition.

To supplement the automated analysis of fish tracks, we also conducted visual observations of the video output for subsets of the data. From these direct observations, we found that individual fish and schools that were headed toward rotating blades usually avoided the blades by adjusting horizontal swimming direction slightly and angling away. Others disappeared just before encountering the rotor (i.e., within $1 \mathrm{~m}$ ), which we assume to have happened because the fish changed vertical direction, swimming either above or below the turbine and therefore moving out of view of the DIDSON beam. A direct contact with the rotor by a large fish $(>50 \mathrm{~cm})$ would likely have been apparent if it had occurred, but the DIDSON resolution makes it difficult to observe actual contact for fish smaller than $50 \mathrm{~cm}$.

\subsection{INTERPRETATION OF FISH INTERACTION MODEL}

As discussed in Section 3, the integration of the results of the DIDSON and SBT analysis into the KFIM was a key result of this effort. The changes to the model parameters under the two cases are summarized in Table 4-1 and a biological discussion follows. 
Table 4-1. KFIM parameters as updated-2015

\begin{tabular}{|c|c|c|c|c|}
\hline Term & Parameter description & RITE 2010 KFIM & ORNL base case & $\begin{array}{c}\text { Verdant P-12611 } \\
\text { case }\end{array}$ \\
\hline $\mathrm{P} 1$ & $\begin{array}{l}\text { Probability of blade } \\
\text { rotation }\end{array}$ & $\begin{array}{l}\mathrm{P} 1=1 \text { for flows } \\
\text { greater than } 1 \mathrm{~m} / \mathrm{s}\end{array}$ & No change & No change \\
\hline $\mathrm{P} 2$ & $\begin{array}{l}\text { Distribution of water } \\
\text { velocity over the tidal } \\
\text { cycle }\end{array}$ & $\begin{array}{l}\text { See RITE Vw } \\
\text { probability distribution }\end{array}$ & No change & No change \\
\hline P3 & $\begin{array}{l}\text { Fish distribution between } \\
\text { east and west channels }\end{array}$ & $\mathrm{P} 3=0.5$ & No change & $\begin{array}{l}\text { Modified to } \mathrm{P} 3=0.25 \\
\text { based on concurrent } \\
\text { RMEE-4 observation } \\
2012-2015\end{array}$ \\
\hline $\mathrm{P} 4$ & $\begin{array}{l}\text { Effective KHPS turbine } \\
\text { rotor area }\end{array}$ & $\mathrm{P} 4=0.0066$ & No change & No change \\
\hline \multirow[t]{2}{*}{ P5 } & $\begin{array}{l}\text { Blade interaction with } \\
\text { fish passing through } \\
\text { turbine disk }\end{array}$ & $\begin{array}{l}\text { P5 follows formulae } \\
\text { discussed below. Two } \\
\text { major parameters: } \\
\text { (1) } 80 / 20 \text { rule: assumes } \\
80 \% \text { of fish swim with } \\
\text { current, } 20 \% \text { against }\end{array}$ & $\begin{array}{l}\text { P5 } 80 / 20 \text { rule-ORNL work } \\
\text { indicates a stronger case for } \\
84 \% / 16 \% \text { as a setting for P5 }\end{array}$ & Same as ORNL case \\
\hline & & $\begin{array}{l}\text { (2) Angle of incidence } \\
\text { - assumes all fish } \\
\text { approach blade from } \\
\text { all angles within } 180^{\circ} \\
\text { uniformly }\end{array}$ & $\begin{array}{l}\text { P5 Angle of incidence-- } \\
\text { ORNL work strongly } \\
\text { indicates a more narrow } \\
\text { angle of incidence of } 90^{\circ}+/- \\
15^{\circ} \text { degrees }\end{array}$ & Same as ORNL case \\
\hline P6 & ESA fish distribution & $\begin{array}{l}\mathrm{P} 6=1 \text { Equal likelihood } \\
\text { that ESA fish are in } \\
\text { east channel }\end{array}$ & $\begin{array}{l}\text { DIDSON and SBT analysis } \\
\text { confirms P6 could be } \\
\text { lowered. } \\
\text { P6= see revised distribution } \\
\text { (Table 4-4) }\end{array}$ & Same as ORNL case \\
\hline P7 & Fish avoidance behavior & $\begin{array}{l}\mathrm{P} 7=1 \text { conservative }- \text { no } \\
\text { avoidance }\end{array}$ & No change & $\begin{array}{l}\text { DIDSON data seems } \\
\text { to show some } \\
\text { avoidance. } \\
\text { Assume P7 }=0.98\end{array}$ \\
\hline
\end{tabular}

\subsubsection{ORNL Base Case}

The KFIM can be adjusted for two significant parameters, P5 and P6.

\subsubsection{P5: Blade interaction with fish passing through turbine disk}

Many factors make up parameter P5, including fish length, L; fish-incident angle, $\theta$; fish burst and endurance velocity, $\mathrm{Vb}$ and $\mathrm{Ve}$; water velocity, $\mathrm{Vw}$; and rotor geometry. The following three changes can be made based on the ORNL analysis: 


\section{(1) P5 (Fish swimming with/against the current; 80/20 rule)}

A review of the 2012 DIDSON data as well as the 2009 SBT data showed a confirmation and reduction of this parameter over a range of water velocities, as shown in Table 4-2, representing 83-88\% with the current and $17-12 \%$ against the current, which was incorporated in the KFIM.

Table 4-2. Parameter P5-Ve

\begin{tabular}{|c|c|c|c|c|c|c|c|c|c|}
\hline \multicolumn{10}{|c|}{ P5.Current $==$ Fish swimming with the current } \\
\hline \multicolumn{10}{|c|}{2010 ASSUMPTION: } \\
\hline$V_{w}(\mathrm{~m} / \mathrm{s})$ & $0-1$ & $1-1.2$ & 1.2-1.4 & 1.4-1.6 & 1.6-1.8 & $1.8-2$ & $2-2.2$ & 2.2-2.4 & 2.4-2.6 \\
\hline Atlantic sturgeon & .8 & .8 & .8 & .8 & .8 & .8 & 1 & 1 & 1 \\
\hline Black sea bass & 1 & 1 & 1 & 1 & 1 & 1 & 1 & 1 & 1 \\
\hline \multicolumn{10}{|c|}{2015 FINDINGS (SBT) } \\
\hline $\mathrm{Vw}(\mathrm{m} / \mathrm{s})$ & $0-1$ & $1-1.2$ & 1.2-1.4 & 1.4-1.6 & 1.6-1.8 & $1.8-2$ & $2-2.2$ & 2.2-2.4 & $2.4-2.6$ \\
\hline $\mathrm{L}>30 \mathrm{~cm}$ & .79 & .91 & .88 & .92 & .84 & .88 & 1 & 1 & 1 \\
\hline $\mathrm{L}<30 \mathrm{~cm}$ & .65 & .9 & .96 & .97 & .97 & .98 & 1 & 1 & 1 \\
\hline
\end{tabular}

The original model (RITE 2010 KFIM) parameter P5 assumes $80 \%$ of the fish swim with the current and $20 \%$ swim against it. The recent ORNL work indicates a stronger case for $84 \% / 16 \%$ as a setting for model parameter P5. Fish are able to adjust swim speed and timing of activity during migration to changes in current velocity to minimize energy use (Brodersen et al. 2008). As migration requires energy, the timing of migration may depend on changes in current velocity for migrating fish. Fish can take advantage of changing environmental conditions to minimize their energy expenditure (Brodersen et al. 2008). Swimming with the current or swimming at slack tide requires less expenditure of energy and is a strategy often used in high current energy environments (Brodersen et al. 2008).

\section{(2) P5 (incident angle change)}

$\Theta=$ fish incident angle to the rotor disk

As shown in Table 4-3, the angle of incidence for any fish on the blades was assumed to be an even probability over $180^{\circ}$ in $15^{\circ}$ bins. As shown in the DIDSON analysis, the concentration of the angle of incidence observed was much more compact over a range of $\pm 15^{\circ}$, increasing the risk of impact should a fish encounter a blade. Therefore, this increased density of angle of incidence on the blade was used in the ORNL 2015 case run. 
Table 4-3. Parameter P5-angle of incidence

\begin{tabular}{ccc}
\hline Degree & 2010 KFIM assumptions & 2015 Findings DIDSON \\
\hline 7.5 & 0.08 & $\mathbf{0}$ \\
22.5 & 0.08 & $\mathbf{0}$ \\
37.5 & 0.08 & $\mathbf{0}$ \\
52.5 & 0.08 & $\mathbf{0}$ \\
67.5 & 0.08 & $\mathbf{0 . 0 1}$ \\
82.5 & 0.08 & $\mathbf{0 . 4 9}$ \\
97.5 & 0.08 & $\mathbf{0 . 4 9}$ \\
112.5 & 0.08 & $\mathbf{0 . 0 1}$ \\
127.5 & 0.08 & $\mathbf{0}$ \\
142.5 & 0.08 & $\mathbf{0}$ \\
157.5 & 0.08 & $\mathbf{0}$ \\
172.5 & 0.08 & $\mathbf{0}$ \\
\hline
\end{tabular}

\section{(3) P6 (ESA fish distribution)}

This parameter was included in the KFIM for RITE to account for the transit of ESA species within the configuration at RITE. For the 2010 RITE KFIM cases, in the absence of further information on ESA fish species, the model assumed an even distribution of ESA fish in the East River. Therefore, P6 $=1$ for all velocities.

On further review, this parameter set at 1 for each velocity was applied in 2010 as an extremely conservative value, rather than representing a uniform probability of 0.08 per velocity bin. Table 4-4 shows the original 2010 assumption, now considered inappropriate; a uniform distribution that would be applicable in the absence of data; and a hybrid DIDSON-SBT distribution of fish size over water velocity based on the data of in excess of 40,000 fish targets.

Table 4-4. KFIM parameter P6 fish distribution 1-2015 update

\begin{tabular}{lccccccccc}
\hline \multicolumn{1}{c}{ Vw } & $\mathbf{0 - 1}$ & $\mathbf{1 . 0 - 1 . 2}$ & $\mathbf{1 . 2 - 1 . 4}$ & $\mathbf{1 . 4 - 1 . 6}$ & $\mathbf{1 . 6 - 1 . 8}$ & $\mathbf{1 . 8}-2.0$ & $\mathbf{2 . 0 - 2 . 2}$ & $\mathbf{2 . 2 - 2 . 4}$ & $\mathbf{2 . 4 - 2 . 6}$ \\
\hline 2010 & 1 & 1 & 1 & 1 & 1 & 1 & 1 & 1 & 1 \\
2010 revised & 0.38 & 0.08 & 0.08 & 0.08 & 0.08 & 0.08 & 0.08 & 0.08 & 0.08 \\
2015 ESA & 0.30 & 0.12 & 0.12 & 0.14 & 0.11 & 0.08 & 0.05 & 0.04 & 0.04 \\
2015 EFH & 0.38 & 0.08 & 0.08 & 0.10 & 0.08 & 0.07 & 0.07 & 0.07 & 0.07 \\
\hline
\end{tabular}

Figure 4-1 shows the resulting model run for the ORNL 2015 case using the modified P5 and P6 values resulting from this analysis. It reduces the probability of a blade strike to below $0.50 \%$ for all arrays up to 30 turbines. 


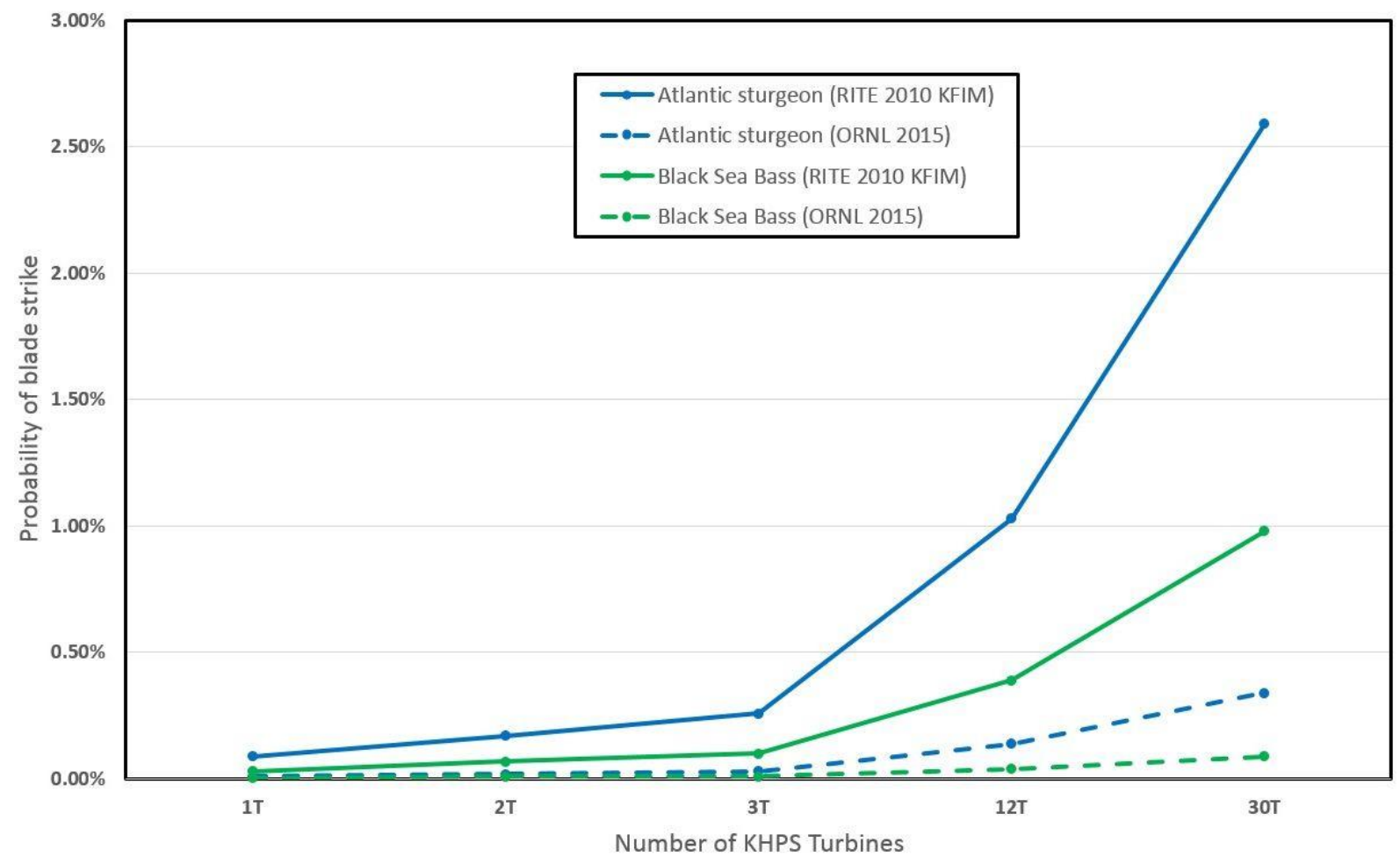

Figure 4-1. ORNL 2015 case-modification to P5 and P6; comparative KHPS-fish strike probabilities, RITE project.

\subsubsection{Verdant P-12611 Case}

For the Verdant case, in addition to the modifications described in the ORNL case, two other parameters can be modified.

\section{P3 Fish Distribution-East/West Channel}

The 2010 KFIM runs initially included a probability of $0.5(50 \%)$ to represent the equal likelihood that fish will take the east channel (and be at risk) over the west channel (and have no risk). This probability is fixed and is not dependent upon the water velocity. Based on concurrent RMEE-4 work, discussed in the referenced papers, the value for this parameter can be reduced to $0.25 \%$ based on evidence of tagged fish, using the west channel over the east channel where the RITE project is located.

\section{P7 Fish Avoidance Behavior}

In the KFIM, it was acknowledged that fish could indeed avoid the turbine blade; however, for the sake of completeness, the initial model runs took a conservative approach and assumed no avoidance behavior other than assuming the fish will speed up to avoid being struck. Thus for the 2010 model, $P 7=1$, no fish avoidance behavior was used for the Biological Assessment.

As a result of the further examination of the DIDSON video evidence, we found:

- Not enough data to allow for quantification of avoidance by fish approaching the turbine blade-swept area, because so few fish were seen in this area. 
- Not enough evidence to quantify differences in behavior of fish within a few meters of the turbine compared to those further away (i.e., closer to the DIDSON) or when a turbine was absent or not operating. That is, there was little difference in swimming velocity or direction of track.

- However, the number of fish in the vicinity of the turbine decreased noticeably when the turbine was present versus absent, and even more when the turbine was operating. This is true at all distances from the turbine.

So while it is difficult to suggest a quantification metric for reduction of the P7 parameter (as shown in the video evidence), the researchers generally acknowledge that the parameter could be modified to $\mathrm{P}=0.98$. Doing so would practically result in no change to the overall results but would account for the effort of observing some fish movement as a result of the presence of an operating KHPS. Figure 4-2 shows the resulting model run of changes to both $\mathrm{P} 3$ and $\mathrm{P} 7$, along with the previous changes to P5 and P6. As shown on Figure 4-2, additional modification to P3 distribution and allowance for a slight reduction to account for fish avoidance behavior reduces the results further below $0.50 \%$ with 30 turbines.

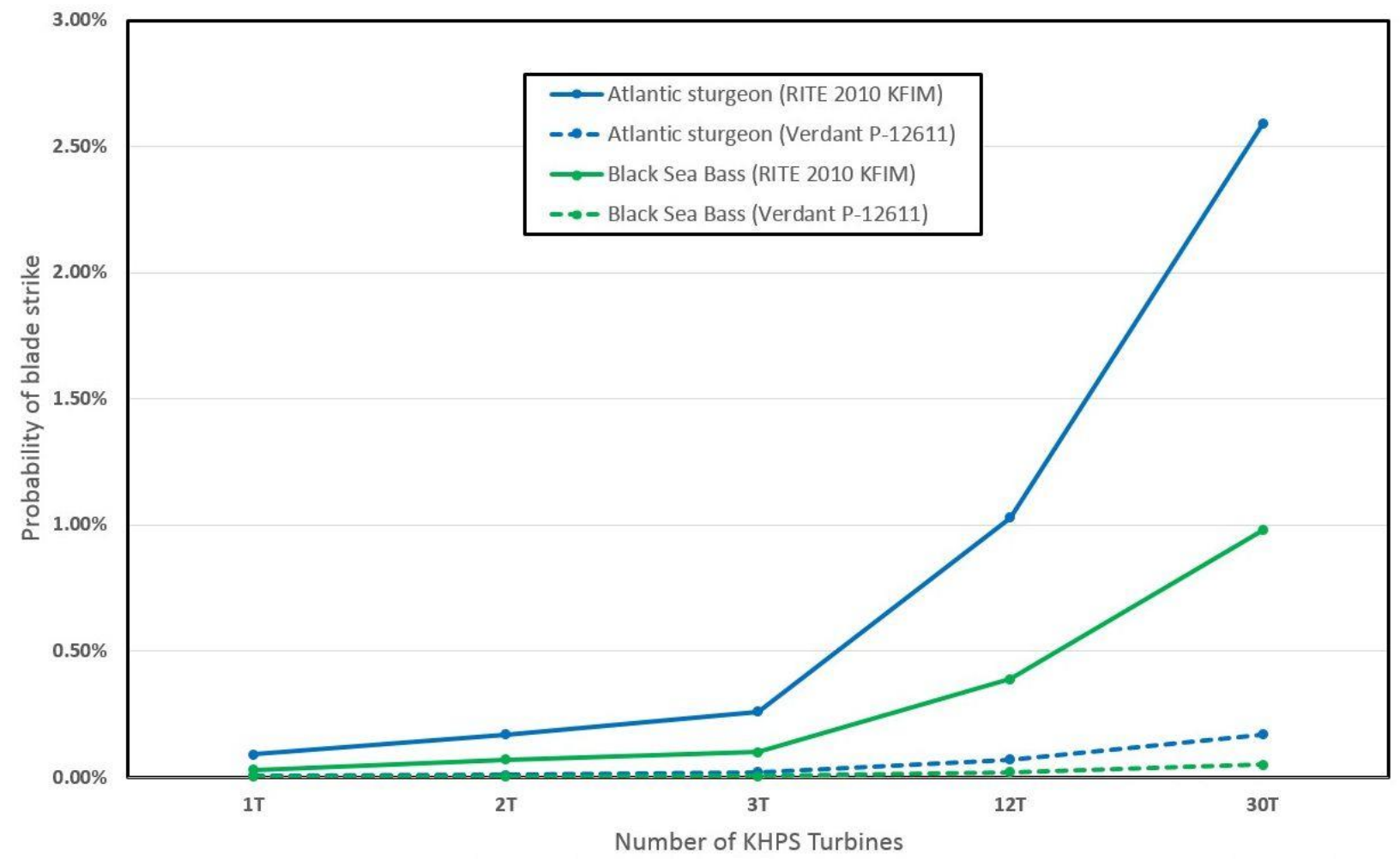

Figure 4-2. P-12611 case-modification to P3, P5, P6 and P7; comparative KHPS-fish strike probabilities, RITE project.

\subsection{RESULTS OF UPDATE TO THE KHPS-FISH INTERACTION MODEL}

The model determines the probability that a fish entering the East River will be struck by a turbine. Structurally, the model determines this strike likelihood by combining various parameters, including the water velocity distribution, the channel geometry, the KHPS physical and operating characteristics, and the specific fish characteristics (e.g., length, burst speed, and swimming velocity in relationship to water velocity). The model is designed to be customizable and incorporate elements of various parameters as they become known. For example, Verdant's sampling at the RITE site has demonstrated that fish move with the tide in the east channel and are most abundant at slack tide. Since the turbines do not operate in 
currents slower than $1 \mathrm{~m} / \mathrm{s}$, there is no risk to fish during the period of their highest abundance, which occurs over $27 \%$ of the tidal cycle. This type of site-specific knowledge is incorporated as parameters in the model.

The original model assumed very little fish behavior. Unknowns include temporal and spatial distribution throughout the river and the directions, shapes, and timing of their paths in the East River. The RITE RMEE plans were designed to improve site-specific knowledge, which can then be incorporated into the model.

The model uses nine parameters and is applied to calculate the strike probability for 1-30 turbines. For a multi-turbine array, another probability parameter is added to reflect the number of turbines, and their spacing in the turbine field. The turbines in the field are treated as if the fish had an equal opportunity to go through all 30. In reality, because the turbines would be grouped together in threes on a TriFrame, it would be likely that a fish going through one turbine in a Triframe would not be lined up to pass through either of the other two turbines. However, it is difficult to quantify this interaction, so the simple but worst case of treating the turbines as independent is modeled. The strike probability for one TriFrame is simply the strike probability for a single turbine multiplied by the three turbines in the single TriFrame.

The model determines only the probability of a strike by a turbine blade, not the probability of mortality. The model does differentiate between a strike that is determined to be too slow to cause any injury and one that could cause injury or mortality. Strikes that are deemed too slow to cause any injury are treated as non-strikes. While there are some early injury and mortality studies of turbine blades on smaller fish (Amaral et al. 2008), predictions of mortality for the larger fish are left out of the model at present. Thus the output of the model is a strike probability, not an injury or mortality probability.

The results of the modifications to the KFIM are shown for comparison with the 2010 KFIM results in Figure 4.3. The comparative results of the 2010 model results at RITE and the two cases examined in this report act to reduce the conclusions for a potential array of up to 30 KHPS turbines at the RITE pilot site. 


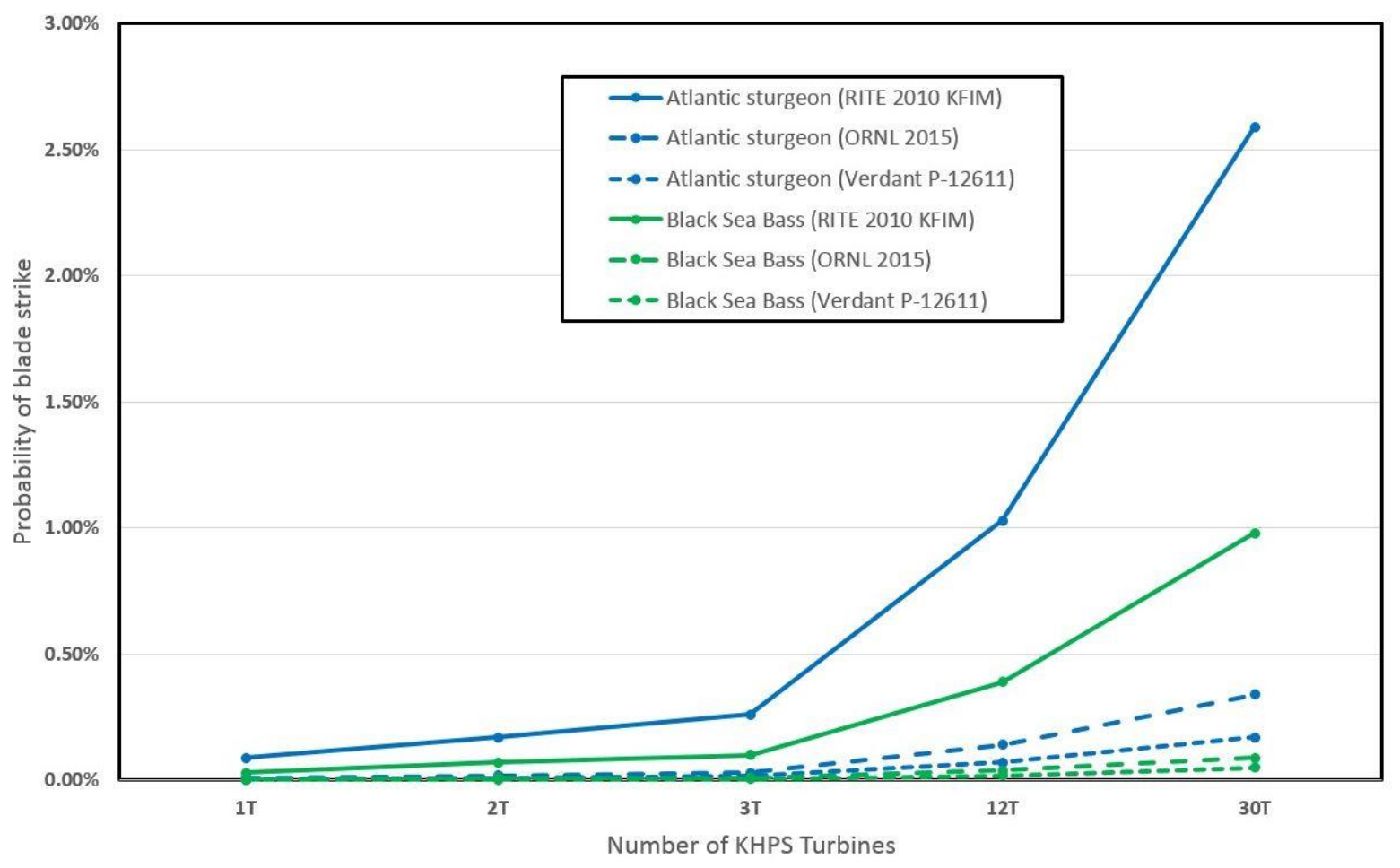

Figure 4-3. RITE project KFIM model output comparisons. 


\section{MONITORING TOOLS FOR TURBINE ARRAYS}

The last objective of this task was to

Use study results to assess which approaches (i.e., field observation, experimentation, models, etc.) will be most effective for predicting or monitoring the effects of a turbine array.

This section discusses the scale of monitoring and our perspective on scaled-up monitoring for arrays. Additionally, a review of opportunities for field observation, experimentation and modeling is provided.

\subsection{MICRO-MESO-MACRO SCALE}

A key aspect of the 2006-2008 RITE demonstration (six turbines, 2006-08) was to assess the interactions of Verdant Power's KHPS with the environment. Verdant worked with regulatory agencies and other key local stakeholders to develop and execute a number of study plans that have served as the basis for understanding the interactions and importance of moving forward with pilot and commercial-scale projects. During the demonstration, Verdant conducted a number of first-time fish interaction studies to examine biological issues regarding the operation of the KHPS in fast waters.

Verdant Power's experience is that it is useful to consider the following terminology in developing relevant monitoring methods and protocols for its KHPS projects. This process includes examining key biological parameters (e.g. fish movement, migration) and matching monitoring protocols at three different scales:

- Micro scale: In and around an individual turbine (1 diameter (1D) $=5 \mathrm{~m}$ at RITE), rotating at $<40 \mathrm{rpm}$ and only during high-velocity periods over $1 \mathrm{~m} / \mathrm{s}$. At this scale, resident and migratory fish interactions, as well as micro hydrodynamics are being studied. The DIDSON data discussed in this report were collected at this scale.

- Meso scale: In front/back of the turbine TriFrame

- $\quad{ }^{6}$. Here the reaction around a TriFrame of three turbines is being studied, as well as the interdependencies and recovery distance to the next TriFrame in the array - generally 12D (at RITE) to 20D (other sites) in distance. The splitbeam data discussed in this report were collected at this scale.

- Macro scale: Well beyond the TriFrame (and the fully developed array) extending to points where organisms first sense/encounter the minor hydrodynamic presence of the KHPS array. This is a broader-scale study conducted for longer-term deployments.

In developing the RITE RMEE plans for the licensed pilot project array of up to 30 KHPS turbines, this perspective was particularly challenging. Therefore, as the work conducted under this grant agreement is focused on observing the micro- and mesoscale impacts around a single turbine (or closely spaced operating turbines), how does one examine an array of up to 30 or more turbines in a commercial setting at the macro scale?

\footnotetext{
${ }^{6}$ The TriFrame is a riverbed foundation structure that will mount three turbines in a triangular configuration. When installed on the frame, the $5 \mathrm{~m}$ Gen 5 turbines will each be spaced approximately 2 diameters apart.
} 


\subsection{ARRAY AND FULL FIELD EFFECTS}

In licensing the RITE site, Verdant had to address the issue of potential full-field effects of a multipleturbine array. Despite a lack of clear empirical data or robust monitoring techniques, it was necessary to provide an adaptive management monitoring plan for observing a full array of operating KHPS turbines, within the context of possible fish interactions. The approach taken was twofold:

1. Extending the KFIM to conservatively account for increasing the number of installed turbines to increase the probability of strike and evaluating the probability of strike under this macro circumstance.

2. Providing a longer-term macro observational monitoring plan, the RMEE-1 Seasonal Fixed Hydroacoustics, to attempt to observe these effects when multiple turbines are operating.

These efforts, in conjunction with the other RMEE plans through the adaptive management process, provide for opportunity to continue to refine at the micro, meso, and macro scale the understanding of fish interaction and risk within an array setting.

\subsubsection{KFIM Model to Array}

The most conservative estimate for the impact of the full field of 30 KHPS turbines is to multiply the single unit probability by the number of installed units.

However, this assumption does not take into account the physical location of the KHPS turbines. This is a worst-case assumption that may be overly conservative. As the KHPS turbines will be clustered in a single location, any fish entering the full array would likely try to leave the area once passing close to or through a small number of units. Nevertheless, there is little validated or published data to support this assumption; as a result, this model assumes no inherent avoidance of the array.

Using this conservative parameter that assumes that once a fish encounters the array it never leaves, results for the strike probabilities are as shown in Table 5-1. For comparison, the model was run for an essential fish habitat (EFH) species of smaller length as well. As a result of the 2015 work, the fish strike probability in an array was reduced and was further reduced when parameters P3 and P6 are incorporated.

Table 5-1. Overall KHPS-fish strike probabilities for proposed RITE project

\begin{tabular}{lccc}
\hline \multicolumn{1}{c}{ Species } & Single KHPS turbine & $\begin{array}{c}\text { Array } \\
\text { (30 turbines) 2010 }\end{array}$ & $\begin{array}{c}\text { Array-2015 ORNL } \\
\text { case }\end{array}$ \\
\hline Atlantic sturgeon & $0.09 \%$ & $2.59 \%$ & $0.34 \%$ \\
EFH-25 & $0.03 \%$ & $0.98 \%$ & $0.09 \%$ \\
\hline
\end{tabular}

\section{RMEE-1 Seasonal Fixed Hydroacoustic Plan}

As part of the RITE FERC licensing, and to gain insight into the meso and macro behavior of fish in an array condition, Verdant proposed a seasonal deployment of two bottom-mounted SBTs within the array, with attendant software improvements to attempt to gain insight on presence, abundance, and trajectory behavior of fish encountering multiple KHPS turbines. Optimistically, this system was geared to actually follow a fish as it approached the array and, using proprietary BioSonics software, link its track potential through multiple KHPS turbines. This is a costly system, however, and at the time of the license application, it was considered a 'potential' technique for addressing the array-scale effects of fish 
behavior in the presence of an operating KHPS and was included in the requirements of the FERC license for the RITE Project. Under the adaptive management process for environmental monitoring to be implemented during the phased build-out at the RITE Project, the details of RMEE-1 and the deployment of SBTs will be re-evaluated to ensure effective data collection to increase the understanding of fish interaction and risk within an array.

\subsection{OPPORTUNITIES FOR FIELD OBSERVATION}

\subsubsection{Methods and Limitations}

Conducting a real-time field observation of an operating KHPS — or any HK device — involves a significant commitment of time and effort. The available equipment, be it a DIDSON, SBT, or other sensitive fish detection device, involves not only the equipment but also the mount, cabling or battery data recording system, and the considerations of in-water time and replacement. Almost as important is the cost and time associated with post-processing. Therefore, it is relevant to consider these costs and risks in proportion to the data and the biological questions that can be answered.

Verdant has had significant experience with monitoring device deployments and efficacy since 2006, as discussed in the licensing documents and other reports (NYSERDA 2012). For example, the 24-SBT array first deployed at RITE cost over \$1.4 million. The most recent 2012 DIDSON video, the subject of this study, represented nearly $\$ 250,000$ of effort plus this DOE-funded post processing. To put this in context, the power production of a 1MW array (30-turbine KHPS) is expected to generate revenues of approximately $\$ 350,000$ per year.

\subsubsection{Opportunities}

Even given the high costs, field observation does have substantial merit. At the RITE project, both the RMEE-2 DIDSON program and some modification of the RMEE-1 protocol for arrays will be undertaken as the project progresses.

In conducting field observation of individual devices or field arrays, lessons learned include:

- Deploy monitoring in periods of seasonal abundance of fish. This was the case in the 2012 DIDSON deployment; however, as indicated by our analysis, a low number of large fish resulted despite best efforts.

- Simplify the in-water recording to facilitate post-processing. This became apparent in the most recent case with multiple DIDSON aims and several repositioning movements complicating the analysis.

- Limit in-water duration to match the functionality of the equipment. Practically, for a DIDSON, 3-4 weeks is the maximum for uninterrupted service due to bio-fouling.

\subsection{OPPORTUNITIES FOR EXPERIMENTATION}

\subsubsection{Methods and Limitations}

Direct experimentation - as conducted by EPRI/Alden (Amaral et al. 2015) on fish behavior and encounters - is useful to the industry and contributes to the microscale body of knowledge as the industry progresses, in conjunction with other methods discussed. It is recognized that these efforts are generally device-specific and controlled, to the extent that proxy size fish are directly controlled into the device strike without accounting for avoidance behavior, which is a key parameter. In addition, laboratory cost 
can be a significant factor in these controlled efforts. For arrays, laboratory experimentation is probably not a viable option.

\subsubsection{Opportunities}

In moving toward array monitoring and prediction, two experimental possibilities that might provide insight into fish behavior in the presence of multiple KHPS at RITE are:

1) Use a triangulated network of passive acoustic transmitters and receivers to create 3-D tracks of fish movement through the array of previously tagged species.

2) Release of fish tagged with a combination of an acoustic transmitter and a balloon-tag in front of a turbine array during full operation followed by retrieval downstream of the array.

\section{Tagged Species Detection—-triangulation in arrays}

As discussed in Sections 3 and 4, Verdant has established a VEMCO tagged species detection platform to gain information on fish passing near the KHPS at RITE which is effective only if researchers tagging fish participate in mutual data exchange. A further limitation of this approach is that the current technology as deployed detects presence but not specific location in relationship to the KHPS. An improvement to this protocol, in the presence of multiple operating KHPS turbines, would be to deploy additional VEMCO receivers and conduct triangulation analyses of detected tags to XYZ locate a tagged fish and its track as it passes by multiple KHPS turbines. Verdant has unsuccessfully attempted to gain funding for this research but considers this a significant opportunity to begin to determine fish behavior within an array.

\section{Tagged Species Controlled Release-arrays}

Similarly, at RITE, because of the narrow channel configuration, an opportunity for a controlled release of balloon-tagged fish in open water upstream of the operating KHPS turbines could be accomplished, with immediate recovery and tracking downstream. Again, a coordinated field effort could be accomplished, which might provide significant new information on multiple turbine encounter behavior, albeit with the limitations of size, species, and recovery of tagged fish. As detection technology improves for passive integrated transponder tags, this technology also holds promise for detecting fine-scaled behavioral responses during turbine encounters.

\subsection{OPPORTUNITIES FOR MODELING}

\subsubsection{Methods and Limitations}

The KFIM proved to be a useful tool for evaluating conditions at RITE for a single turbine, as well as extending to arrays. The 2010 model, in the absence of data, used conservative assumptions to arrive at a fish-strike probability acceptable for obtaining a license. The 2015 work described in this report better defined certain parameters to refine the application of the model. Clearly, we believe this is a useful tool not only for the Verdant Gen5 KHPS but also for other HK device applications.

It is interesting to note that the United Kingdom's Marine Mammal Scientific Support Research Programme (2015) uses a similar type of model to predict marine mammal encounters; therefore, this method of array modeling will likely be useful to the industry. 
Although the actual development and running of models is probably a cost-effective solution, acquiring and adapting useful field and experimental data to support the model remains the costly limitation. However, as demonstrated in this DOE-funded project, the effort and results significantly enhance the understanding of the biological impact of HK devices in the environment.

\subsubsection{Opportunities}

Given the effort and results reported here, the following opportunities for array modeling can be recommended:

- Continued population of existing models with new data: As was done with the RITE KFIM in this project, the updating of parameters with monitoring data improves the understanding of fish strike risk. For arrays, implementing monitoring protocols that would support array extension would additionally improve the efficacy.

- Adaptation and development of models for different device types and array sites: Since the parameters in a model are very specific to a device and site conditions, efforts should be made to continue to apply models at different sites to improve quality, transferability, and acceptance.

- Ongoing collaborative research to incorporate model similarities with marine mammal models: For arrays in open water, this issue will continue to be a significant effort, and ongoing research to develop tools and models for marine mammal risk should benefit predictions of fish risk.

The different options for monitoring turbine arrays as described above are summarized in Table 5-2.

Table 5-2. Summary matrix of monitoring tools useful for monitoring turbine arrays.

\begin{tabular}{|c|c|c|c|c|}
\hline Technique & $\begin{array}{l}\text { Monitoring } \\
\text { scale }\end{array}$ & $\begin{array}{l}\text { Efficacy } \\
+ \text { to }+++\end{array}$ & $\begin{array}{c}\text { Limitations \& } \\
\text { relative cost } \$-\$ \$ \$\end{array}$ & Opportunities \\
\hline \multicolumn{5}{|c|}{ Field Observation } \\
\hline $\begin{array}{l}\text { RMEE- }{ }^{*} \\
\text { RAD- DIDSON at RITE, } \\
\text { New York }\end{array}$ & Micro/meso & +++ & $\begin{array}{l}\text { Short duration } \\
\text { Post-processing costs } \\
\$ \$ \$\end{array}$ & $\begin{array}{l}\text { Detect near-field } \\
\text { responses during } \\
\text { turbine encounters }\end{array}$ \\
\hline $\begin{array}{l}\text { RMEE- } 1 * \\
\text { SBT deployment }\end{array}$ & Meso/macro & Unknown & $\begin{array}{l}\text { Short duration } \\
\text { Algorithms unproven } \\
\$ \$ \$\end{array}$ & $\begin{array}{l}\text { Detect far-field } \\
\text { responses during } \\
\text { turbine encounters }\end{array}$ \\
\hline \multicolumn{5}{|c|}{ Experimentation } \\
\hline $\begin{array}{l}\text { Tagged species detection- } \\
\text { triangulation } * *\end{array}$ & Macro & Likely +++ & $\$$ & $\begin{array}{l}\text { Improves } \\
\text { understanding of } \\
\text { fish tracks in } \\
\text { relation to KHPS }\end{array}$ \\
\hline $\begin{array}{l}\text { Controlled release of } \\
\text { tagged species } * *\end{array}$ & Macro & $\begin{array}{l}\text { Likely }++ \text { to }+++ \\
\text { for fish behavior }\end{array}$ & $\$ \$$ & $\begin{array}{l}\text { Observes fish } \\
\text { tracks in presence } \\
\text { of multiple turbines }\end{array}$ \\
\hline \multicolumn{5}{|c|}{ Modeling } \\
\hline Verdant KFIM & Micro/macro & $\begin{array}{l}+++ \text { conservative } \\
\text { values }\end{array}$ & $\begin{array}{l}\text { Device- and site- } \\
\text { specific } \\
\text { Limited data } \\
\$\end{array}$ & $\begin{array}{l}\text { Continue to refine } \\
\text { parameters with } \\
\text { other techniques } \\
\text { and data }\end{array}$ \\
\hline
\end{tabular}





\section{CONCLUSIONS AND OPPORTUNITIES FOR FUTURE RESEARCH}

\subsection{HYDROACOUSTICS ANALYSIS}

The automated analysis of nearly three weeks of multibeam hydroacoustics data identified nearly 35,000 fish tracks for further analysis. These tracks included both individual fish and schools during periods with the KHPS turbine absent and present, operating and not operating, and during all phases of the tidal cycle, ebb, flood, and slack.

Various metrics of location, and swimming direction and velocity were evaluated for indication of behavioral responses to the operating turbine (i.e., attraction or avoidance). These metrics were grouped into classes based on tidal cycle, current velocity, and swimming direction and evaluated with respect to turbine presence and operation and with respect to distance from the turbine. Significant findings from the automated analysis included:

- The density of fish in the DIDSON sample area when the turbine was absent was roughly twice what it was when the turbine was in place, both when rotating and when not rotating. This suggests that some avoidance may be occurring before fish are close enough to the turbine to be observed by the DIDSON.

- In the near-field within the $10 \mathrm{~m}$ window viewed by the DIDSON, the number of tracks observed decreased sharply from a maximum near the DIDSON (away from the turbine) to near the turbine location (away from the DISON) regardless of whether the turbine was in place and rotating or not.

- For fish swimming past the turbine, there were no significant changes in vertical, horizontal, or lateral trajectories of fish when the turbine was present or operating but some differences were noted that suggested hints of avoidance.

- Turbine presence, however, whether operating or not, resulted in more crooked tracks for fish near the turbine than for fish in the same location when the turbine was absent, suggesting that normal swimming behavior was affected.

- The last metric evaluated for change in behavior was swimming velocity which we found to be slower in the presence of the operating turbine versus an absent turbine condition.

From our direct observations of small subsets of the DIDSON videos, we found that individual fish and schools that were headed toward rotating blades usually avoided the blades by adjusting their horizontal swimming direction slightly and angling away. Others disappeared just before encountering the rotor (i.e., within $1 \mathrm{~m}$ ), which we assume to have happened because the fish changed vertical direction, swimming either above or below the turbine and therefore out of view of the DIDSON beam. Close encounters that might result in blade contact were practically non-existent.

In summary, our analysis suggests that fish might be making small adjustments to swimming direction and velocity as they pass near an operating turbine. However, large adjustments in swimming direction or velocity were not observed, and we do not believe that the presence of the turbine interrupts in any significant way the normal movements of fish through the area. We also believe based on our analysis that the risk of actual contact with the rotor is extremely small. 


\subsection{CONCLUSIONS AT RITE}

As required in the RITE Pilot License (P-12611) RMEE-2 Plan (V3.2 December 2010) and Article 401 of the WQC11 Water Quality Certification (WQC) Permit, Verdant is required to address specific questions relative to the RMEE-2 DIDSON observations. As a result of the analyses presented in this report, we can add the following responses to these questions and to the evolving body of knowledge.

1. How do fish behave around operating KHPS turbines, and are they injured through direct contact with the blades?

- The review of 239 hours of DIDSON video (September 2012) in the presence of an operating Gen5 KHPS turbine revealed no drastic changes in swimming behavior as a result of exposure to the turbine.

- Fish tend to behave as generally is assumed in the KFIM model, confirming the $80 \%$ movement with current; but movement is now shown to be $\sim 84 \%$ favoring the current

- The angle of incidence to the blades was the most significant fish observation, narrowing the angle at which a fish approaches the blade to approximately $\pm 15^{\circ}$ from the original $180^{\circ}$. This has the effect of increasing the likelihood of strike for a fish approaching the KHPS.

- A few occasional instances were recorded of avoidance behavior by large fish $(>80 \mathrm{~cm})$ as discussed in KFIM Parameter 7, but it is not possible to put a precise estimate on the probability that a fish will avoid the turbine.

- From our direct observations of small subsets of the DIDSON videos, we found that individual fish and schools that were headed toward rotating blades usually avoided the blades by adjusting their horizontal swimming direction slightly and angling away.

2. Can fish behavior be inferred by tracking a fish's swimming location and direction in the visualization and fish reaction in relation to the rotating blades?

- The techniques for review of 239 hours of DIDSON video (September 2012) in the presence of an operating Gen5 KHPS have been significantly advanced through the methods developed in this study. However, this post-processing (as described in Section 2) requires significant skill and effort to reveal the conclusions noted.

- Generally, if a fish track can be isolated (a process that includes both filtering operating turbine blade signature and time-stamp tracking of water velocity and location), a visualization of the fish track in XYZ plane can be observed relative to the operating KHPS (videos to be posted and referenced later).

- The DIDSON observational technique is useful, recognizing the limited observations in real time at RITE (e.g., due to low densities of fish in proximity to an operating turbine or low densities in general, even though September was considered to be a peak density season from prior baseline monitoring).

- However, as was determined during the preliminary RMEE-2 on-water testing in September, 2012, the deployment of this remotely aimed DIDSON (RAD) system requires expertise and expense associated with accurate placement near an operating KHPS. Also, based on 
manufacturing recommendations and in-water experience, the RAD can be in-water only for 3-4 weeks without loss of acuity.

- In conjunction with the expense of post-processing video, the use of RAD monitoring of fish tracks should be considered a short-term, micro-observation technique likely used within an adaptive management framework for confirmation of expected KHPS fish interaction.

3. Do the DIDSON observations provide some added meaning and value (correlation) to the body of collected data on fish presence, abundance, movement pattern and species in and around the operating KHPS turbine?

- Yes, as discussed in Sections 3 and 4 the body of work accomplished under the ORNL effort supports, confirms, and expands the understanding of fish presence, abundance, movement, and (to a limited extent) species identification in the presence of the operating turbine.

- As discussed in Section 4, the 2015 analysis allows us to modify the KFIM with additional information on parameters that were previously conservatively set because of lack of knowledge. This is a significant advancement as the result of this work.

- From a biological point of view, the 2015 DIDSON analysis work supports, confirms, and expands the understanding outlined in the December 2010 Final License Application and the 2011 Biological Assessment /Opinion. This study confirms the following:

- Most fish swim with the tide, especially at times of high current.

- Fish are most abundant at slack tide when the turbines are not operating.

- Large fish species such as sturgeon do not occur in high numbers in the East River.

- Fish are transiting through the project area rather than residing there.

- The overall probability of a fish-turbine interaction is low.

4. What, if anything should be changed in the DIDSON operating protocol to improve evaluation of the effects of operating a KHPS?

- Based on the 2012 DIDSON effort at RITE and the ORNL analysis, we remain confident that a single seasonal deployment for 3-4 weeks maximum is possible to observe KHPS-fish interactions at the micro scale. This field effort ( $\$ 75,000$ using existing equipment) and the required post-processing (on the order of $\$ 100,000$ ) should serve to confirm these findings in the operation of a single KHPS.

- Some improvements stemming from the DIDSON analysis could include the following.

- Position the RAD so that the DIDSON field maximizes the amount of sampled area upstream of the rotors; that is, so that the rotors are at the very edge of the field.

- Limit the number of DIDSON aims to two, one each for ebb and flood tides.

- Collect data with the turbine removed (as in this study) or in a nearby control location.

Beyond this RMEE-2 effort, it is doubtful that further RAD deployments to observe multiple operating turbines is a useful technique at RITE or that it would yield further data. Verdant will probably pursue an adaptive management conclusion of the RMEE-2 effort, if appropriate. 


\subsection{RECOMMENDATIONS}

From a biological and research study aspect:

- Whereas multibeam hydroacoustics provides the best opportunity to 'visually' assess fish interactions with turbines in low visibility systems, the limited range of this technique and the post-processing requirements make this technique less than ideal. For example, the diameter of the KHPS rotor is about twice the vertical range of the DIDSON field so that we were not able to capture the entire swept area.

- Precise positioning and strategic aiming of the RAD are crucial to capturing fish interactions with the turbine. Given the current range and width of field of the DIDSON unit, it would be beneficial to position two DIDSON units in tandem to fully capture fish entering and leaving the blade swept zone, although this option is quite likely cost prohibitive.

- Automated data analysis was a challenge because of the rotating turbine, however, analytical software and techniques continue to improve and this obstacle can likely be overcome in the near future.

- In the case of the RITE project, the ability to couple the multibeam results with those from a splitbeam hydroacoustics analysis and from netting studies provides valuable insight into fish behavior at the RITE project.

From the perspective of an HK developer:

- Although we were confident that the 2012 data confirmed the conservative assumptions regarding fish interaction, the added analysis and scientific third-party effort by ORNL to quantify these parameters with the significant video post-processing significantly enhances and advances the understanding of KHPS interaction.

- Pending the deployment of more Verdant Power Gen5 KHPS turbines at RITE, the post-processing expertise will be valuable to streamline the RMEE-2 study effort. Funding for this deployment and analysis should benefit the HK industry at large and RITE in particular.

- This monitoring protocol is focused as discussed on the observation of a single (or few) operating KHPS turbines at the micro scale. It is likely not applicable for multiple turbines in an array condition. Moving toward such studies, it is recommended that research and development funding for alternative techniques or algorithms be undertaken to address the array condition.

- Another supportive recommendation would be to fund a field tagging experiment when multiple KHPS turbines are operating at RITE (as discussed in Section 5).

- Ongoing research and development at various sites and for other HK developers along these lines is warranted. The model development and parameterization may be useful for others in the HK industry. 


\section{ACKNOWLEDGMENTS}

This research was funded by the US DOE Office of Energy Efficiency and Renewable Energy, Wind and Water Power Program, and by Verdant Power. Verdant Power provided the hydroacoustics and flow data that were collected during turbine testing that was partially funded by NYSERDA. We appreciate the program management provided by J. Brown-Saracino of the DOE Wind and Water Power Program. M. Schramm (ORNL) assisted with analysis of the splitbeam data. S. Curd Hetrick (ORNL) provided valuable project management and contracting services. ORNL is managed by UT-Battelle, LLC, for DOE under contract DEAC0500OR22725. 



\section{REFERENCES}

Amaral, S., G. Hecker, P. Stacy, and D. Dixon. 2008. Effects of Leading Edge Turbine Blade Thickness on Fish Strike Survival and Injury. Proceedings of Hydrovision International 2008. HCI Publications, St. Louis, Missouri.

Amaral, S., N. Perkins, G. Allen, G. Hecker, D. Dixon, and P. Jacobson. 2010. Evaluation of the Effects of Hydrokinetic Turbines on Fish. Proceedings of Hydrovision International 2010. PennWell Corporation, Tulsa, Oklahoma.

Amaral, S. V., M. S. Bevelhimer, G. F. Čada, D. J. Giza, P. T. Jacobson, B. J. McMahon, and B. M. Pracheil. 2015. Evaluation of Behavior and Survival of Fish Exposed to an Axial-Flow Hydrokinetic Turbine. N. Am. J. Fish. Mgmt. 35(1): 97-113.

Brodersen, J., P. Nilsson, J. Ammitzbøll, L. Hansson, C. Skov, and C. Brönmark. 2008. Optimal Swimming Speed in Head Currents and Effects on Distance Movement of Winter-Migrating Fish. PLoS ONE. 2008; 3(5): e2156. Published online May 14.

Cada, G. F., and M.S. Bevelhimer. 2011. Attraction To and Avoidance of Instream Hydrokinetic Turbines by Freshwater Aquatic Organisms. Prepared for the Wind and Water Power Program Office of Energy Efficiency and Renewable Energy. US Department of Energy. Washington, D.C. ORNL/TM2011/131.

Castro-Santos, T., and A. Haro. 2015. Survival and behavioral effects of exposure to a hydrokinetic turbine on juvenile Atlantic salmon and adult American shad. Estuaries and Coasts 38 (Suppl 1), pp. 203-214.

DOE (US Department of Energy). 2009. Report to Congress on the Potential Environmental Effects of Marine and Hydrokinetic Energy Technologies. Prepared in response to the Energy Independence and Security Act of 2007, Section 633(b). Wind and Water Power Technologies Program, US Department of Energy, Washington, DC. 89 p. + appendices.

EPRI (Electric Power Research Institute). 2011. Evaluation of Fish Injury and Mortality Associated with Hydrokinetic Turbines. EPRI report 1024569.

FERC (Federal Energy Regulatory Commission). 2012. Order Issuing Pilot License P- 12611 (Verdant's RITE project). January 23,.

Hammar, L., S. Andersson, L. Eggertsen, J. Haglund, M. Gullstrom, J. Ehnberg, and S. Molander. 2013. Hydrokinetic Turbine Effects on Fish Swimming Behaviour. PLoS ONE, 8(12), e84141, doi: 10.1371/journal.pone. 0084141.

Johnson, R. L., and R. A. Moursund. 2000. Evaluation of Juvenile Salmon Behavior at Bonneville Dam, Columbia River, Using a Multibeam Technique. Aquat. Living Resour. 13:313-318.

Love, R.H. 1977. Target strength of an individual fish at any aspect. Journal of the Acoustical Society of America 62:1397-1403.

Marine Mammal Scientific Support Research Programme. 2015. Collision Risk and Impact Study: Examination of Models for Estimating the Risk of Collisions between Seals and Tidal Turbines. MMSS/001/11 MR 7.2.2 Report .Available at www.smru.st-andrews.ac.uk/. Accessed December 2015.

National Marine Fisheries Service. 2012. Comments on the Biological Opinion re Verdant Power's Roosevelt Island Tidal Energy (RITE) Project Required by Article 401 under P-12611. September 28, 2012. NYSERDA New York State Energy Research and Development Authority. Marine and Hydrokinetic Environmental Policy Workshop: Marine and Hydrokinetic Technology Background 
and Perspective for New York State and 12-27c A Review of Regulatory and Policy Requirements for Hydrokinetic Power Projects in New York State. Report: 12-27b. May 2012. Available at http://www.nyserda.ny.gov/-/media/Files/Publications/Research/Environmental/review-regulatorypolicy-requirements.pdf. Accessed January 2016.

NAI (Normandeau Associates Inc.). 2009. An Estimation of Survival and Injury of Fish Passed through the Hydro Green Energy Hydrokinetic System, and a Characterization of Fish Entrainment Potential at the Mississippi Lock and Dam No. 2 Hydroelectric Project (P-4306), Hastings, Minnesota. Prepared for Hydro Green Energy LLC, Houston, Texas.

NOAA (National Oceanic and Atmospheric Administration). 2012. NOAA Biological Opinion. October.

Schweizer, P., G. Čada, and M. Bevelhimer. 2011. Estimation of the Risks of Collision or Strike to Freshwater Aquatic Organisms Resulting from Operation of Instream Hydrokinetic Turbines. ORNL/TM-2011/133, Oak Ridge National Laboratory.

Shen, H., G. B. Zydlewski, H. A. Viehman, and G. Staines. 2015. Estimating the Probability of Fish Encountering a Marine Hydrokinetic Device. Proceedings of the 3rd Marine Energy Technology Symposium. April 27-29, 2015, Washington, DC.

Tomichek, C., J. Colby, and M.A. Adonizio. 2015. Improvements to Probabilistic Tidal Turbine-Fish Interaction Model Parameters. Marine Energy Technical Symposium. Washington, D.C.

Tomichek, C., J. Colby, M. Bevelhimer, and M.A. Adonizio. 2016. Parameter Updates to Probabilistic Tidal Turbine-fish Interaction Model. Proceedings of the 4th Marine Energy Technology Symposium. Washington, D.C.

Turnpenny, A.W.H., M. H. Davis, J. M. Fleming, and J. K. Davies. 1992. Experimental Studies Relating to the Passage of Fish And Shrimps through Tidal Power Turbines. Marine and Freshwater Biology Unit, National Power, Fawley, Southhampton, Hampshire, England.

Verdant Power, LLC. 2008. Draft License Application Roosevelt Island Tidal Energy Project. November.

Verdant Power, LLC. 2010. Final License Application, Roosevelt Tidal Energy Project. December.

Verdant Power. 2011. Roosevelt Island Tidal Energy (Rite) Environmental Assessment Project: Final Report. NYSERDA report 11-04. Prepared for the New York State Energy Research and Development Authority, Albany, N.Y.

Viehman, H. A., and G. B. Zydlewski. 2015. Fish Interactions with a Commercial-Scale Tidal Energy Device in the Natural Environment. Estuaries Coasts 38 (Suppl 1): 241-252.

Wilson, B., R. S. Batty, F. Daunt, and C. Carter. 2007. Collision Risks between Marine Renewable Energy Devices and Mammals, Fish and Diving Birds. Report to the Scottish Executive. Scottish Association for Marine Science, Oban, Scotland. PA25 1QA. 110 p. 